\title{
Charles Gide
}

Professeur d’Économie sociale à la Faculté de Droit de l’Université de Paris

\section{(1919)}

\section{Cours \\ d’Économie politique}

\section{Tome II}

$4^{\mathrm{e}}$ édition refondue et augmentée

(Livre II)
Un document produit en version numérique par Mme Marcelle Bergeron, bénévole Professeure à la retraite de l'École Dominique-Racine de Chicoutimi, Québec et collaboratrice bénévole Courriel : mailto:mabergeron@videotron.ca

Dans le cadre de la collection : "Les classiques des sciences sociales" dirigée et fondée par Jean-Marie Tremblay, professeur de sociologie au Cégep de Chicoutimi Site web : http://classiques.uqac.ca/

Une collection développée en collaboration avec la Bibliothèque Paul-Émile-Boulet de l'Université du Québec à Chicoutimi Site web : http://bibliotheque.uqac.uquebec.ca/index.htm 
Un document produit en version numérique par Mme Marcelle Bergeron, bénévole, professeure à la retraite de l’École Dominique-Racine de Chicoutimi, Québec courriel : mailto:mabergeron@videotron.ca

Charles Gide.

Une édition électronique réalisée à partir du texte de Charles Gide, Cours d'Économie politique - tome II, $4^{e}$ édition, refondue et augmentée, Livre II. Paris, Librairie de la Société du Recueil Sirey. 1919, 589 pp.

\section{Tome II : Livre II}

Polices de caractères utilisés :

Pour le texte : Times, 12 points.

Pour les citations : Times 10 points.

Pour les notes de bas de page : Times, 10 points.

Édition électronique réalisée avec le traitement de textes Microsoft Word 2003 pour Macintosh.

Mise en page sur papier format

LETTRE (US letter), 8.5'’ x 11’’)

Édition complétée le 6 avril, 2006 à Chicoutimi, Ville de Saguenay, Province de Québec. 


\section{Charles Gide}

Cours d'Économie politique - tome II.

$4^{\mathrm{e}}$ édition, refondue et augmentée

\section{HH. חIVE \\ 마단 \\ couns

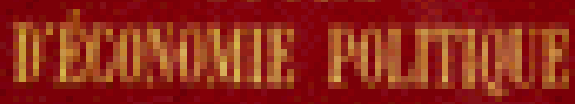

Tome II 


\title{
Table des matières du $2^{\mathrm{e}}$ volume
}

\author{
LIVRE DEUXIÈME : LA CIRCULATION \\ Chapitre $1:$ L'échange international
}

I. Les statistiques du commerce international

II. Pourquoi le commerce international tend toujours à prendre la forme du $\underline{\text { troc }}$

III. Ce qu'il faut entendre par balancé du commerce

IV. En quoi consistent les avantages de l'échange international

$\S 1$. Avantages des exportations

$\S 2$. Avantages des importations

\section{Chapitre II : La politique commerciale}

I. Historique du commerce international

II. Le libre-échange

III. Le système protectionniste

$\S 1$. Les dangers de la concurrence

$\S 2$. L'indépendance économique

$\S 3$. L'argument du travail national

$\S 4$. L'argument de la balance du commerce

$\S 5$. Le grief de cherté

$\S 6$. Les droits compensateurs. - Le dumping

$\S 7$. L'argument fiscal

IV. Le régime des traités

V. La législation douanière

VI. Les primes à la production

VII. De quelques atténuations du régime protectionniste (Admissions temporaires. - Ports francs)

VIII. De la protection de la marine marchande

IX. Le commerce colonial

$X$. Le commerce international pendant la guerre

XI. Les perturbations du change pendant la guerre

XII. L'échange international en ce qui concerne les capitaux et les personnes

§1. Exportation et importation des capitaux

§2. Émigration et immigration des personnes 


\section{LIVRE TROISIÈME : LA RÉPARTITION}

Première PARTIE : Les divers modes de répartition

Chapitre I : Le mode existant

I. L'inégalité des richesses

II. De la richesse des nations

III. Comment s'opère la répartition des biens

IV. Comment on acquiert la propriété

V. Quels biens peuvent faire l'objet du droit de propriété

VI. Quelles personnes peuvent être propriétaires

VII. Les attributs du droit de propriété. - L'hérédité

Chapitre II : Les modes socialistes

I. Les divers systèmes socialistes

II. Le communisme

III. Le collectivisme

IV. Le syndicalisme

V. Le coopératisme

DEUXIÈME PARTIE : Les diverses catégories de copartageants.

Les classes sociales

Chapitre I : Les propriétaires fonciers

I. L'évolution de la propriété foncière

II. Le revenu foncier. - La loi de la rente

III. La hausse de la rente et la plus-value

IV. Le fermage

$\mathrm{V}$. Le métayage

VI. De la légitimité de la propriété foncière

VII. Les systèmes de socialisation de la terre

$\S 1$. Communisme agraire

$\S 2$. Rachat de la terre par l'État

$\S 3$. La confiscation de la rente par l'impôt

VIII. Les systèmes de démocratisation de la propriété foncière IX. Les systèmes de conservation de la propriété foncière

X. La propriété urbaine

XI. La propriété des forêts 
XII. La propriété des mines

XIII. La propriété de l'eau

\section{Chapitre II. : Les capitalistes rentiers}

I. De la situation du rentier

II. Historique du prêt à intérêt. - L'usure et la réglementation de l'intérêt

III. Quelle est la cause de l'intérêt ?

$\S 1$. De la cause juridique de l'intérêt

$\S 2$. De la cause économique de l'intérêt

IV. Qu'est-ce qui détermine le taux de l'intérêt ?

V. Si le taux de l'intérêt tend à la baisse

Chapitre III. : Les salariés

I. Qui sont les salariés ?

II. Historique du salariat

III. Le contrat de salariat

IV. Les lois du salaire

$\S 1$. Théorie du fonds des salaires

$\S 2$. Théorie de la loi d'airain

$\S 3$. Théorie de la productivité du travail

V. Du juste salaire et des moyens de s'en rapprocher

VI. De la hausse des salaires.

VII. Les syndicats ouvriers

VIII. Les grèves

IX. La conciliation et l'arbitrage

$X$. La réglementation du travail

XI. Les garanties contre les risques

$\S 1$. La maladie

$\S 2$. Les accidents du travail

$\S 3$. La vieillesse

$\S 4$. L'invalidité

$\S 5$. La mort prématurée

$\S 6$. Le chômage

XII. La participation aux bénéfices et l'actionnariat ouvrier

XIII. De l'avenir du salariat

\section{Chapitre IV. : Les entrepreneurs}

I. L'évolution historique du patronat

II. Qu'est-ce que le profit ?

III. De la légitimité du profit et de l'avenir du patronat

IV. Du taux des profits 


\section{Chapitre V. : Les indigents}

I. Les différentes catégories d'indigents

II. Les divers modes d'assistance

III. L'organisation de l'Assistance publique

$$
\text { Chapitre VI. : L'État }
$$

I. Du rôle de l'État dans la répartition

II. La classification des revenus de l'État. - Les diverses catégories d'impôts

$\S 1$. Revenus domaniaux et industriels

$\S 2$. Droit sur les marchandises

$\S 3$. Taxes sur les actes

$\S 4$. Impôts sur les personnes

\section{LIVRE QUATRIÈME : LA CONSOMMATION}

Chapitre I. : La fonction du consommateur

I. Que faut-il entendre par le mot consommation ?

II. De la répartition des consommations

III. Les droits et les devoirs du consommateur

IV. La société coopérative de consommation

\section{Chapitre II. : La dépense}

I. Les dépenses de ménage

II. Le logement. - Les sociétés de construction

III. Le crédit à la consommation. - Les Monts-de-piété

IV. Les dépenses de luxe

V. Les consommations nocives. - L'alcoolisme

VI. L'absentéisme

VII. Du contrôle de la consommation par l'État

VIII. Les dépenses publiques

Chapitre III. : L'épargne

I. Les deux aspects de l'épargne

$\S 1$. L'épargne économie

$\S 2$. L'épargne prévoyance

II. Les conditions de l'épargne

III. Les institutions destinées à faciliter l'épargne

IV. L'assurance 
V. Le placement

Chapitre IV. : Si la production pourra suffire à la consommation

I. De la surpopulation. - Les lois de Malthus

II. De la dépopulation. - Les mesures proposées pour le relèvement de la natalité

INDEX ALPHABÉTIQUE 


\section{PrincipauX OUVRages du MÊMe AUTEUR}

La Coopération (Conférences de propagande), $3^{\mathrm{e}}$ édition, 1910.

Les Sociétés coopératives de consommation, $3^{\mathrm{e}}$ édition, 1916.

Les Institutions de progrès social, $4^{\mathrm{e}}$ édition, 1911.

Histoire des Doctrines économiques depuis les Physiocrates jusqu'à nos jours, par GIDE et RIST, 2 édition, 1919.

Principes d'Économie politique, 20édition, 1919.

TRADUCTIONS. - Tchèque, par l'Association d'étudiants, le Vsehrd », Prague, 1894. - Espagnole, par le professeur de Oloscoaga, Madrid, 1896. Polonaise, 3e édition, 1907, par le professeur Czerkowski. - Anglaise, 2e édition, 1901, par le professeur Veditz, Boston. - Finnoise, par le professeur Forsmann, Helsingfors, 1904. - Allemande, par le Dr Weiss von Wellenstein, Vienne, 1905. - Italienne, 2e édition, Milan, 1909, par M. Mortara. - Turque, par Hamid Bey et Tahin, Constantinople, 1909. Hollandaise, 4e édition, 1913, par le professeur Herckenrath. - Suédoise, 4e édition, 1915, par MM. Schauman et Braun, Stockholm. - Russe, 2e édition, 1916, par le professeur Totomiantz. — Japonaise, par M. Manji-Jijima, 1918.

Cours. - TRADUCTIONS. - Grecque, Par M. Krokidas, Athènes, 1911. Espagnole, par M. Docteur, Mexico, 1911. — Anglaise, par Mlle Archibald, Londres, 1914. 


\section{LIVRE II \\ LA CIRCULATION}

CHAPITRE 1

\section{L'ÉCHANGE INTERNATIONAL}

$\underline{\text { Retour à la table des matières }}$

Nous disons l'échange international et non le commerce international : c'est qu'en effet les échanges de pays à pays ne portent pas uniquement, comme le mot trop restreint de commerce, semble l'indiquer, sur les marchandises mais aussi sur les capitaux et sur les personnes. À côté des importations et exportations de marchandises et parallèlement on voit se former d'autres courants d'exportation et d'importation, capitaux en quête de placement, ouvriers qui apportent leur maind'œuvre, comme aussi riches absentéistes qui viennent dépenser leur argent. L'importance de ces nouvelles relations internationales va s'accentuant chaque jour : nous leur réserverons une section spéciale à la fin de ce chapitre.

\section{I}

\section{Les statistiques du commerce international.}

Le mouvement des échanges entre tous les pays du monde était évalué, à la veille de la guerre, à 220 milliards de francs. Il n'était évalué qu'à moins de 40 milliards en 1860, à 110 milliards en 1900 ; donc en un demi-siècle environ, il avait plus que quintuplé et doublé en ces derniers treize ans. Rien mieux que ces 
chiffres ne peut faire mesurer les progrès de la solidarité commerciale internationale — bien fragile pourtant, puisqu'un coup d'épée a suffi pour rompre presque totalement tous les fils de cette trame si bien tissée. Sur ces 220 milliards, les trois quarts sont au compte des États de l'Europe occidentale et centrale, de leurs colonies, et des États-Unis.

Il faut remarquer pourtant que ce gros chiffre doit être réduit de moitié si l'on veut simplement chiffrer la valeur des marchandises qui passent d'un pays à l'autre. En effet, ce chiffre global comprend les importations et les exportations totales, ce qui veut dire que chaque marchandise y figure deux fois, à l'entrée et à la sortie.

Quand on veut évaluer non le commerce mondial mais celui de chaque pays, alors il faut distinguer entre le commerce général et le commerce spécial. On entend par commerce général le mouvement de toutes les marchandises qui passent la frontière, à l'entrée ou à la sortie, alors même qu'elles ne sont pas destinées à rester dans le pays, qu'elles ne font que transiter, comme on dit. On entend par commerce spécial le mouvement des marchandises qui, à l'importation, sont destinées à la consommation du pays et qui, à l'exportation, sont de provenance nationale ${ }^{1}$. Il en résulte donc que les chiffres du commerce général sont toujours supérieurs à ceux du commerce spécial, mais la différence entre les deux chiffres est plus ou moins grande selon qu'il s'agit d'un pays qui, par sa situation géographique ou par ses traditions commerciales, est plus ou moins qualifié pour jouer le rôle de courtier international. Ainsi pour l'Angleterre, et plus encore pour la Hollande, la Belgique, la Suisse, la marge entre le commerce général et le commerce spécial est énorme ${ }^{2}$. Le commerce de transit a moins d'importance pour un pays que son commerce national ${ }^{3}$, mais pourtant il peut être une source de bénéfices considérables, et la preuve c'est qu'il est fort disputé. Quand on veut comparer le commerce de deux pays, il importe donc de ne pas mettre en balance les chiffres du commerce spécial de l'un avec les chiffres du commerce général de l'autre (et surtout ne pas additionner ceux du commerce spécial et ceux du commerce général !)

1 Les marchandises qui entrent sous le régime de l'admission temporaire (voir ci-après) - de même que celles en transit - ne figurent qu'au commerce général, à moins qu'au lieu d'être réexportées elles ne soient retenues pour la vente à l'intérieur.

2 Pour la France même la différence est assez importante, un quart environ ; c'est ainsi qu'en chiffres ronds (pour l'année 1913), nous avons 20 milliards de francs au commerce général et 15 milliards seulement au commerce spécial.

3 Généralement, mais pas toujours, les statistiques indiquent si les chiffres donnés sont ceux du commerce spécial ou du commerce général. C'est indiqué dans les tableaux de l'Annuaire Statistique de la France. Mais on ne trouve pas toujours pour chaque pays les deux à la fais. Ainsi, l'Angleterre ne donne que les chiffres du commerce général, ou, plus exactement, elle divise les chiffres de son commerce en trois catégories: importations, exportations, réexportations (des marchandises étrangères ou coloniales), ce qui veut dire que la distinction entre le commerce général et spécial est faite pour la sortie, mais non pour l'entrée. 
Il faut remarquer aussi que tous les chiffres donnés pour le commerce international se réfèrent aux valeurs et non aux quantités (celles-ci sont données seulement dans certaines publications spéciales) : il en résulte donc que ce qui paraît être un accroissement ou une diminution du commerce international peut ne correspondre à aucune variation réelle dans le volume du commerce international. C'est ainsi que depuis la guerre nous voyons que le chiffre des importations en France a doublé, tandis qu'au contraire la quantité de marchandises importées a plutôt diminué. Il y a donc là une cause d'erreur possible quand on compare les mouvements du commerce à des dates différentes. Ces évaluations sont faites dans les bureaux des douanes, mais en France elles sont rectifiées par une Commission spéciale composée de négociants. Elle doit se réunir une fois par an, mais il y a parfois lassez longs retards, en sorte que les chiffres de la dernière ou parfois même avant-dernière année ne sont donnés qu'à titre " provisoire » : tel a été le cas pour ceux des premières années de la guerre ${ }^{1}$.

Enfin, même pris à leur source, c'est-à-dire à l'administration des douanes, les chiffres sont loin d'offrir toutes garanties d'exactitude. Quand il s'agit d'importations et que les droits de douane sont perçus ad valorem, il y a chance que les évaluations de la douane soient exactes (si toutefois les déclarations des importateurs le sont), mais quand il s'agit d'exportations, lesquelles sont presque toujours exemptes de droits, ou même d'importations qui ne paient que des droits spécifiques, c'est-à-dire sans relations avec leur valeur (voir ci-après), il importe peu à la douane de faire des évaluations exactes ${ }^{2}$. Et il n’y a pas alors à s’étonner si les évaluations de la douane qui reçoit ne sont pas les mêmes que celle de la douane de sortie.

Telle est l'explication d'un fait au premier abord inexplicable, c'est que les statistiques du commerce international ne concordent jamais d'un pays à l'autre. Si elles étaient exactes, il est évident, par exemple, que le chiffre donné en France pour les exportations en Allemagne serait le même que celui donné en Allemagne pour les importations venant de France puisque ce sont les mêmes marchandises qui figurent sous ces deux rubriques. Or, tel n'est point le cas : nous trouvons, par exemple pour 1913, sur la statistique française 866 millions de francs d'exportations vers l'Allemagne, et sur la statistique allemande seulement 721 millions de francs (584 millions de marks) d'importations françaises en Allemagne !

Il n'y aurait pas lieu de s’en étonner si c'était l’inverse, c'est-à-dire si l'on voyait les mêmes marchandises évaluées plus haut quand elles entrent au pays de destination que quand elles sortent du pays de provenance, et cela par la raison

\footnotetext{
Les évaluations de "la Commission des valeurs en douane " sont utilisées en France pour l'établissement des Index Numbers (vol. I, p. 86).

2 Dans une thèse de doctorat de M. Schuller, La Statistique douanière et ses méthodes (1911), nous trouvons cette anecdote amusante. Dans une ville frontière, la Direction remarqua un jour que les chiffres des exportations avaient subi des écarts inexplicables: enquête faite sur ce phénomène, il se trouva tout simplement que l'employé avait été changé !
} 
bien simple que leur valeur peut se trouver majorée des frais de transport, surtout quand il s'agit de marchandises transportées à travers les mers. C'es, précisément ce que l'on constate dans la statistique du commerce mondial dont nous venons de donner les chiffres. Le chiffre global des importations s'y trouve toujours supérieur de quelques milliards au chiffre global des exportations ${ }^{1}$. Cette différence qui, à première vue, semble une absurdité - d'autant plus que par suite des naufrages et déchets une certaine quantité de marchandises se perd en route - s'explique précisément par ce fait que la valeur de toutes ces marchandises s'est accrue en cours de route de tout le montant des frais de transport et d'assurance ${ }^{2}$. Mais quant à la supériorité du chiffre de sortie sur celui à l'entrée, comme dans le cas cidessus, elle ne peut s'expliquer que parce qu'une partie des marchandises déclarées pour l'Allemagne n'y allaient qu'en transit.

Quelle est l'importance du commerce extérieur par rapport au commerce intérieur ? C'est assez difficile à dire, le commerce intérieur ne donnant lieu à aucune statistique en ce qui concerne les valeurs : il y en a une seulement en ce qui concerne les quantités (nombre de tonnes) transportées par chemins de fer ou canaux. Tout ce qu'on peut dire c'est que cette proportion est considérable. En effet, le revenu total de la France, c'est-à-dire la valeur globale de toute sa production, était évalué avant la guerre à 30 milliards environ — or le chiffre de ses exportations et celui de ses importations étant de 7 ou 8 milliards chacun, il faut en conclure que la France demande à l'étranger une somme de produits au moins égale au quart de sa production nationale et lui cède en échange un quart de sa production. Mais si l'on voulait évaluer le mouvement d'affaires auxquels donne lieu le commerce extérieur et intérieur, la proportion serait beaucoup plus forte pour le second parce que la marchandise exportée ou importée n'est comptée qu'une fois, à l'entrée ou à la sortie, tandis que les produits nationaux, y compris les marchandises importées, donnent lieu à une série indéfinie de ventes et reventes, et devraient par conséquent être comptées peut-être dix fois.

1 M. March, directeur de la statistique de la France, en évaluant à 220 milliards de francs l'ensemble du commerce du monde, évalue à 116 milliards celui des importations, donc il reste 104 milliards comme chiffre des exportations.

2 C'est ce qu'on exprime par la formule $c$ a $f$, ce qui veut dire que la valeur indiquée pour la marchandise est celle comprenant à la fois le coût d'achat $(c)$, l'assurance $(a)$ et le fret $(f)$. 


\section{II}

\section{Pourquoi le commerce international tend toujours à prendre la forme du troc.}

Retour à la table des matières

Dans les statistiques commerciales on voit tous les pays figurer à la fois comme importateurs et comme exportateurs ; et même il semble qu'il y ait toujours une certaine solidarité entre les importations et les exportations, non au sens d'une égalité, ce qui n'arrive presque jamais, mais en ce sens qu'elles se meuvent généralement sur des lignes parallèles: elles montent ou descendent simultanément.

Pourquoi ? Quel est donc le lien qui, dans tout pays, relie les importations et les exportations? Pourquoi ne voit-on pas de pays qui vende au dehors sans acheter ou, inversement, qui achète sans vendre ? On le voit pourtant quand il s'agit d'individus : par exemple, le rentier achète toujours mais ne vend jamais, n'ayant rien à vendre, ni produits, ni services, tandis qu'inversement tel paysan qui vit sur sa terre et de sa terre s'enrichit en vendant l'excédent de ses récoltes sur sa consommation et n'achète presque jamais rien. - Oui, cela est possible pour un individu parce que la quantité d'argent qu'il retire du marché par ses ventes, on celle qu'il y apporte par ses achats, est insignifiante par rapport au stock monétaire existant, mais quand il s'agit des milliards achetés ou vendus par un pays, la quantité de monnaie existant ne peut suffire à de telles opérations. Si, par exemple, la France était uniquement importatrice et si elle devait payer en monnaie les 8 à 9 milliards auxquels s'élève la valeur de ses importations, il ne lui resterait plus un sou dès la première année, puisque tout son stock monétaire or (le seul qui serve aux paiements à l'étranger) n'est pas même égal à ce chiffre. Ce serait bien pis pour l'Angleterre, puisque le chiffre de ses importations s'élève à 20 milliards et son stock monétaire seulement à 3 ou 4 milliards ! En deux mois il serait ratissé !

Les achats faits à l'étranger sous forme d'importations ne se paient donc presque jamais en argent, mais par le moyen de lettres de change ou titres de créance similaires. Mais d'où viennent ces lettres de change, quelle est leur origine ? Chacune d'elles représente une vente faite à l'étranger, une exportation ${ }^{1}$.

\footnotetext{
Nous disons : vente faite à l'étranger, c'est-à-dire à un pays quelconque. Il n'est pas nécessaire en effet que la lettre de change représente une vente faite précisément au pays auquel la France a acheté : c'est une coïncidence ; il est peu probable qu'achat et vente se balancent exactement s'il n'y avait que deux pays en jeu. Mais si la France a acheté pour 1 million de thé en Chine et que, ne lui ayant rien vendu, elle n'ait point de traite sur Shangaï ou Hong-Kong à lui envoyer, elle pourra aussi bien s'acquitter en lui envoyant 1 million en traites sur Londres qui
} 
Et c'est bien mieux que la monnaie, car le stock monétaire s’épuise tandis que cette source se renouvelle sans cesse.

Il n'y a donc qu'un moyen pour un pays de payer ses importations — du moins s'il s'agit d'un courant régulier d'importation — c'est de le payer en marchandises, c'est-à-dire par des exportations. Que se passerait-il s'il n'était pas en mesure de le faire ? Eh bien ! la monnaie disparaissant, ou devenant rarissime, acquerrait une plus-value énorme, conformément à la loi de l'offre et de la demande, ce qui veut dire qu'il y aurait une baisse énorme du prix de toutes choses. Or il est clair que du jour où toute chose serait à plus bas prix dans le pays qu'à l'étranger, personne ne serait assez fou pour continuer à acheter au dehors ce qu'il pourrait se procurer à bien meilleur marché chez lui. On ne voit guère les marchandises aller des endroits où elles sont chères vers ceux où elles sont à bas prix ${ }^{1}$, pas plus qu'on ne voit les fleuves remonter leur pente. Donc les importations s'arrêteraient absolument. C'est pourquoi on formule cette loi : un pays ne peut importer qu'autant qu'il peut exporter et dans la mesure de ses exportations ${ }^{2}$.

Soit ! dira-t-on, on comprend qu'un pays ne puisse jouer toujours le rôle d'importateur, faute de numéraire en quantité suffisante, mais pourquoi ne pourrait-il exporter indéfiniment et sans contrepartie? — Exactement par les mêmes raisons que tout à l'heure.

$1^{\circ}$ D’abord, parce que pour qu'un pays pût toujours jouer le rôle d'exportateur sans importer jamais, il faudrait que les autres pays acceptent le rôle inverse, c'està-dire celui d'importateurs sans exporter ; or nous venons d'expliquer pourquoi ils ne le pourraient pas, alors même qu'ils le voudraient $;-2^{\circ}$ de plus, en supposant même qu'un pays pût trouver, par force ou par ruse, le moyen d'exporter sans importer, que se passerait-il ? Il se trouverait accumuler une telle quantité de monnaie que celle-ci se trouverait énormément dépréciée et qu'il s'ensuivrait une hausse générale des prix, laquelle aurait nécessairement pour effet d'arrêter ses exportations. Comment, en effet, des marchandises qui seraient beaucoup plus chères à l'intérieur qu'à l'étranger pourraient-elles trouver acheteur à l'étranger ? Si la France, par exemple, devait toucher en monnaie le prix de ses 7 milliards d'exportation, son stock numéraire se trouverait plus que doublé en une seule année et augmenterait d'autant chaque année — et que pourrait-elle faire de cette

représenteront peut-être du vin français vendu en Angleterre. Et si on n'arrive point encore en se mettant à trois de jeu, on pourra arriver à quatre ou cinq (Vol. I, p. 96).

D'ailleurs, à défaut de traite provenant de la vente de marchandises, on peut employer comme instrument de paiement tout autre titre de créance sur l'étranger provenant d'une des nombreuses sources énumérées ci-après (pp. 12-15).

Sauf dans un cas particulier que nous expliquerons ci-après (p. 23).

Seulement il faut prendre garde qu'il n'y a pas seulement des exportations sous forme de marchandises, mais aussi des exportations invisibles, comme on dit, c'est-à-dire celles qui ne figurent pas dans les statistiques des douanes — tout ce qu'ont consommé sur place les voyageurs étrangers ou qu'ils emportent dans leurs malles, les approvisionnements en charbon des navires en partance, les navires eux-mêmes s'ils ont été construits dans le pays, etc. 
masse de numéraire dépréciée, sinon l'employer précisément à faire des achats à l'étranger, c'est-à-dire l'utiliser là où elle ne serait pas dépréciée comme chez elle ?

L'engrenage des faits se présente donc ainsi :

Y a-t-il excès d'importations ? Alors il y a une sortie de numéraire, laquelle détermine une baisse des prix, laquelle baisse a pour effet tout à la fois d'enrayer l'importation et de stimuler les achats de l'étranger, c'est-à-dire les exportations ;

Y a-t-il excès d'exportations? Alors il y a une inondation de numéraire, laquelle détermine une hausse des prix, laquelle hausse a pour effet tout à la fois d'arrêter les achats de l'étranger, c'est-à-dire les exportations, et de stimuler au contraire les achats des nationaux au dehors, c'est-à-dire les importations.

Il n'est même pas besoin d'attendre que la baisse ou la hausse des prix se soit réalisée pour que le courant des importations et des exportations se renverse : un mécanisme plus subtil suffit à déclencher ce mouvement. C'est le cours du change. Chaque exportation crée une créance qui est généralement représentée par une lettre de change ou, comme on dit, du papier sur l'étranger (Voir Le change, I, pp. 519 à $555^{1}$ ). Ce papier est donc d'autant plus abondant que les exportations auront été plus nombreuses — et il est d'autant plus demandé que l'importation a été plus active, car ce sont les importateurs qui le recherchent comme moyen de paiement plus commode que l'envoi de numéraire. Le cours de ce papier subit donc l'action de l'offre et de la demande, comme n'importe quelle marchandise. Ceci compris, supposons un pays qui a beaucoup importé et très peu exporté. Il en résultera que le papier sur l'étranger sera rare et fera prime : une lettre de change de 1.000 francs sur Genève ou Bruxelles se négociera peut-être à 1.010 francs ; ce sera donc une véritable prime à l'exportation, qui ne peut que la stimuler, tandis qu'à l'inverse ce sera une perte égale infligée aux importateurs qui en auraient besoin pour leurs paiements et par conséquent une sorte de pénalisation infligée à l'importation qui ne peut que l'enrayer. Et par conséquent, la hausse du change tend à intervertir la situation qui l'a créée et que nous avons prise comme point de départ. C'est le même mécanisme automatique que celui de la hausse des prix, mis qui agit en sens inverse, la hausse des prix étant causée par l'excès d'exportation et provoquant l'accroissement des importations, tandis que la hausse du change est causée par l'excès des importations et tend à provoquer des exportations.

En résumé, il y a un jeu automatique dans la balance des comptes qui lui permet de reprendre d'elle-même la position d'équilibre quand elle s'en est écartée - la variation de valeur de la monnaie opérant à la façon de ces régulateurs des machines à vapeur qui tendent à ramener toujours la vitesse de la machine à sa

1 [N.B. Les numéros de pages et de notes de bas de page font référence aux numéros de pages et de notes de bas de page de l'édition de papier et non de cette édition numérique. L'édition numérique du volume I est disponible sur ce site. $M B]$ 
position d'équilibre. Le courant ne peut jamais persister dans le même sens, pas plus qu'un courant de marée : tôt ou tard il se renverse et, après avoir emporté le numéraire, il le rapporte.

C'est Ricardo qui a donné à cette démonstration une formule très frappante en disant que l'échange international tend toujours à prendre la forme du troc comme chez les sauvages, sauf, bien entendu, la supériorité des procédés employés, c'est-à-dire que l'échange ne se fait pas en nature, en troquant marchandises contre marchandises ${ }^{1}$, mais plus exactement en compensant les titres de créances qui représentent les marchandises échangées.

Ce raisonnement a priori se trouve d'ailleurs confirmé par les faits, car l'expérience a démontré que toutes les fois que, à la suite d'un traité de commerce ou par toute autre cause, un pays a vu ses importations augmenter dans une forte proportion, il n'a jamais manqué de voir ses exportations augmenter parallèlement. Et réciproquement si, par le moyen d'un tarif protectionniste, il réussit à diminuer ses importations, il doit s'attendre à voir diminuer proportionnellement ses exportations ${ }^{2}$.

D'ailleurs, comme nous l'avons vu, toutes les statistiques démontrent que le numéraire n'intervient que pour une très faible part dans le règlement du commerce international -3 à 4 p. 100 environ ${ }^{3}$. Il faut donc bien admettre que la balance des comptes se règle d'elle-même et que créances et dettes tendent à s'équilibrer. C'est ce que, dans l'école de Bastiat, on appelait « une harmonie économique ».

1 M. Herckenrath, dans la traduction hollandaise, fait remarquer que pour les pays, comme pour les individus, l'échange ne se fait pas toujours marchandise contre marchandise mais peut se faire marchandise contre service ou vice versa. Cela est vrai : lorsque, par exemple, la Suisse donne, en échange de l'argent des touristes, la vue de ses cascades, ou l'Italie celle de ses tableaux, ces pays n'ont besoin de fournir aucune marchandise comme contre-partie. Il faut donc prendre le mot de troc dans le sens le plus large comme embrassant les services aussi bien que les marchandises.

2 Toutes choses égales d'ailleurs, faut-il avoir soin d'ajouter, car il ne faudrait pas en conclure que dans l'histoire commerciale d'un pays les courbes des exportations et des importations restent nécessairement parallèles. Sous l'influence de causes propres à chacune d'elles, elles se rapprochent ou s'éloignent : la différence maximum a été de 1.565 millions en 1880 ; elle tend à diminuer depuis lors, et les protectionnistes l'attribuent avec orgueil au régime douanier de 1892 - et même une fois, en 1905, les exportations ont dépassé les importations.

3 Mettons en regard pour la France le mouvement des marchandises et celui des métaux précieux des cinq années avant la guerre, 1909-1913 (exportations et importations réunies), en additionnant les chiffres donnés à la page suivante :
Marchandises
69.758 millions de francs.
Monnaies
4.782

Ce mouvement de la monnaie ne représente donc que la quinzième partie $(6,87$ p. 100$)$ du mouvement des marchandises. Et encore le chiffre est-il trompeur, car ces métaux précieux sont pour une grande partie des lingots destinés à des emplois industriels et constituent par conséquent une véritable marchandise. Il ne faut compter que les deux tiers de ces chiffres pour le mouvement de la monnaie proprement dite : donc 3 milliards de monnaie environ contre 70 milliards de marchandises, soit 4 p. 100 seulement. 


\section{Ce qu'il faut entendre par balance du commerce.}

Retour à la table des matières

On appelle balance du commerce la différence entre la valeur des importations et celle des exportations. Si nous consultons les statistiques des exportations et des importations dans tous les pays, nous voyons cette balance du commerce pencher tantôt du côté des importations, tantôt du côté des exportations : toutefois, le premier cas est de beaucoup le plus fréquent.

Prenons pour exemple la France. Voici les chiffres du commerce de la France (commerce spécial) dans les cinq années qui ont précédé la guerre ${ }^{1}$.

\section{Importations}

1909

1910

1911

1912

1913
6.246 millions

7.173

8.066

8.231

8.421

Total

\section{$\underline{\text { Exportations }}$}

5.718 millions

$6.234 »$

$6.077 »$

$6.172 »$

$\underline{6.880 »}$

$31.621 "$

Les chiffres ci-dessus sont ceux de l'Annuaire Statistique de la France publié annuellement par le ministère du Travail.

Nous prenons les années antérieures à la guerre parce que, depuis la guerre, la balance du commerce ne joue plus : l'échange entre tous les pays a été complètement bouleversé et devra faire l'objet d'explications spéciales que l'on trouvera plus loin.

Pour le commerce général en 1913 les chiffres sont :

$\begin{array}{cc}\text { Importations } & 10.724 \text { millions, } \\ \text { Exportations } & 9.260 ~ \\ \text { Total } & \mathbf{1 9 . 9 8 4} »\end{array}$


En comparant ces deux colonnes on voit donc que, dans une période de cinq ans seulement la France a acheté à l'étranger pour 6.516 millions de francs de marchandises de plus qu'elle ne lui en a vendu, ce qui représente un excédent annuel des importations sur les exportations de 1.300 millions ${ }^{1}$.

Faut-il conclure de ces chiffres que la France était obligée de payer tous les ans à l'étranger 1.300 millions de francs en monnaie ? Ce n'est pas probable, car il est facile de constater par l'observation la plus superficielle que la quantité de monnaie en circulation ne paraît pas avoir sensiblement diminué. Mieux que cela ! elle a augmenté. En effet, les mêmes douanes qui enregistrent les exportations et les importations de marchandises, enregistrent aussi les entrées et les sorties de métaux précieux. Or voici les chiffres relatifs à la même période pour l'or entré et sorti $^{2}$ :

1 Voici, comme terme de comparaison, les chiffres ci-dessous qui sont ceux donnés dans la $1^{\text {re }}$ édition de nos Principes :

$\begin{array}{lcc} & \underline{\text { Importations }} & \text { Exportations } \\ 1876 & 3.988 \text { millions } & 3.576 \text { millions } \\ 1877 & 3.670 " & 3.436 " \\ 1878 & 4.176 " & 3.180 " \\ 1879 & 4.595 " & 3.231 " \\ 1880 & \underline{5.033} " & \underline{3.468} " \\ \text { Total } & \mathbf{2 1 . 4 6 2} " & \mathbf{1 6 . 8 9 1} "\end{array}$

En comparant ces deux périodes quinquennales, à trente-trois années de distance, en remarquera : $-1^{\circ}$ que l'ensemble du commerce (exportations ou importations) a presque doublé (de $7 \frac{1}{2}$ milliards en moyenne à près de 15 milliards) $;-2^{\circ}$ que l'accroissement est un peu plus grand sur les exportations (87 p. 100) que sur les importations (78 p. 100) ; - $3^{\circ}$ que, par conséquent, la balance du commerce est devenue moins défavorable (dans le sens que nous allons définir) ; le rapport entre les exportations et les importations qui était comme 79 à 100 est aujourd'hui comme 83 à 100.

Toutefois, il ne faut pas oublier que les prix ont changé au cours de ces trente années (I p. 90) et que, par conséquent, les accroissements en valeurs chiffrés ci-dessus ne correspondent pas exactement aux accroissements en quantités.

2 Ces chiffres sont ceux donnés par L'Économiste Français (7 février 1914).

Sans doute, les relevés de la douane ne sont pas exacts : la monnaie que les voyageurs portent sur eux, par exemple, n'y figurant pas. Mais les erreurs ou omissions devant être à peu près les mêmes pour les entrées et les sorties, le rapport entre les deux termes n'en doit pas être sensiblement modifié.

D'ailleurs, la même preuve est fournie aussi par les encaisses des banques, par exemple celle de la Banque de France qui n'a cessé de monter depuis trente ans et a passé de 1.824 millions de francs en 1881 à 4.500 millions à la veille de la guerre. L'augmentation est encore plus frappante si l'on ne regarde que l'encaisse or : elle a passé de 604 millions en 1881 à un peu plus de 4 milliards en juillet 1914, soit environ 3.500 millions d'accroissement dans ces trentecinq années. 


\section{Importations}

1909

1910

1911

1912

1913

\begin{tabular}{|c|c|c|c|c|}
\hline & 540 & illions & 361 & nillion \\
\hline & 406 & $»$ & 390 & $»$ \\
\hline & 455 & » & 285 & $»$ \\
\hline & 531 & » & 325 & $»$ \\
\hline & $\underline{1.054}$ & $»$ & $\underline{435}$ & $»$ \\
\hline lat & 2.986 & & 1.796 & $"$ \\
\hline
\end{tabular}

Le stock numéraire de la France s'est donc accru, durant cette Mme période de 1.190 millions, soit 240 millions par an! C'est donc précisément l'inverse de ce que nous attendons !

Si nous prenions l'Angleterre, les chiffres seraient plus surprenants encore. L'excédent annuel des importations sur les exportations atteint régulièrement 3 à 4 milliards de francs ${ }^{1}$, c'est-à-dire que chaque année devrait suffire pour enlever tout le numéraire de l'Angleterre, car il ne dépasse guère 3 milliards de francs ! Il n'en est rien pourtant et nous voyons au contraire, là comme en France, les entrées de numéraire dépasser ordinairement les sorties.

Quel est donc le mot de l'énigme ? Celui-ci tout simplement : pour savoir si un pays exportera ou importera du numéraire, ce n'est point uniquement la balance de ses exportations et de ses importations qu'il faut considérer, comme on le fait généralement dans le public mais la balance de ses créances et de ses dettes. Or, la balance des comptes n'est pas la même que la balance du commerce: les exportations constituent bien une créance sur l'étranger et même la principale, mais il peut exister d'autres moyens de se procurer de l'or: les importations constituent bien aussi la principale dette vis-à-vis de l'étranger, mais elle n'est pas la seule.

Et quelles sont donc ces créances ou ces dettes internationales distinctes des exportations et des importations, que l'on a appelées très bien les exportations ou importations invisibles?

Voici les chiffres du commerce de l'Angleterre pour les trois dernières années avant la guerre commerce général (la livre sterling comptée au pair de 25 fr. 22) :

$\begin{array}{ccccc}1911 & \text { Importations } & 17.115 & \text { Exportations } & 14.024 \\ 1912 & » & 18.763 & » & 14.627 \\ 1913 & » & \underline{19.394} & » & \underline{\mathbf{1 6 . 0 1 4}} \\ & & \mathbf{5 5 . 2 7 2} & & \mathbf{4 4 . 6 6 5}\end{array}$

Ainsi dans cette période de trois années seulement, l'excédent des importations est de plus de 10 milliards de francs, ce qui représente trois fois la valeur des monnaies existant en Angleterre, laquelle n'est pas évaluée à plus de 3.500 millions.

De même pour l'Allemagne et la plupart des pays. Il n'y a guère que la Russie, les États-Unis, la République Argentine, dans lesquels les exportations dépassent notablement les importations. 
Elles sont nombreuses, voici les principales ${ }^{1}$

$1^{\circ}$ Les frais de transport des marchandises exportées c'est-à-dire le fret et l'assurance. - Si le pays qui exporte fait lui-même le transport de ces marchandises, ce qui n'est pas toujours le cas, il acquiert une créance sur l'étranger qui assurément ne figurera pas dans les exportations, puisqu'elle ne prend naissance qu'après que la marchandise est sortie du port et en route pour sa destination. Un pays comme l'Angleterre a de ce chef une créance énorme sur l'étranger : elle a été évaluée par le Board of Trade à 2 1/2 milliards de francs par an. Non seulement en effet l'Angleterre transporte la totalité de ses propres marchandises, mais encore la plus grande partie des marchandises des autres pays, et naturellement elle ne le fait pas gratis.

La France au contraire a, de ce chef, une dette évaluée à 300 ou 400 millions de francs. En effet elle ne transporte sur ses propres navires que moins de moitié du tonnage de ses exportations et guère plus du quart de ses importations par voie de mer.

$2^{\circ}$ Les intérêts des capitaux placés à l'étranger. - Les pays riches placent à l'étranger une grande partie de leurs épargnes et, de ce chef, ont à toucher au dehors tous les ans des sommes très considérables en coupons de rentes, d'actions ou d'obligations, ou même sous forme de fermages ou de profits d'entreprises industrielles ou commerciales. On évaluait le montant des capitaux placés au dehors, avant la guerre, à près de 4 milliards de livres (100 milliards de francs), dont 60 milliards aux Indes et dans les autres colonies britanniques, 40 milliards à l'étranger - ce qui représentait un tribut annuel de 4 à 5 milliards de francs que l'Angleterre prélevait de ce chef sur l'étranger ou sur ses propres colonies. Non seulement c'est sur la place de Londres que les Indes et les colonies d'Australasie ont négocié la presque totalité de leurs emprunts, mais encore que d'entreprises que les Anglais dirigent ou commanditent dans le monde entier ! Ils se sont rendus acquéreurs aux États-Unis de terrains dont la superficie est évaluée à 8 millions d'hectares, la superficie de l'Irlande. - La France aussi a des créances considérables sur l'étranger. On les évaluait à 40 milliards de francs, représentant donc un revenu annuel de 2 milliards environ. Il est vrai que depuis la guerre les créances de ces deux pays sur l'étranger mais surtout celles de l'Angleterre, ont subi une forte diminution et même se trouvent compensées en partie par des dettes contractées vis-à-vis de l'étranger, presque exclusivement vis-à-vis des États-Unis (voir ci-après).

\footnotetext{
Mais il faut se garder d'y faire figurer, comme le font parfois des traités d'Économie politique, les profits des exportateurs. Ces profits sont déjà comptés dans la valeur des exportations et cela ferait donc double emploi. Nous avons dit que ces valeurs sont fixées par une commission dite Commission des valeurs en douane, d'après le cours des marchandises ; or, ce cours correspond au prix de vente et comprend non seulement les profits des fabricants, mais les frais de transport et d'assurance, ce qu'on appelle $c$ a $f$ (voir ci-dessus, p. 4).
} 
L'Allemagne aussi était créancière de ce chef, quoique pour une somme probablement inférieure, non qu'elle soit moins riche, non qu'elle épargne moins, mais parce qu'elle trouvait chez elle plus facilement l'emploi de ses épargnes. Néanmoins ses placements au dehors étaient en voie d'augmentation rapide.

Au contraire, la Russie ${ }^{1}$, l'Espagne, la Turquie, l'Égypte, les Indes, les républiques de l'Amérique du Sud, figurent toujours comme débitrices.

Toutefois, remarquez que lorsque les pays obérés émettent un emprunt — et aussi longtemps que cet emprunt n'est pas entièrement souscrit - les rôles sont renversés : ce sont eux qui deviennent momentanément créanciers des pays qui ont à leur envoyer des fonds, et ce sont ceux-ci qui sont constitués leurs débiteurs. Tous les ans la France fait des placements nouveaux à l'étranger et doit, par conséquent, envoyer de l'or qui est à déduire de celui qu'elle fait venir pour les intérêts de ses placements anciens. Il peut y avoir telle année où elle ait plus de numéraire à envoyer qu'à recevoir.

$3^{\circ}$ Les dépenses faites par les étrangers résidant dans le pays. Lorsque l'argent qu'ils dépensent n'est pas le produit de leur travail, mais qu'ils le tirent de leurs terres ou des capitaux placés dans leur pays d'origine, il y a là, pour tout pays fréquenté par de riches étrangers, un courant de créances continu ${ }^{2}$. Elles ont été évaluées à 450 millions de francs pour l'Italie, à 300 millions de francs pour la Suisse. Elles doivent s'élever à un chiffre au moins égal à celui de l'Italie pour la France, qui héberge à Paris, à Nice, à Pau, etc., un nombre considérable de rentiers étrangers ${ }^{3}$.

Et il y a lieu de croire que ce chiffre augmentera considérablement après la guerre, non seulement parce que les champs de bataille deviendront lieux de pèlerinage, mais parce qu'il est à prévoir que bon nombre d'Américains et d'Anglais se fixeront en France comme industriels et même comme propriétaires (voir ci-après).

\footnotetext{
La Russie devait payer à l'étranger, surtout à la France, 700 millions d'intérêt pour ses emprunts, plus une centaine de millions de dividendes pour les entreprises industrielles commanditées par des capitalistes étrangers.

2 Les achats de vêtements ou objets mobiliers faits par les voyageurs et emportés dans leurs malles ne figurent pas dans la statistique des exportations, quoiqu'ils en soient parfaitement.

3 On inscrivait à Paris, dans les hôtels et maisons meublées, de 500.000 à 600.000 étrangers chaque année. Admettons que chacun d'eux dépensât en moyenne 500 francs pour son séjour, hypothèse très inférieure à la réalité, car il en est qui dépensent cette somme chaque jour - cela ferait 250 à 300 millions de francs. Mais il n'y a pas en France que Paris comme rendez-vous pour les étrangers : on évaluait à 300 millions les dépenses faites par les étrangers sur la Côte d'Azur, et il y a d'autres centres de colonies étrangères, à Pau dans les Pyrénées, au Puy en Haute-Loire, en Bretagne, etc.
} 
Divers pays commencent à se rendre compte que le tourisme peut donner une source considérable de revenus et cherchent à utiliser à cet effet leurs curiosités naturelles ou artistiques — Norvège, Portugal, Égypte, Japon, etc.

Au contraire, les États-Unis, l'Angleterre et la Russie sont débitrices de ce chef de centaines de millions. C'est comme un prix de pension que ces pays ont à payer pour leurs nationaux.

$4^{\circ}$ Les envois d'argent des émigrants pour les pays d'émigration. — Ainsi pour l'Italie ils sont évalués à 450 millions ${ }^{1}$, déduction faite des sommes relativement minimes que les émigrants emportent sur eux à leur départ, et pour la Hongrie à 200 millions de francs.

Inversement on évaluait à près de 1.300 millions de francs (270 millions de dollars) le montant des paiements faits annuellement par les États-Unis à l'Europe, sous forme de mandats-poste ou de chèques envoyés par les émigrants.

$5^{\circ}$ Les commissions des banquiers quand ils étendent leurs opérations à l'étranger. - Des places comme celles de Londres, de Paris ou de Berlin, reçoivent des ordres et font des opérations pour le monde entier, et, comme elles ne les font pas gratis, elles sont créancières de ce chef de sommes considérables.

$6^{\circ}$ La vente des navires. - Les navires achetés ne figurent pas sur les registres des douanes, pas plus à l'entrée qu'à la sortie. Or, l'Angleterre, qui construit des navires pour tous les pays, est créancière de ce chef d'une somme énorme, tandis que la France à cet égard est plutôt débitrice.

On voit que, dans les relations internationales, les créances résultant des exportations et les dettes résultant des importations ne sont que des chapitres faisant partie d'un vaste ensemble - et que, par conséquent, la balance du commerce proprement dite peut se trouver favorable ou défavorable sans que la balance générale des comptes le soit. Sans doute, de toutes les créances ou dettes, ce sont bien celles résultant des opérations commerciales qui sont les plus considérables —néanmoins, comme on vient de le voir, les autres aussi peuvent s'élever à des chiffres très importants. Le milliard, ou peu s'en faut, que l'Italie reçoit de ses visiteurs et de ses émigrants n'a pas peu contribué à améliorer sa situation financière.

Si l'on pouvait connaître assez exactement le montant des créances et des dettes de chaque pays - y compris, bien entendu, les exportations et les importations on saurait quel est le solde qui reste au crédit ou au débit de chaque pays, et on constaterait que la quantité de numéraire qui entre ou qui sort est égale à ce solde.

D'après un rapport du Directeur de la Banque d'Italie à l'Institut national de statistique, M. Stringher. Et cette évaluation remonte déjà à 1909-1910. 
Ainsi, pour la France, on pourrait dresser la balance des comptes sous la forme du tableau que voici, simplement comme illustration et sans prétendre à l'exactitude des chiffres inscrits :

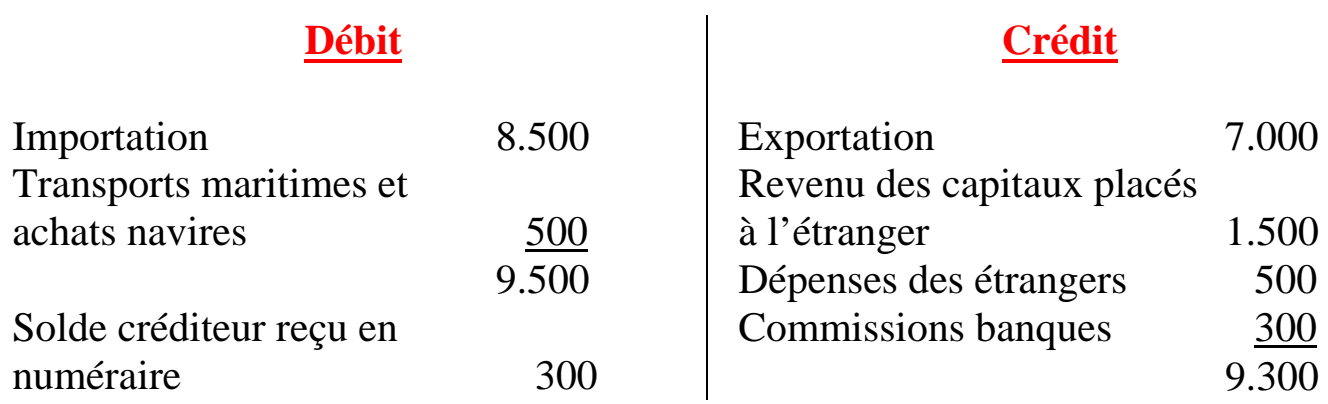

\section{En quoi consistent les avantages de l'échange international.}

\section{$\underline{\text { Retour à la table des matières }}$}

Ne sont-ils pas les mêmes que ceux de l'échange entre individus ? Or rappelons-nous ceux-ci. En ce qui concerne l'avantage individuel pour chacun des coéchangistes, c'est de recevoir plus qu'il ne cède : plus non en valeur puisque par définition, les valeurs échangées sont égales, mais plus en utilité finale (I, p. 368). En ce qui concerne la société, l'avantage est d'utiliser des richesses qui, sans l'échange, n’auraient servi à rien et aussi par l'extension de la division du travail, d'utiliser pour le mieux les aptitudes de chacun.

D'après les libre-échangistes, tels sont bien, en effet, les avantages de l'échange international : il n'y a pas à en chercher d'autres. C'est pour chaque pays d'obtenir le plus possible en échange de ce qu'il donne et, par conséquent, le bénéfice du commerce international se mesure par l'excédent de ses importations sur ses exportations. Si la France importe pour une valeur de 8 milliards de marchandises moyennant une exportation de 7 milliards, la différence de 1 milliard représente le gain réalisé. Nous avons expliqué tout à l'heure comment l'échange international prend toujours la forme d'un troc : l'exportation n'est donc pour un pays que le prix en nature qu'il doit payer pour acquérir les marchandises qu'il a besoin d'importer, 
le seul moyen qui soit à sa disposition parce qu'il ne peut que momentanément et accidentellement payer en monnaie ${ }^{1}$.

Mais les protectionnistes se placent à un point de vue précisément inverse ! Pour eux c'est l'exportation qui est le but. L'importation peut être une nécessité pour fournir, soit à la consommation, soit à l'industrie, les produits ou les matières premières qui lui font défaut, et il faut bien qu'elle s'y résigne si elle ne peut faire autrement, mais c'est en ce cas une dépense qui doit être inscrite à son débit. Par conséquent, si la France, pour reprendre les chiffres précédents, n'exportait que 7 milliards et importait 8 milliards, elle serait en perte de 1 milliard par an. Mais heureusement elle a, comme nous l'avons vu, à côté de ses exportations en marchandises, des exportations invisibles qui rétablissent l'équilibre et même lui laissent un solde créditeur. Il n'en est pas moins vrai que c'est l'exportation qui constitue l'actif et l'importation le passif. N'est-ce pas ainsi que n'importe quel commerçant ou fabricant fait son compte ? S'il a acheté pour 100.000 francs de marchandises et de matières premières et qu'il en ait vendu pour 120.000 francs, il dira qu'il a gagné la différence - et s'il avait eu le malheur de ne vendre que pour 80.000 francs, il dirait qu'il a perdu la différence. Ne serait-il pas dans le vrai ?

Le raisonnement des libre-échangistes serait irréfutable si un pays n'exportait que pour importer, l'exportation n'étant que le moyen et l'importation la fin — de même qu'un sauvage qui cède (exporte) une dent d'éléphant pour obtenir un fusil et croit avoir fait une bonne affaire - ou, si l'on veut une autre comparaison, comme la Suisse qui, depuis la guerre, vend à l'Allemagne du bétail ou des montres pour avoir le charbon qui lui manque. Et de même serait irréfutable le raisonnement des protectionnistes si un pays n'importait que pour exporter, l'importation n'étant que le moyen et l'exportation étant le but, de même qu'un commerçant qui par définition même, achète pour revendre. Mais ce qui différencie l'échange international de l'échange individuel c'est que dans celui-ci l'échange forme un tout inséparable et qu'il serait absurde de rechercher ce qui vaut le mieux de l'achat ou de la vente, l'un et l'autre n'étant que les deux faces d'un même acte, tandis qu'au contraire dans l'échange international exportations et importations constituent des opérations tout à fait indépendantes, faites par des personnes différentes et qui s'ignorent, chacun des millions de vendeurs ou d'acheteurs opérant pour son propre compte.

Cette démonstration revient sans cesse, sous des formes ingénieuses d'ailleurs, dans les Sophismes de Bastiat, mais on la trouvera aussi dans les publications les plus récentes, notamment dans celles du leader de l'école libre-échangiste, AI. Yves Guyot. Dans un petit livre de propagande, L'A B C du Libre-Échange, il écrit (p. 47) : "Un marchand ne fait de bénéfices que s'il reçoit plus qu'il ne donne, qu'il vende à ses compatriotes ou à des étrangers. Tous les commerçants qui vendent à l'étranger font la même constatation : et, par conséquent, leurs bénéfices se traduisent par un excédent d'importation pour chacun d'eux et pour la nation tout entière. Bien loin de désigner l'excédent des importations par le mot déficit, il faut le désigner par celui-ci : profit ».

L'assimilation faite ici entre un marchand et un pays semblerait pourtant plutôt favorable à la thèse protectionniste. 
Le marchand de vin français qui vend du vin à un consommateur anglais ne le fait pas avec l'intention de faire revenir en échange du charbon - quoiqu'il puisse arriver en effet que la traite qu'il aura tirée sur son acheteur soit employée à payer un achat de charbon d'autre part, mais peu lui importe. Et inversement, le fabricant français qui achète du charbon en Angleterre ne le fait pas en vue de le revendre à l'étranger.

Sans doute, s'il n'y a pas de solidarité consciente et réfléchie entre ces deux catégories d'opérations, il y a néanmoins, au-dessus de la mêlée, des lois économiques qui, par un jeu admirable, tendent à les ramener sans cesse, importations et exportations, à un état d'équilibre : nous venons de l'expliquer. Néanmoins leurs avantages ou inconvénients doivent être examinés séparément. Ce qui prête à confusion c'est cette façon de parler que nous sommes bien obligés d'employer quand nous disons: la France, l'Angleterre, l'Allemagne. Mais il ne faut pas se laisser prendre à cet anthropomorphisme : en réalité, il n'y a que des Français, des Anglais, des Allemands, qui vendent ou achètent, mais jamais un pays qui vende ou achète à un autre pays. En tout cas, si on tient à les personnifier, il faudrait plutôt que ce fût sous la figure d'un propriétaire foncier, un. paysan qui vit des produits de son domaine, mais va de temps en temps au marché échanger l'excédent de ses récoltes contre les objets dont il a besoin, soit pour son exploitation, soit pour sa maison ; et qui trouve non moins d'avantage sur ce qu'il rapporte du marché que de profit sur ce qu'il y apporte.

Analysons donc séparément les avantages de l'exportation et ceux de l'importation.

D'abord il y a, cela va sans dire, les avantages individuels sous forme de profits que peuvent retirer tous ceux qui, professionnellement, négociants, courtiers ou banquiers, sont engagés dans le commerce international, soit comme importateurs, soit comme exportateurs. Le commerce international a été de tout temps — qu'on se rappelle les marchands de Tyr et de Venise - une des sources des plus grandes fortunes. Mais nous ne parlerons ici que des avantages nationaux.

\section{§ 1. Avantages des exportations.}

$\underline{\text { Retour à la table des matières }}$

Il faut reconnaître que l'opinion publique partage entièrement l'opinion des protectionnistes en ce sens que c'est uniquement du côté de l'exportation qu'elle regarde. Au cours de cette guerre, innombrables sont les articles et même les livres qui ont été publiés en vue d'étudier les moyens d'étendre nos exportations banques d'exportation, sociétés d'exportation, agences à l'étranger, enseignement commercial, etc. - tandis que je ne sache pas qu'aucune étude ait été publiée en vue de développer nos importations, si ce n'est dans le cas particulier 
d'importations de nos colonies. Même on ne craint pas de faire des sacrifices en vendant à perte, à seule fin de créer ou soutenir l'exportation, comme nous le verrons à propos du dumping. Et on déclare qu'après la guerre la restauration économique de la France dépendra du développement de ses exportations. Il faut donc bien que les avantages de l'exportation soient frappants. Pourquoi ?

$1^{\circ}$ Il y a d'abord dans l'exportation un prestige dû à cette idée toujours vivace, et maintenant plus que jamais, que le commerce international est une des formes de la guerre. Et alors comme l'art de la guerre consiste à envahir et à occuper le territoire ennemi, sans laisser l'ennemi envahir et occuper notre propre territoire, de même on croit que la tactique du commerce international doit être d'envahir et d'occuper les marchés étrangers sans permettre à l'étranger de mettre le pied sur nos propres marchés. L'exportation prend ainsi les caractères de l'offensive économique, tandis que les tranchées et les fils barbelés, qui sont les droits de douane, servent à la défensive.

Tout en repoussant ce militarisme économique, il faut reconnaître que l'exportation peut mieux que l'importation servir la politique d'expansion d'un pays : l'importation est la forme passive du commerce, tandis que l'exportation est la forme active. Pour s'ouvrir des débouchés, il faut plus d'initiative, un sens commercial plus développé, que pour faire venir des marchandises, de même d'ailleurs qu'entre individus il est assurément plus difficile de vendre que d'acheter. Toute industrie qui est en état d'exporter prouve, par cette faculté même, qu'elle n'a plus besoin de protection, qu'elle est émancipée, qu'elle peut sortir et aller seule dans le monde, qu'elle s'est élevée du rang d'industrie nationale à celui d'industrie internationale.

L'exportation des produits est une des formes de la propagande - tout comme celle de la langue, des idées et des modes, et comme celles-ci elle crée une clientèle non pas seulement au sens commercial, mais au sens antique et politique de ce mot - propagande qui peut d'ailleurs être acceptée même par les libreéchangistes, car on peut très bien la concevoir pacifique et réciproque.

On pourrait objecter, il est vrai, que les pays les plus avancés industriellement ne sont pas ceux où les exportations dépassent les importations : généralement c'est précisément l'inverse (ci-après, p. 53) Mais la contradiction n'est qu'apparente, car comme nous l'avons déjà expliqué, pour ces pays il faut compter, en outre de leur exportation en marchandises, ce qu'on appelle les exportations invisibles sous forme de capitaux prêtés, de services rendus, de consommation faite sur place par les étrangers.

$2^{\circ}$ L'exportation permet de développer l'industrie nationale non seulement en étendant le nombre de ses clients, mais surtout en permettant de pousser aux dernières limites les perfectionnements de la division du travail et de l'intégration, car nous savons que ces modes d'organisation sont toujours en raison de l'étendue 
du marché (I, pp. 265-283) — et par là d'abaisser indéfiniment le coût de production. L'Angleterre, les États-Unis ou l'Allemagne n'auraient pu pousser aussi loin qu'ils l'ont fait leur outillage industriel, s'ils n'avaient exporté dans le monde entier. Pour prendre un seul exemple, c'est parce que les chantiers de construction navale de l'Angleterre fournissent des bateaux à tous les pays, qu'ils peuvent les construire par séries et à meilleur marché que partout ailleurs.

$3^{\circ}$ L'exportation permet d'utiliser certaines richesses naturelles qui, si elles ne trouvaient un emploi au dehors, resteraient sans valeur et inexploitées. Sans l'exportation, l'Angleterre ne saurait que faire de son charbon, l'Australie de sa laine, le Brésil de son caoutchouc, la Tunisie de ses phosphates et le Transvaal de son or!

$4^{\circ}$ Enfin l'exportation peut servir à faire rentrer l'or quand on en a besoin et quoique nous ayons expliqué que cette préoccupation a beaucoup moins d'importance que ne lui en attribuaient les mercantilistes, elle ne laisse pas cependant que d'en avoir une en certaines circonstances. Tel sera le cas précisément après la guerre quand les pays belligérants, couverts de dettes et saturés de papier-monnaie, s'efforceront de reconstituer leur stock métallique.

Heureux en cette occurrence ceux qui auront les moyens d'exporter au dehors !

Si le pays n'a pas besoin d'importer de l'or, tout au moins l'exportation lui permet-elle de garder celui qu'elle possède en lui fournissant les moyens de payer ses importations avec les traites tirées sur les acheteurs étrangers (ci-dessus, p. 6).

À côté des avantages de l'exportation on pourrait signaler certains effets fâcheux. Par exemple, les pays qui exportent régulièrement leur blé et leur fourrage et qui ne réparent pas par des engrais chimiques l'appauvrissement de leur sol, comme la Russie, finissent par appauvrir leurs terres de tous les éléments fertilisants que ces récoltes enlèvent au sol : c'est comme s'ils exportaient petit à petit la terre elle-même ! Le Pérou et le Chili, qui ont déjà exporté tout leur guano et sont en train d'exporter leurs nitrates, quelque argent qu'ils puissent y gagner provisoirement, dévorent les réserves fertilisantes de l'avenir.

C'est pourquoi certains pays mettent des droits sur l'exportation, mais ces droits, à vrai dire, ont moins pour but de retenir à l'intérieur des matériaux utiles que de procurer des ressources au Trésor en mettant à profit le quasi-monopole dont la nature les a dotés. C'est ainsi que le Canada et la Suède ont des droits d'exportation sur la pulpe de bois (pour papier), l'Espagne sur le minerai de fer, le Chili sur les nitrates et même l'Angleterre en avait établi un sur le charbon (en 1901) mais y a renoncé, et l'Allemagne y a songé aussi pour la potasse.

\section{$\S 2$. Avantages des importations.}


Si nous regardons maintenant du côté des importations, les avantages sont moins apparents, même discutés, mais plus intéressants aussi au point de vue théorique parce qu'ils ont donné matière à des controverses célèbres dans l'histoire des doctrines.

$1^{\circ}$ Il y a d'abord toute une catégorie de produits pour lesquels les bienfaits de l'importation ne peuvent être niés : ce sont tous ceux qu'un pays se trouve dans l'impossibilité de produire lui-même parce que les conditions de son climat ou la pauvreté de son sous-sol ne le lui permettent pas. Nos pays d'Europe ne peuvent évidemment se procurer que par l'importation tous les produits exotiques qui, pour ne parler que du café, du thé, du riz, du coton, tiennent une si grande place dans nos consommations, et l'Angleterre est bien obligée de demander aux pays qui sont plus près du soleil les raisins secs de son pudding national. On sait que la France ne possède point de mines de cuivre, la Suisse point de mines de houille, et l'Allemagne, quoique assez bien pourvue, a dû s'évertuer pour trouver des succédanés à des milliers d'articles qui lui faisaient cruellement défaut par suite du blocus.

$2^{\circ}$ Même pour les articles qu'un pays est en situation de produire, il peut arriver qu'ils se trouvent en quantité insuffisante pour ses besoins. C'est le cas pour la plupart des pays de l'Europe Occidentale et Centrale en ce qui concerne leurs aliments les plus essentiels, le pain et la viande. La densité de leur population a déjà dépassé les limites que comportent les ressources de leur territoire, du moins en l'état actuel de l'industrie agricole. L'importation est donc pour eux une question de vie ou de mort. Il est vrai que le blocus auquel tous les pays belligérants auront été soumis, à des degrés divers, au cours de la guerre actuelle, aura montré que l'élasticité des besoins, même de ceux considérés comme vitaux, était plus grande qu'on ne le croyait. Néanmoins il est certain que la question des importations de matières premières sera une des plus importantes qui se posera dans les négociations après la guerre, les uns voulant s'en faire un moyen de contrainte, les autres s'en assurer le libre usage.

$3^{\circ}$ Mais le cas le plus fréquent c'est quand il s'agit de richesses que le pays importateur pourrait produire, s'il le fallait, mais qu'il ne pourrait produire qu'avec plus de peine et plus de frais que le pays d'origine, parce que celui-ci se trouve dans des conditions de supériorité naturelle ou acquise. La France, par exemple, pourrait bien faire elle-même ses machines et elle en fait de très belles, ne fussent que les moteurs de ses automobiles et de ses aéroplanes, mais elle a souvent plus d'avantage à les faire venir d'Angleterre ou des États-Unis, ces pays étant par la nature mieux dotés de fer et de houille et possédant un outillage mécanique plus perfectionné.

En ce cas, l'avantage de l'importation consiste dans l'économie de travail réalisée par le pays importateur et se mesure par la différence entre le prix à payer pour la marchandise importée et le prix auquel elle reviendrait s'il fallait la 
produire sur place. Si une auto américaine ne représente que 500 journées de travail américain, alors qu'en France elle exigerait 1.000 journées de travail, il est clair que si la France peut acheter à sa valeur, c'est-à-dire en donnant en échange une marchandise n'ayant coûté en France que 500, disons (pour tenir compte du bénéfice et du transport) 600 journées de travail ou avec une somme d'argent équivalente à ces 600 journées, elle aura économisé, c'est-à-dire gagné la différence, soit 400 journées de travail.

Cet avantage-là est celui que la théorie classique met au premier rang dans l'échange international. Bastiat le formulait en ces termes: "Obtenir une satisfaction égale avec moins d'efforts ». Et, en effet, tel est bien l'avantage de l'échange entre individus, tel que nous l'avons expliqué (I, p. 368 : c'est comme un élargissement de la division du travail.

$4^{\circ}$ Le cas que nous venons d'indiquer implique, par définition, une infériorité relative du pays importateur en ce qui concerne le produit importé. Mais il peut arriver, quoique assez rarement, qu'il en soit autrement. Un pays peut avoir avantage à se procurer par l'importation certaines richesses, alors même qu'il serait en mesure de les produire dans des conditions plus favorables que le pays qui les lui vend. Supposons qu'une province du Brésil pût produire du vin dans des conditions plus favorables que la France — par exemple avec 6 journées de travail par hectolitre au lieu de 10 en France - il n'en résulte $\mathrm{p}$ as nécessairement qu'il fût plus avantageux pour elle, en ce cas, de produire son vin plutôt que de le faire venir de France.

En effet, il est très possible qu'elle trouve le moyen de payer ce vin français avec une denrée qu'elle pourra produire dans des conditions encore plus favorables que le vin, par exemple avec du café, du maté ou des bananes qui ne lui coûteront qu'une journée de travail. Il est clair que cette opération lui serait très avantageuse puisqu'elle lui procurerait la même quantité de vin avec un travail six fois moindre que si elle le produisait elle-même ${ }^{1}$.

Il résulte de cette explication que les coûts de production des produits échangés (évalués en travail ou argent, il n'importe) peuvent être très différents dans chacun des deux pays, autrement dit qu'il n'y a aucun lien nécessaire entre eux, puisque dans l'exemple ci-dessus nous supposons qu'un produit dont le coût de production est 1 jour de travail s'échange contre un produit coûtant 10 jours de travail.

Ceci est assez surprenant quand on y réfléchit, car la règle ordinaire dans les échanges entre individus, sous le régime de la libre concurrence, c'est que les coûts de production des objets échangés sont égaux. Pourquoi ? Parce que si l'objet A, coûtant seulement 1 journée de travail, pouvait s'échanger régulièrement contre $\mathrm{B}$, coûtant 10 journées, tout le monde préférerait produire A plutôt que B, et alors l'abondance de $\mathrm{A}$ et la raréfaction de $\mathrm{B}$ feraient bientôt baisser la valeur de $\mathrm{A}$ et monter la valeur de $\mathrm{B}$ jusqu'à ce que l'échange se fit sur le pied de leurs coûts de production respectifs, $10 \mathrm{~A}$ contre $1 \mathrm{~B}$. Mais d'un pays à un autre cette égalisation ne se fait pas, parce que le déplacement de travail et de capital qu'elle implique est difficile ou impossible. On ne voit guère les agriculteurs français, alors même que la production du café serait plus avantageuse que celle du vin, aller se faire planteurs au Brésil, ni inversement. Les 
Un pays pourrait donc se trouver en situation de produire toutes choses à moins de frais que ses voisins et avoir néanmoins intérêt à importer leurs produits. Car, même en ce cas, il trouverait avantage à se consacrer à la production des articles pour lesquels sa supériorité est la plus grande et à les offrir à ses voisins moins privilégiés pour se procurer en échange les produits pour lesquels sa supériorité, quoique réelle encore, est pourtant moins accentuée. En ce cas, l'exportation n'est plus qu'un moyen d'obtenir une importation : c'est un do ut des.

pays ne sont pas des vases communicants où l'équilibre se rétablit incessamment ; ils sont séparés par des cloisons, sinon étanches, du moins peu perméables.

Alors, qu'est-ce qui détermine le rapport des quantités échangées ? Qui dira combien la France doit donner de vin, en échange de café ou bananes ? - Ce sera le jeu de l'offre et de la demande, ce sera le marchandage. Celui des deux pays dont le produit sera le plus recherché par l'autre réussira à en donner le moins possible en échange et par conséquent à obtenir plus d'avantages que l'autre. C'est là ce qu'on appelle la loi des valeurs internationales, qui tient une grande place dans l'histoire des doctrines.

C'est Ricardo d'abord et ensuite Stuart Mill qui ont attiré l'attention sur ce fait curieux qu'on pourrait appeler un paradoxe économique, car il n'est pas normal que si Jean peut faire une chose plus facilement que Pierre, il ait l'idée de l'acheter à Pierre. Cependant ce cas, quoique rare, n'est pas spécial à l'échange entre pays, car, comme l'avait fait remarquer déjà Ricardo, cela peut se présenter aussi pour des individus. Un professeur de botanique on un docteur peuvent être de très habiles jardiniers et néanmoins, même en ce cas, trouver avantage à confier leur jardin à un jardinier, quoique moins habile qu'eux, pour consacrer tout leur temps, celui-ci à ses malades, celui-là à ses études.

Voir Histoire des Doctrines, par Gide et Rist ; Cournot, Principes mathématiques de la théorie des richesses, chap. 12, et Bastiat, Théorie du commerce international, traduction SauvaireJourdan. 


\section{CHAPITRE II}

\section{LA POLITIQUE COMMERCIALE}

Historique du commerce international.

\section{$\underline{\text { Retour à la table des matières }}$}

Le commerce international, durant l'antiquité et le moyen âge, n'avait pas le caractère général qu'il a revêtu de nos jours. Il était aux mains de quelques petits peuples qui, à raison de leur situation maritime - Tyr et Carthage dans l'antiquité, les républiques d'Italie ou les villes de la Hanse au moyen âge, la Hollande au commencement de l'histoire moderne - avaient pris le monopole du commerce et des transports. Les autres peuples jouaient un rôle purement passif. Ils accueillaient les commerçants étrangers comme les peuplades nègres de l'Afrique reçoivent aujourd'hui les marchands musulmans ou européens - avec une certaine bienveillance, puisqu'ils se procuraient par là des marchandises qu'ils n'auraient pu produire eux-mêmes : ils cherchaient même à les attirer, ils leur concédaient au besoin des privilèges ${ }^{1}$. Toutefois, ils leur faisaient payer, en échange de la protection qu'ils leur accordaient, certains droits qui étaient comme une sorte de participation sur leurs bénéfices; ainsi font les petits rois africains sur les caravanes qui traversent leurs territoires. Les droits de douane, si on peut leur donner déjà ce nom, n'avaient donc au début qu'un caractère fiscal et nullement protecteur. Qu'auraient-ils protégé, en effet, puisqu'il n’y avait point d'industrie nationale?

Mais au XVI ${ }^{\mathrm{e}}$ siècle, la question changea de face, et cela pour deux raisons :

$1^{\circ}$ Parce que l'ouverture des grandes routes maritimes du monde donna au commerce international un développement inconnu jusqu'alors. La concurrence internationale — dont il ne pouvait être question quand le commerce ne

Quand Louis XI, fort en avant des idées de son temps, voulut, en 1442, organiser un système protectionniste et écarter les marchands étrangers, il se heurta à l'opposition des députés marchands de toutes les villes de France convoqués à Tours, qui voulaient attirer «toutes nations estranges » (voir dans la Revue des questions historiques, juillet 1895, un article de M. de la Roncière). 
transportait guère que des objets de luxe: pourpre de Tyr, brocarts de Venise, lames d'épées de Tolède, épices des îles — commença à se faire sentir du jour où ce commerce fut assez bien outillé pour transporter des articles de consommation courante, tels que les draps des Flandres ;

$2^{\circ}$ Parce qu'à cette date se constituaient les grands États modernes de notre Europe, et une de leurs préoccupations fut de se donner une politique nationale, c'est-à-dire de faire servir le commerce international à l'agrandissement de leur richesse et de leur puissance.

Cette politique s'appuya sur un ensemble de doctrines et aboutit à un ensemble de règlements que l'on a appelé le système mercantile ${ }^{1}$.

Voici comment, il n'y a pas longtemps encore, on exposait ce système. On disait que les mercantilistes croyaient que l'argent était la seule et véritable richesse, que par conséquent ce qui importait à un pays c'était de se la procurer ; que pour cela, un pays, lorsqu'il n'avait pas la chance d'avoir des mines d'or ou d'argent, n'avait d'autre moyen que de vendre le plus possible aux autres pays qui avaient de l'argent et par là de le leur soutirer peu à peu. Si au contraire il avait l'imprudence d'acheter au dehors, il se dépouillait par là de son numéraire. — Donc exporter le plus possible, importer le moins possible, en un mot chercher à obtenir toujours une balance du commerce favorable, telle était la conclusion du système mercantile.

Aujourd'hui on estime que cette façon de présenter le mercantilisme est un peu simpliste, sinon même caricaturale. Elle conviendrait mieux aux auteurs qui ont précédé les mercantilistes et qu'on appelle quelquefois les bullionistes (du mot anglais bullion, lingots) ${ }^{2}$. Ceux-ci attribuaient en effet une importance unique aux métaux précieux — opinion d'ailleurs qui n'était pas si puérile qu'on le croit, à une époque où l'or et l'argent étaient plus rares qu'ils ne l'ont été peut-être à toute époque de l'histoire, où les besoins du commerce grandissant et de l'industrie naissante, sans parler des budgets des États nouveau-nés, créaient une véritable famine de monnaie et où l'on commençait à peine à inventer les moyens de crédit qui allaient permettre de la mieux utiliser. Si la découverte des mines du Nouveau Monde fut pour les hommes de ce temps un éblouissement et provoqua de si grandes convoitises, ce n'était point sans sujet; elle vint juste au moment psychologique, providentiel, aurait dit Bastiat.

Mais quant aux mercantilistes, tout en attribuant au numéraire une importance justifiée, ils ne le confondirent point avec la richesse ou le capital et n’assignèrent

1 Le livre de Thomas de Mun, riche marchand de Londres, avec ce titre significatif Le commerce étranger trésor de l'Angleterre (1664), marque l'apogée du mercantilisme. Et pour la France celui de Montchrétien, Traité d'Économie politique, 1615.

2 Qualificatif usité par M. Deschamps dans son cours sur l'Histoire des Doctrine, à la Faculté de Droit de Paris. 
point pour unique but à la politique commerciale des peuples d'en acquérir le plus possible. Leur but c'était de créer l'industrie nationale. En cela, ils furent les collaborateurs des hommes d'État qui créèrent ces États modernes dont nous venons de parler et les précurseurs de ceux que l'on appelle aujourd'hui « économistes nationalistes " ${ }^{1}$. D'ailleurs les droits de douane ou les prohibitions ne furent pas les seules mesures qu'ils préconisèrent. Ils fondèrent les premières manufactures nationales et cherchèrent surtout à attirer les bons ouvriers qui leur paraissaient une richesse non moins précieuse que l'or ${ }^{2}$.

Mais ce qui est vrai c'est qu'ils conçurent l'idée de faire servir les droits de douane à écarter la concurrence étrangère et à développer l'industrie nationale : avec eux ces droits perdirent leur caractère fiscal pour devenir protecteurs. Ce fut avec Cromwell, en Angleterre, et Colbert, en France, que ce système, logiquement bien enchaîné, arriva à son plein épanouissement. On peut le résumer en trois points :

$1^{\circ}$ Repousser par des droits protecteurs l'importation des produits fabriqués ;

$2^{\circ} \mathrm{Au}$ contraire favoriser, par une réduction des droits, l'importation des denrées alimentaires, des matières premières et de tout ce qui sert aux fabriques ;

$3^{\circ}$ Stimuler, par des encouragements aux manufactures ou par des primes, l'exportation des produits du pays.

Ce système, qu’on désigne généralement sous le nom de Colbertisme, a régné sans conteste jusqu'à l'apparition des économistes. On sait que les Physiocrates démolirent impitoyablement toutes les théories du mercantilisme, que, prenant le contre-pied, ils arborèrent la devise: laissez faire, laissez passer, et qu'ils ne combattirent pas moins énergiquement pour la liberté des échanges contre le système protectionniste que pour la liberté du travail contre le régime corporatif. Mais la Révolution française, qui fit triompher leur doctrine en ce qui concerne la liberté du travail, ne la réalisa nullement en ce qui concerne la liberté du commerce. Il est vrai que les vingt ans de guerre européenne qui suivirent n'étaient guère propres à préparer l'avènement du libre-échange.

1 Cependant nous ne pouvons reconnaître aux mercantilistes le titre de précurseurs de la science économique parce que, s'ils ont été des politiciens économistes, ils n'ont pas introduit dans la science économique l'idée de lois naturelles qui constitue la gloire des Physiocrates I, p. 8).

2 Pour marquer d'un seul trait la différence entre les bullionnistes et les mercantilistes, rappelons que tandis que les premiers voulaient prohiber la sortie du numéraire et qu'en effet des pénalités sévères furent plus d'une fois appliquées par les gouvernants, les seconds se préoccupaient plutôt d'empêcher la sortie des ouvriers habiles, et pareillement des pénalités sévères sanctionnèrent ce système. C'est ainsi qu'à Bordeaux, en 1726 et en 1752, des ouvriers drapiers et des ouvriers cordiers, qui voulaient se rendre en Espagne, furent rattrapés et emprisonnés. 
En Angleterre, cependant, les idées d'Adam Smith avaient mûri. Au reste, l'Angleterre n'avait jamais été très protectionniste sinon pour s'assurer le commerce maritime et le monopole avec ses colonies. Les traités célèbres de Methuen avec le Portugal en 1703 et d'Eden avec la France en 1786 (ainsi appelés des ministres qui les négocièrent) seraient considérés aujourd'hui comme libreéchangistes. Et dès que les guerres avec Napoléon eurent cessé, on commença à abaisser les droits sur les produits industriels. Sur les céréales le Gouvernement anglais resta longtemps intraitable parce que l'aristocratie anglaise, où se recrute la Chambre des Lords, y était intéressée. Aussi fut-ce précisément contre ces droits protecteurs du blé (Corn Laws) que, en 1838, Cobden commença, à Manchester, la mémorable campagne qui devait renverser le système protecteur. C'était en effet un spectacle particulièrement odieux que de voir les lords d'Angleterre, propriétaires par droit de conquête de presque toutes les terres du royaume, repousser le blé étranger pour vendre plus cher le leur et profiter des besoins croissants de la population pour toucher des rentes de plus en plus élevées ! La Chambre des Lords se trouvait donc en mauvaise posture pour résister au mouvement d'indignation déchaîné par la Ligue et, en 1846, à la suite de la conversion éclatante du ministre sir Robert Peel, elle fut obligée de céder. Les droits sur les blés une fois abolis, tout le reste de l'édifice protectionniste (y compris le fameux «Act de Navigation » de Cromwell auquel on attribuait la grandeur maritime de l'Angleterre) croula.

La France, au contraire, n'avait pas dévié de la voie protectionniste, malgré ses nombreux changements de gouvernement, et ce n'est pas assez dire que de parler de protection : c'est le régime prohibitif absolu, c'est-à-dire l'exclusion, qui frappait un grand nombre de marchandises et des plus importantes, tels que tissus de laine ou de coton. En 1846, une Ligue fondée par Bastiat, à l'exemple de la ligue anglaise, échoua, malgré les discours éloquents et les très spirituels pamphlets de cet ardent libre-échangiste, les conditions sociales étant bien différentes. Mais l'empereur Napoléon III, dont la politique fut fondée sur l'alliance avec l'Angleterre et dont les instincts étaient assez démocratiques profita du pouvoir qu'il s'était réservé par la Constitution pour signer avec le Gouvernement anglais, sans consulter la Chambre, un traité de commerce. Ce traité fameux de 1860, que la France subit d’assez mauvaise grâce et seulement faute de pouvoir l'empêcher, eut un retentissement prodigieux en Europe et fut immédiatement suivi de la négociation de traités analogues entre toutes les puissances européennes, en sorte qu'on crut partout qu'il marquait la fin du régime séculaire du protectionnisme et ouvrait l'ère du libre-échange définitif ${ }^{1}$.

Libre-échange très relatif, car la libre importation n'était admise que pour les matières premières et produits agricoles. Pour les produits manufacturés, les droits étaient de 15 p. 100 environ ad valorem. Mais, du moins, le régime des prohibitions, qui portait sur de nombreux et très importants produits, notamment sur presque tous les tissus, était-il abrogé - et l'abrogation a été définitive. 
Cependant le règne du libre-échange ne devait pas être de longue durée. D'abord les États-Unis étaient restés en dehors de ce mouvement libre-échangiste. Ils ont toujours été protectionnistes, non seulement dans les faits, mais aussi dans la doctrine, puisque c'est là que se sont formés les deux plus grands théoriciens du protectionnisme, Carey, et même List quoique celui-ci fût allemand. Les ÉtatsUnis furent protectionnistes dès leur naissance, parce qu'une des principales causes de leur révolte contre la mère-patrie ayant été que celle-ci ne leur permettait pas de faire " même un fer à cheval ", il était naturel que leur première préoccupation fût de reconquérir leur autonomie industrielle ${ }^{1}$. Mais les droits protecteurs, très modérés au début, allèrent s'aggravant de période en période et toujours par quelque motif nouveau. D'abord ce fut pour protéger leur industrie naissante : c'est de là que s'inspira le système de List ; - après 1866 ce fut pour payer les frais de la grande guerre civile (voir ci-après, p. 62), — plus tard cette raison disparut, car, la plus grande partie de leur dette étant remboursée, les États-Unis ne surent plus que faire de l'argent de leurs douanes, tellement que pour l'utiliser ils distribuèrent un milliard de pensions à de soi-disant invalides de la guerre, mais alors on trouva un nouveau motif pour les droits de douane, la nécessité de défendre les hauts prix et les hauts salaires d'Amérique contre les bas prix et les bas salaires d'Europe. Le tarif célèbre de Mac-Kinley en 1890 était sévère : celui dit de Dingley en 1897 l'avait aggravé ${ }^{2}$. Puis, selon que le parti des républicains (ultra-protectionniste) ou le parti des démocrates (modérément protectionniste) arrivait au pouvoir, le régime des tarifs des droits de douane s'élevait ou s'abaissait. Cependant, dans ces derniers temps, le développement des Trusts a donné à craindre qu'ils ne monopolisent toute l'industrie si on leur livrait le marché en continuant à exclure toute concurrence des étrangers ; c'est pourquoi les tarifs sont devenus un peu moins exclusifs. Ce n'est pas seulement l'élévation des tarifs, mais, comme nous le verrons plus loin, la rigueur avec laquelle ils sont appliqués qui provoque des protestations de la part des pays d'Europe.

Au reste, quand on parle du régime protectionniste des États-Unis, il ne faut pas oublier que les États-Unis sont une Union de quarante-huit États dont quelques-uns sont aussi grands que la France et entre lesquels le libre-échange est absolu; c'est donc à peu près la même chose que si tous les États d'Europe

En 1879, le général Grant, ex-président des États-Unis, lors d'une réception à Manchester où on espérait le convertir au libre-échange, disait ironiquement :

«Messieurs, l'Angleterre s'est servie pendant deux cents ans du système protecteur, elle l'a poussé à outrance et s'en est bien trouvée, c'est à ce système qu'elle doit sa puissance industrielle, cela ne fait aucun doute. Après ces deux cents ans, l'Angleterre a jugé convenable d'adopter le libre-échange, parce qu'elle ne pouvait plus rien tirer de la protection.

» Eh bien ! Messieurs, je connais assez mes compatriotes pour croire que, dans deux cents ans, quand l'Amérique aura tiré du système protecteur tout ce qu'elle peut en tirer, elle marchera résolument vers le libre-échange ».

2 Les droits, qui dans le tarif Mac-Kinley étaient de 50 p. 100 sur la valeur des marchandises, avaient été portés dans le tarif Dingley à 57 p. 100 en moyenne, mais pour certaines marchandises à beaucoup plus. Dans le tarif actuel ils ne descendent guère au-dessous de $40 \mathrm{p}$. 100 et s'élèvent jusqu'à 55 et 60 p. 100 pour les produits de luxe tels que porcelaines, dentelles. 
s'unissaient en une Union douanière, un Zollverein, et opposaient une barrière de douane aux produits américains, ce qui serait considéré néanmoins comme un grand pas dans la voie du libre-échange.

La France, en 1872, à la suite de la guerre franco-allemande, voulut suivre l'exemple des États-Unis en rejetant sur les produits étrangers le poids des impôts nouveaux qu'elle était obligée de créer pour payer ses défaites. Le chef du gouvernement d'alors était $M$. Thiers qui avait toujours été protectionniste et avait prédit que le libre-échange ruinerait la France : il essaya d'établir des droits même sur les matières premières, mais cette tentative échoua par suite des traités alors encore en vigueur.

Ce fut en 1892 seulement que la France, libérée enfin des traités de commerce conclus sous l'Empire et qui avaient été renouvelés ensuite, put revenir à une politique résolument protectionniste et n'a fait, depuis lors, qu'accentuer sa marche en ce sens (voir ci-après le chapitre sur la Législation douanière).

L'Allemagne a suivi une politique opportuniste en matière commerciale et qui lui a très bien réussi. En 1833, par l'Union douanière entre les différents États allemands, elle prépara son unité politique. Quand vint la période libre-échangiste, elle s'y rallia pleinement. Mais quand son unité politique fut faite, elle eut l'ambition de devenir une grande puissance industrielle et fit volte-face vers un protectionnisme autonome. On peut même dire que ce fut elle, avec l'Autriche, qui, en 1879, ouvrit l'ère de la réaction protectionniste ${ }^{1}$ qui devait rapidement gagner l'Europe entière. Pourtant, plus récemment (1892-1894) lorsque, ayant atteint ce premier but, elle a dû chercher des débouchés au dehors, elle a adopté le système mixte des traités de commerce qui est déjà comme une ébauche d'un nouveau Zollverein embrassant toute l'Europe centrale. Comme nous le verrons plus loin, le traité de Francfort lui donnait dans ses rapports avec la France tous les avantages concédés aux autres nations et, quoique cette clause fût parfaitement réciproque, elle a su en jouer beaucoup mieux que nous. Et enfin quand le grand programme naval a commencé vers 1897, c'est aux droits de douane que l'Empire a dû demander les ressources nécessaires.

Enfin, il n'est pas jusqu'à l'Angleterre, la terre classique du libre-échange, où il ne commence à être ébranlé. C'est $\mathrm{M}$. Chamberlain, premier ministre pendant la guerre du Transvaal, qui a inauguré cette campagne contre la vieille école de Manchester. Ce néo-protectionnisme s'est d'abord présenté sous la forme dite impérialiste, c'est-à-dire inspiré surtout par un motif politique, celui de réunir par des liens d'intérêt les peuples qui composent l'immense Empire britannique. Pour

À vrai dire, la première en date est l'Autriche, tarif du 27 juin 1878, mais son initiative eut beaucoup moins de retentissement (voir pour les détails et l'historique, Lexis, Revue d'Économie politique, 1895). Et même, si l'on ne regarde qu'à l'intention, ce fut la France sous le gouvernement de M. Thiers qui donna le signal en 1873, seulement ses intentions ne purent se réaliser de sitôt. 
cela, il faudrait que les colonies, pour la plupart déjà fortement protectionnistes, accordassent des réductions de droits aux produits de la métropole - et inversement que l'Angleterre réservât la libre entrée aux produits de ses colonies, ce qui implique l'établissement de droits sur les produits étrangers. La première partie de ce programme n'est pas d'une réalisation très difficile, car déjà les Fédérations du Canada, de l'Afrique australe, probablement bientôt de l'Australie, en tout cas déjà la Nouvelle-Zélande, accordent aux produits anglais un traitement de faveur, des réductions qui varient de 25 à 33 p. 100. Mais c'est la seconde partie du programme qui jusqu'à présent n'a pu aboutir, parce que l'Angleterre ne se souciait pas de compromettre son commerce avec les pays étrangers au profit de ses colonies, le commerce avec celles-ci ne représentant qu'un quart de ses échanges.

D'ailleurs, en dehors de la raison impérialiste, d'autres forces poussaient l'Angleterre, comme les autres pays, dans la voie protectionniste, entr'autres la nécessité de se procurer des ressources pour l'accroissement énorme des dépenses militaires et des dépenses de solidarité sociale, notamment pour les pensions de retraite aux ouvriers indigents, et aussi les préoccupations du chômage, fléau que certains attribuaient à l'entrée libre des produits étrangers, allemands surtout.

Il n'y a donc plus guère en Europe à cette heure, en dehors de l'Angleterre, que quelques petits pays, Hollande, Danemark, Belgique, restés fidèles au free trade, parce que leur étendue est trop limitée pour qu'ils puissent prétendre se suffire ; partout ailleurs, les barrières de douane ont été relevées et les guerres de tarifs ont remplacé les traités de commerce, et même des petits pays comme la Suisse, la Suède, la Norvège, le Portugal, ont été à leur tour gagnés par la contagion ${ }^{1}$.

Le développement rapide des moyens de transport a permis l'importation par grandes masses de marchandises qui, telles que le blé et les matières premières, ne pouvaient guère autrefois faire une concurrence bien efficace. Les agriculteurs en ont été inquiets et ont apporté au parti protectionniste, jusqu'alors recruté surtout parmi les industriels, un appui formidable par le nombre ${ }^{2}$.

On aurait pu croire que, par contre, le parti socialiste apporterait son appoint formidable du côté du libre-échange. Mais il n'en est rien. Les socialistes se sont désintéressés de cette grande question qu'ils considèrent comme une querelle entre bourgeois, et beaucoup, même parmi les chefs du parti ouvrier en Angleterre,

De tous les petits pays c'est le Danemark qui est resté le plus fidèle au libre-échange, même après que ses deux sœurs scandinaves se furent ralliées au protectionnisme, la Suède en 1888, la Norvège en 1897 - et cela lui a fort bien réussi.

2 En France, les vignobles à partir de 1875 ont été dévastés par le phylloxera : les vins étrangers sont venus remplacer les vins français, et les viticulteurs, qui jusqu'alors avaient été libreéchangistes, ont fait demi-tour et sont devenus ardents protectionnistes. 
déclarent qu'ils n'ont pas plus à gagner sous un régime que sous l'autre ${ }^{1}$. Cependant il en est autrement des coopérateurs qui en Angleterre sont une puissance et qui, eux, émus par la hausse des prix, se sont mis résolument du côté du free trade.

La réaction violente qui s'est manifestée de nos jours contre l'école classique, bien qu'elle n'ait pas porté spécialement sur la question du protectionnisme, a cependant contribué à ébranler la foi dans des principes absolus, et ceux-là surtout qui se rallient à l'école historique ou réaliste admettent que le régime commercial de chaque pays doit être approprié à sa situation particulière. Néanmoins, on ne constate pas dans la doctrine une réaction protectionniste aussi marquée que dans la politique commerciale : on peut même dire que la majorité des économistes est restée fidèle aux doctrines libre-échangistes quoique dès 1841 List (Allemand) dans son Système National d'Économie politique (voir ci-après p. 44, et plus tard Carey (Américain), dans ses Principes de Science Sociale (1859) aient fait brèche à la doctrine de Manchester à l'époque même où celle-ci était à l'apogée.

Il faut bien qu'il y ait des causes générales pour expliquer cette épidémie soudaine, irrésistible et grandissante du protectionnisme, mais il n'est pas très aisé de les découvrir ou du moins de les préciser. Peut-être faut-il y voir un sentiment analogue à celui qui créa le mercantilisme au $\mathrm{XVI}^{\mathrm{e}}$ siècle - une poussée de l'esprit nationaliste. Le principe de nationalité, dans la seconde moitié du XIX siècle, a créé deux grands États en Europe et a éveillé les ambitions de beaucoup d'autres. Tout pays, pourvu qu'il ait une certaine étendue territoriale, prétend se suffire à lui-même et voit dans cette indépendance économique une condition de son indépendance politique. D'autre part, rien n'est contagieux comme le protectionnisme, car, dès qu'un pays l'adopte, les autres suivent de crainte de jouer le rôle de dupe. Ajoutez enfin que la foi dans le libre-échange a été singulièrement ébranlée depuis que l'exemple des États-Unis et de l'Allemagne a montré que le protectionnisme pouvait tout aussi bien conduire un pays à la suprématie industrielle.

Quand fut promulgué le tarif Mac-Kinley, un économiste anglais prophétisait ceci : «Si ce tarif doit réussir, notre politique économique est fondée sur une erreur colossale qui amènera notre ruine comme nation ». Or, le tarif a parfaitement réussi en ce qui concerne les États-Unis. Comment alors ne pas se demander si la protection ou le libre-échange sont aussi puissants pour le bien ou pour le mal que le prétendent leurs partisans ou leurs adversaires ? Vraiment la prospérité industrielle d'un pays tient à d'autres causes que le système douanier dont on s'est singulièrement exagéré l'importance. Si l'on compare les progrès du commerce dans les pays libre-échangistes et dans les pays protectionnistes, on ne

\footnotetext{
L'ex-ministre australien Hughes, un des chefs du parti ouvrier en Australie, a déclaré à maintes reprises au cours de la guerre : « Préparons-nous à renoncer au principe du libre-échange... Le parti ouvrier ne doit rien au laisser-faire et ne combattra pas pour un tel principe ».
} 
voit aucun rapport de cause à effet entre leur développement commercial et leur régime douanier, ce qui est bien fait pour inspirer un certain scepticisme sur les bienfaits comme sur les méfaits du protectionnisme. On en vient presque à se demander si, au cas où l'option entre l'un ou l'autre régime eût été tirée au sort, l'évolution commerciale de ces divers pays n'aurait pas été la même que ce qu'elle est ! Et quand on pense pourtant à combien de règlements et de négociations, de froissements et de conflits l'élaboration de ce système a donné lieu et qu'ils ont été un des facteurs de la Grande Guerre actuelle, l'histoire économique apparaît sous un jour assez mélancolique.

Comme preuve, voici la progression du commerce international dans cinq pays à quarante ans de distance depuis 1880 date qui marque à peu près l'ère de la généralisation du régime protectionniste en Europe (en millions de francs) ${ }^{1}$.

$\begin{array}{lccccc} & \text { France } & \text { Angleterre } & \text { États-Unis } & \text { Belgique } & \text { Allemagne } \\ \mathbf{1 8 8 0} & 8.500 & 17.600 & 7.500 & 2.898 & 7.100 \\ \mathbf{1 9 1 3} & \underline{15.301} & \underline{35.408} & \underline{21.700} & \underline{8.766} & \underline{26.000} \\ \text { Accroissement } & \mathbf{8 0 \%} & \mathbf{1 0 1 \%} & \mathbf{1 8 9 \%} & \mathbf{2 0 2 \%} & \mathbf{2 6 6 \%}\end{array}$

De ces cinq pays, deux sont libre-échangistes (Angleterre et Belgique), trois plus ou moins protectionnistes États-Unis, France, Allemagne). Si la différence de ces deux régimes devait donner la principale explication du plus ou moins de progrès commercial, on devrait voir une séparation nette en deux groupes, l'un en tête, l'autre en queue. Or il n'en est rien. Des trois pays protectionnistes, l'un figure au premier rang et de beaucoup, comme taux d'accroissement, plus du triple, mais l'autre au dernier. L'Angleterre devance la France, mais pas de beaucoup; les États-Unis ultra-protectionnistes et la Belgique libre-échangiste sont presque au même rang intermédiaire. Ces inégalités dans le développement commercial doivent donc s'expliquer par d'autres causes que celles du régime douanier.

En ce qui concerne l'Angleterre, il est évident que lorsqu'un pays est parvenu à l'apogée de son évolution commerciale, il ne peut grandir aussi vite que des pays relativement nouveaux, comme les États-Unis ou l'Allemagne.

En ce qui concerne la Belgique (et nous aurions pu en dire autant pour la Hollande), le chiffre relativement énorme de son commerce tient, pour partie, à sa situation. Le commerce extérieur d'un pays est relativement d'autant plus important que le pays est plus restreint en superficie et cela s'explique de soi. Un État qui ne comprendrait qu'une ville, comme autrefois Venise ou Tyr, serait bien obligé de vivre presque uniquement du commerce extérieur.

En ce qui concerne la France, l'accroissement relativement plus faible de son commerce, qui l'a fait tomber du deuxième rang qu'elle occupait en 1880 au

1 Annuaire Statistique du Ministère du Travail, 1917. 
quatrième rang, s'explique surtout par l'état stationnaire de sa population. Il n’implique donc point une infériorité dans l'activité de ses habitants. En effet, si l'on divise le chiffre du commerce de chaque pays (en 1913) par le chiffre de la population, on obtient comme quotients les chiffres suivants qui expriment le quantum des échanges par tête d'habitant et montrent que la France resté presque au même rang que l'Allemagne ${ }^{1}$.

\section{PAR TÊTE D'HABITANT}

\section{Commerce total Exportation}

Belgique
Angleterre
Allemagne
France
États-Unis

$1.153 \mathrm{fr}$.
$787 »$
$392 »$
$386 »$
$220 »$

$490 \mathrm{fr}$. $353 »$ $190 »$ $174 »$ $123 »$

Pour l'Angleterre, le chiffre de 35.408 millions comprend les réexportations, c'est-à-dire le commerce général ; si on le déduit, ce qui est plus correct, le chiffre n'est plus que de 32.400 millions et le taux d'accroissement 85 p. 100.

Mais il faut remarquer, d'autre part, que l'Allemagne, et plus encore l'Angleterre et la Belgique, bénéficient d'une source d'exportations indépendante de l'activité commerciale des habitants parce qu'elle est due aux richesses naturelles du sous-sol : c'est l'exportation de la houille. Elle figure pour 600 millions de francs dans les exportations de l'Allemagne et pour 1.500 millions dans celles de l'Angleterre - tandis que la France est obligée, au contraire, d'en importer pour plus de 500 millions de francs ; cela fait une différence ! Il est vrai que, d'autre part, la France bénéficie d'un monopole dans ses colonies.

Quant à l'importation, si elle est moindre en France, c'est là, à certains égards, une marque de supériorité, en car la preuve qu'elle est en situation de se mieux suffire à elle-même (sauf pour la houille).

En ce qui concerne la Belgique, la statistique du commerce belge comprend le transit et les métaux précieux : elle ne comporte donc pas une comparaison exacte avec les autres pays.

$\mathrm{Si}$, au lieu de comparer plusieurs pays, on préfère comparer le même pays dans les diverses phases de son régime commercial, on n'y trouve pas d'indications plus claires. Voici par exemple, pour la France qui a passé par des régimes assez différents, les chiffres du commerce extérieur à diverses dates de son histoire, par périodes d'égale durée à peu près et correspondant aux changements de régime.

\begin{tabular}{|c|c|c|c|}
\hline & $\underline{\text { Importations }}$ & Exportations & $\underline{\text { Totaux }}$ \\
\hline 1830 & 489 & 453 & 942 \\
\hline 1860 & 1.197 & 2.277 & 4.174 \\
\hline 1892 & 4.188 & 3.461 & 7.649 \\
\hline & 8.421 & 6.880 & 15.301 \\
\hline
\end{tabular}

De 1830 à 1860, régime protectionniste ; dans ces trente années le commerce a augmenté de 375 p. 100, c'est-à-dire a plus que quadruplé. De 1860 à 1892, régime relativement libreéchangiste : dans ces trente-deux années le commerce a augmenté de 83 p. 100, c'est-à-dire n'a pas tout à fait doublé. De 1892 à 1913, régime protectionniste renforcé ; dans ces trente et un ans le commerce a augmenté de 100 p. 100, c'est-à-dire a exactement doublé. Et la balance du commerce n'est pas devenue plus favorable, ni la production du blé n'a progressé (voir ci-après, p. 76). 


\section{II}

\section{Le libre-échange.}

$\underline{\text { Retour à la table des matières }}$

Pourquoi le commerce international implique-t-il ce qu'on appelle une question? Et pourquoi même n'est-il pas de question qui ait soulevé plus d'agitations, fait écrire plus de volumes et même fait tirer plus de coups de canon ?

Le commerce de pays à pays n'est-il pas de tous points semblable an commerce de particulier à particulier ? N'est-il pas, tout comme celui-ci, une forme ordinaire et normale de l'échange et dès lors à quoi bon une théorie spéciale pour le commerce international ? Si l'échange en lui-même est un bien, pourquoi deviendrait-il dangereux par cette circonstance purement accidentelle que les deux coéchangistes se trouvent séparés par un poteau frontière ?

Tel est en effet le point de vue de 1'Économie politique classique. Elle n'admet pas que le commerce international puisse être réglé par d'autres principes qu'un commerce quelconque. Pour elle cette célèbre question n'en est pas une : elle doit être rayée de nos préoccupations. L'échange, qu'il soit national ou international, n'est qu'une forme de la coopération et de la division du travail dont nous avons expliqué les merveilleux effets ; ses avantages sont réciproques et égaux pour chacune des deux parties. Qu'importe donc que les échangistes appartiennent à un même pays ou à des pays différents ? Le libre-échange entre tous les peuples du monde sera la dernière étape de cette évolution qui a successivement remplacé le marché domestique par le marché urbain et celui-ci à son tour par le marché national : le voici devenu mondial. Et tous les avantages que nous avons signalés à propos de l'échange, à savoir une meilleure utilisation des choses et des hommes, ne font que grandir au fur et à mesure que s'agrandit le champ de l'échange.

Comment donc expliquer que depuis des siècles les gouvernements mettent en pratique deux politiques opposées, l'une pour le commerce intérieur qui tend à le faciliter par tous les moyens, l'autre pour le commerce extérieur qui tend à l'entraver par tout un réseau de règlements, lesquels sont considérés comme le chef-d'œuvre de la politique économique ?

C'est simplement, disent les économistes libre-échangistes, parce que l'évolution et l'éducation économique des peuples ne sont pas achevées. Les douanes extérieures sont une survivance des douanes intérieures qui existaient autrefois entre les provinces d'un même pays et qui, en France, furent abolies par la Révolution, et elles ont la même cause. Tout producteur désire écarter ses concurrents : il a bien été obligé d'y renoncer vis-à-vis de ses concitoyens à partir du jour où, l'unité nationale étant faite, la loi est devenue la même pour tous, mais 
c'est encore possible vis-à-vis des concurrents étrangers et il en profite. Ces entraves mises aux échanges internationaux à seule fin de satisfaire les intérêts privés disparaîtront comme les autres, mais en attendant elles ont les effets les plus fâcheux dans toutes les sphères de la vie économique. Voici les principaux griefs :

$1^{\circ} \mathrm{Au}$ point de vue de la consommation, les droits protecteurs tendent incontestablement à renchérir le coût de la vie ou tout au moins à l'empêcher de diminuer. La plupart des articles de grande consommation, ceux qui intéressent l'ouvrier, sont meilleur marché dans les pays libre-échangistes, comme l'Angleterre, qu'en France ou en Allemagne. D'une enquête officielle faite avec grand soin par le Département du Travail anglais par des enquêteurs envoyés sur les lieux, il résulte que le coût d'existence de l'ouvrier français ou allemand est de 18 p. 100 supérieur à celui de l'ouvrier anglais ou belge, ce qui ne peut guère être attribué à une autre cause qu'aux droits de douane sur les denrées alimentaires.

Comment pourrait-il en être autrement ? Il va de soi que le commerçant qui importe des marchandises devra ajouter à la valeur d'origine de cette marchandise le montant des droits payés par lui à la douane, exactement comme il doit y ajouter les frais de transport et d'assurance. Et encore, si la majoration de prix ne portait que sur les marchandises importées, ce ne serait que peu de chose, mais cette même majoration se répercute nécessairement sur toutes les marchandises similaires produites dans le pays parce que naturellement leurs producteurs ne veulent pas les vendre à un prix inférieur à celui des marchandises importées. Supposons qu'il entre en France 40 millions de quintaux de blé étranger valant 20 francs au débarquement. Par suite de la concurrence de ce blé étranger, nos 80 millions de quintaux de blé, qui constituent la production moyenne de la France, ne se vendront aussi que 20 francs, et c'est justement ce dont on se plaint. Mettons alors un droit de 7 francs à l'entrée du blé étranger, ce blé se vendra 27 francs. L'État touchera par la main de l'administration des douanes (en supposant que ce droit n'ait pas pour effet de réduire les quantités importées) 10 x $7=70$ millions de francs. Mais regardons maintenant le consommateur : non seulement il paiera 7 francs de plus pour chaque quintal de blé étranger, soit 70 millions — c'est-à-dire qu'il paiera de sa poche tout ce que l'État aura perçu — mais de plus, les producteurs français s'efforçant naturellement de vendre leur blé au même prix que les producteurs étrangers, soit à 27 francs, il paiera 7 francs de plus pour chaque quintal de blé produit en France, disons 80 millions de quintaux, soit donc 80 x $7=$ 560 millions de francs. C'est-à-dire en somme que ces droits protecteurs auront rapporté 70 millions à l'État, et 560 millions aux producteurs nationaux, mais ils auront coûté 630 millions aux consommateurs.

$2^{\circ} \mathrm{Au}$ point de vue de la production nationale qu'ils ont pour but de soutenir, les droits lui portent un préjudice incontestable en renchérissant ses matières premières et son outillage. De là des conflits permanents et insolubles entre les diverses branches de la production. Quand on a voulu mettre des droits à l'entrée des soies pour protéger les producteurs de cocons des Cévennes et des bords du 
Rhône, on a soulevé les protestations violentes des filateurs de soie de Lyon. Si l'on met des droits à l'entrée des fils de laine, de soie ou de coton, on ruine les industries du tissage qui les emploie comme matières premières, etc. - Il est vrai qu'on a inventé ; pour y remédier, les procédés compliqués de « l'admission temporaire », mais ce ne sont que des palliatifs insuffisants (voir ci-après).

Et ils lui portent préjudice aussi d'une autre façon en endormant les industries dans la sécurité que leur crée la suppression de la concurrence extérieure : c’est, comme on l'a dit, un oreiller de paresse. Dans un discours, le prince de Bismarck parlait de ces brochets qu'on place dans les étangs peuplés de carpes pour tenir celles-ci en haleine et les empêcher de prendre le goût de la vase. Cette comparaison serait tout à fait de mise ici. Si l'on veut — et tel est précisément le but des protectionnistes - qu'un pays garde son rang de grande puissance industrielle et commerciale, il faut l'obliger à renouveler constamment son outillage et ses procédés, à éliminer sans cesse les organes usés ou vieillis, comme le serpent qui se rajeunit en changeant de peau: or, une telle opération étant toujours fort désagréable, il est douteux que les producteurs s'y prêtent de bonne grâce s'ils n'y sont contraints par une pression extérieure.

$3^{\circ} \mathrm{Au}$ point de vue du commerce, il ne faut pas oublier que les droits protecteurs, en réduisant les importations de marchandises, et, par là même, en même temps les exportations (voir p. 9), constituent la plus monstrueuse contradiction avec les efforts que font les peuples pour faciliter les communications, pour percer les montagnes, couper les isthmes, sillonner les mers de lignes de paquebots subventionnés et de câbles télégraphiques, ouvrir des Expositions internationales, établir des conventions monétaires, etc. Peut-on imaginer pire folie que de commencer par dépenser des centaines de millions pour percer des tunnels sous les Alpes - Cenis, Gothard, Simplon, demain la Faucille ou le Mont-Blanc, à des coûts toujours grandissants (une centaine de millions à prévoir pour ce dernier) — et, cela fait, mettre des douaniers à chaque bout pour arrêter autant de marchandises que possible ${ }^{1}$ ! On a dépensé des centaines de millions de francs sur la Seine, sur le Rhône, sur la Gironde, et des milliards de francs en canaux, et on rêve de creuser, un chemin de fer sous le Pas-de-Calais, pourquoi ?... pour abaisser de quelques centimes le coût de transport des

\footnotetext{
« Un droit de 20 p. 100 équivaut à une mauvaise route, un droit de 50 p. 100 à un fleuve large et profond sans les moyens nécessaires de le traverser ; un droit de 70 p. 100, c'est un vaste marais qui s'étend des deux côtés du fleuve; un droit de 100 p. 100, c'est une bande de voleurs qui dépouillent le marchand de presque tout ce qu'il a et l'obligent encore à se sentir heureux d'échapper avec la vie sauve! » (David Wells, A primer of tariff reform, 1885). Voir les non moins spirituels pamphlets de Bastiat sur cet argument.

Si l'on croit à l'effet stimulant des droits protecteurs, alors il faut être logique et en dire autant des obstacles de toute nature mis aux échanges, y compris le blocus. Tel est, en effet, l'enseignement que certains ont tiré de la guerre actuelle.

Nous lisions récemment dans un journal de Paris cette déclaration amusante signée d'un sénateur: "Plus les échanges seront difficiles, plus l'ingéniosité humaine tirera parti des ressources de la planète ». C'est certain : voyez Robinson !
} 
marchandises qui viennent par là de l'étranger - mais en même temps, de peur qu'il n'en vienne trop, on relève leur prix de 20 à 30 p. 100 par les droits de douane !

$4^{\circ}$ Au point de vue de la répartition, les droits protecteurs créent une injustice, car ils ont pour effet de garantir un revenu minimum aux propriétaires, revenu qui leur est payé par les consommateurs sous forme de majoration de prix, comme nous venons de le voir, et privilège d'autant plus choquant que la loi refuse de garantir aux salariés le salaire minimum qu'ils réclament aussi ${ }^{1}$.

Et l'avantage procuré est beaucoup plus grand pour les riches que pour les pauvres! Les droits protecteurs aggravent les inégalités déjà existantes. Voici un droit de 7 francs par quintal de blé qui doit élever le prix du blé de 20 à 27 francs. Le propriétaire cultivant dans les terrains médiocres ou ne disposant que de ressources insuffisantes, qui ne produit que 10 quintaux par hectare, n'y trouvera qu'un supplément de revenu de 70 francs, ce qui ne sera peut-être pas suffisant pour couvrir ses frais; mais le propriétaire déjà favorisé par la nature ou employant des procédés perfectionnés, qui récolte 30 quintaux par hectare - et qui, à raison même de sa situation privilégiée, pouvait très bien se passer de toute protection, y trouvera au contraire un supplément de revenu de 210 francs par hectare !

$5^{\circ}$ Enfin, si l'on sort du terrain économique pour se transporter sur celui de la politique internationale, on est en droit d'affirmer que le protectionnisme a été, dans le passé et plus encore de nos jours, une des causes les plus redoutables des guerres internationales. Le vocabulaire des protectionnistes est lui-même tout rempli de mots et limages empruntés à la guerre; on n'y entend parler que de guerre de tarifs, d'invasion de produits étrangers, de conquête des marchés extérieurs. Quand un pays a été nourri de cette idée qu'il ne peut s'enrichir ou même faire vivre sa population qu'en s'ouvrant des débouchés au dehors, il est bien tenté, s'il ne peut y réussir de bonne grâce, de les ouvrir par la force. Et il doit arriver encore ceci que lorsqu'un pays se voit fermer les marchés des pays voisins, alors il va chercher outre-mer les débouchés qu'il estime indispensables à son industrie ou à sa population, en sorte que le protectionnisme apparaît comme un des facteurs de la politique coloniale, et celle-ci engendre à son tour de nouveaux conflits. Sans entrer dans des précisions qui seraient en dehors du cadre de ce livre,

1 M. Méline, le principal auteur du tarif douanier actuel en France, l'a dit aussi clairement que possible : «La philosophie de notre tarif de douane consiste à soutenir les cours de façon à donner à ceux qui voient baisser leurs bénéfices le maintien de prix rémunérateurs ».

Mais alors la justice commanderait de faire ce qu'on voulait faire en Australie où l'on a établi des droits de protection énormes, mais où l'on avait voté une loi qui déclarait que, si le fabricant ne payait pas à ses ouvriers le salaire syndical (ou s'il majore ses prix de vente), il serait soumis à une taxe calculée de façon à lui retirer tout ou partie du bénéfice du droit protecteur ! Il est vrai que la loi n'a pas été appliquée jusqu'à présent, ayant été déclarée inconstitutionnelle. Peu importe : elle n'en est pas moins significative. 
on ne peut mettre en doute que les rivalités coloniales n'aient été pour beaucoup dans l'état de tension qui a précédé et préparé la guerre actuelle.

Inversement, on ne peut contester que le libre-échange, par les relations d'intérêt qu'il établit entre tous les pays, ne constitue un état très favorable au maintien de la paix. Déjà Montesquieu disait : « L'effet naturel du commerce est de porter à la paix $"{ }^{1}$; ce n'est que par une perversion de son caractère, laquelle est précisément le protectionnisme, qu'il a pu devenir un facteur de guerre. La meilleure preuve, d'ailleurs, que tel est bien l'effet naturel du libre-échange, c'est que dans tous les plans proposés pour créer une Société des Nations, comme pour resserrer les liens de l'Empire britannique, comme pour constituer l'Union de l'Europe centrale (Mittel-Europa), on commence par établir sinon une union commerciale complète, tout au moins une réduction des droits de douane. Il ne pourrait en être autrement. Le protectionnisme, c'est la compétition ; le libreéchange, c'est la coopération.

\section{III}

\section{Le système protectionniste.}

$\underline{\text { Retour à la table des matières }}$

Mais voici à leur tour les arguments du protectionnisme.

\section{§ 1. Le danger de la concurrence.}

Les protectionnistes ne se donnent nullement comme ennemis du commerce international et ils le prouvent d'ailleurs surabondamment par les efforts qu'ils font pour se le disputer, comme par les subventions qu'ils donnent à la marine marchande ou aux grands ports en vue de développer le commerce. Seulement, loin de voir dans le commerce, comme les libre -échangistes, une des formes de la division du travail, de la coopération, ils y voient un état de concurrence, disons même une des formes de la lutte pour la vie, entre les nations.

Or si le commerce international a pris de nos jours le caractère d'une lutte pour la vie, il doit produire les fâcheux effets qui sont inhérents à la concurrence, même entre individus, à savoir l'écrasement des faibles. Ainsi les États-Unis, à raison de l'étendue de leurs exploitations agricoles, de la fertilité de certaines régions qui les dispensent des engrais, du bas prix des terres, de la modicité des impôts, peuvent produire le blé dans des conditions beaucoup plus économiques que dans nos contrées d'Europe. Alors si l'importation du blé américain ne permet plus aux cultivateurs français de produire du blé, que feront-ils ? Qu'ils fassent du vin, dirat-on ! Mais l'Espagne et l'Italie, à raison de leur climat, peuvent produire des vins

\footnotetext{
Esprit des lois, liv. XX, chap. 11.
} 
beaucoup plus alcooliques que les nôtres et, grâce au bas prix de leur maind'œuvre, bien meilleur marché. Et, même infériorité pour la soie vis-à-vis de la Chine, pour la laine vis-à-vis de l'Australie, pour la viande vis-à-vis de la République Argentine... Alors quoi ? Faudra-t-il donc que nos cultivateurs, qui représentent la moitié de la population française, abandonnent la terre pour refluer dans les villes? En ce cas, quels dangers pour le pays n'entraînera pas un semblable déplacement, non seulement du point de vue économique, mais au point de vue de la santé publique, de la moralité, de la stabilité politique, de notre force militaire, de l'avenir du pays ! Et qui nous assure d'ailleurs que ces populations chassées des campagnes trouveront dans les villes un travail plus rémunérateur? N'est-il pas possible que l'industrie manufacturière succombe à son tour sous l'importation étrangère ${ }^{1}$ ? Si un pays a le malheur de se trouver inférieur à certains pays étrangers dans toutes les branches de la production, il sera successivement délogé de toutes ses positions, et il ne restera plus qu'une ressource : ce sera de transporter la population et les capitaux, qui peuvent lui rester encore, dans les pays mêmes qui lui font cette concurrence victorieuse, afin d'y bénéficier tout au moins des conditions qui leur assurent cette supériorité ${ }^{2}$ ! Si la France ne peut plus soutenir la concurrence de l'Amérique, qu'elle émigre en Amérique ! - Telle serait la conséquence logique d'un système qui ne voit dans le commerce international que le mode d'organisation le mieux fait pour tirer le meilleur parti possible de la terre et des hommes qui la peuplent, sans s'inquiéter de ce fait que ces hommes sont divisés par nations et que chacune de ces nations a la volonté, le droit et même le devoir de vivre.

Que répondre à cet argument ? Sans doute, si la libre concurrence entre nations devait avoir pour résultat de tuer économiquement la plus faible, la question serait tranchée. En effet, si on comprend à la rigueur, quand il ne s'agit que des individus, qu'un darwinien convaincu puisse les sacrifier en vue des intérêts généraux de l'espèce, on ne peut demander à un pays de se laisser immoler au nom des intérêts généraux de l'humanité. Ce serait d'autant plus absurde qu'il y a ici en jeu bien plus qu'une question de supériorité commerciale : un peuple a un autre rôle à jouer en ce monde que celui de simple producteur économique. Faut-il donc courir le risque que quelque Grèce nouvelle se trouve un jour éliminée d'entre les nations parce que son sol aride ne lui aura pas permis de produire à aussi bon marché que ses rivales?

1 Cet argument est souvent présenté au point de vue des ouvriers. Le protectionnisme, leur dit-on, est la meilleure assurance contre le chômage, et ce fléau est au contraire inévitable sous un régime de libre importation des produits étrangers. Cet argument a fait grand effet sur la classe ouvrière en Angleterre lors de la récente campagne électorale menée par les tariff reformers.

2 Remarquez que c'est précisément le résultat que produit le commerce intérieur entre les différentes parties d'un même pays. N'est-ce pas la liberté et la facilité des communications entre le Cantal ou les Basses-Alpes et Paris qui entraînent la dépopulation et la mort industrielle de ces départements ? Ici, comme c'est une portion de la France qui gagne ce que l'autre perd, il n'y a pas lieu, au point de vue national, d'intervenir, mais si le Cantal était un pays indépendant et qui voulût le rester, il aurait de justes motifs de s'inquiéter et d'essayer de lutter contre l'attraction de Paris. 
Mais cette sinistre vision est purement imaginaire : elle est évoquée par une assimilation purement verbale entre l'échange international et la guerre, entre l'importation et l'invasion. L'importation est nécessairement réciproque, ainsi que nous l'avons démontré ci-dessus (p. 8), tandis que l'invasion est toujours unilatérale. Si pauvre que soit un pays, sa pauvreté ne peut être aggravée par l'importation de produits étrangers et si, en tablant sur le pire, on prévoit qu'il n'aura pas de quoi les payer, eh bien ! en ce cas on peut tenir pour certain que l'importation cessera et avec elle l'invasion et la conquête dont on le croit menacé ${ }^{1}$.

D'ailleurs, quand on parle du devoir de protéger les faibles contre les forts, encore faudrait-il savoir qui sont les faibles et les forts ? L'idée qu'on s'en fait a grandement varié selon les temps et les lieux. Autrefois on entendait par faibles, les jeunes, les industries naissantes jusqu'à ce qu'elles fussent arrivées à l'âge adulte et en situation de se suffire à elles-mêmes, de s'émanciper. La protection ainsi comprise révélait un caractère presque autant moral qu'économique et s'honorait du beau titre de protection-tutelle. C'est ainsi qu'elle était exposée et justifiée dans un système célèbre, celui de l'allemand List, le précurseur sinon le fondateur de l'Économie politique dite nationale. List disait que chaque nation doit passer par une série de phases: agricole, industrielle, commerciale, et que la protection lui était indispensable à cet âge critique qui marque la transition de la première phase à la seconde. Dans son système donc il ne protégeait pas l'agriculture mais seulement l'industrie, et pour celle-ci seulement durant son enfance et jusqu'à sa maturité : aussi approuve-t-il l'Angleterre de s'en être émancipée. List serait aujourd'hui considéré plutôt comme un libre-échangiste.

Ainsi posée, la thèse paraissait assez solide. On comprend que toute industrie qui débute dans un pays aura bien de la peine à tenir tête à des industries déjà anciennes en possession de vastes marchés et qui, grâce à l'étendue de leur production, peuvent pousser au dernier degré les perfectionnements de la division du travail et de la production sur grande échelle. La lutte est d'autant plus difficile que dans ces pays neufs les salaires sont plus élevés et les ouvriers moins expérimentés. On sait bien qu'il n'est pas facile de faire pousser de jeunes arbres dans le voisinage des vieux, parce que ceux-ci, ayant déjà accaparé toute la lumière du ciel et toute la sève du sol, ne leur laissent guère la place d'étendre leurs racines ni leurs branches ${ }^{2}$.

L'argument semblait confirmé par l'expérience des pays neufs, par exemple par celle des jeunes colonies anglaises, telles que l'Australie et le Canada, qui ont sucé

\footnotetext{
1 Pense-t-on, pour prendre comme argument le fait cité plus haut, que si les départements du Cantal ou des Basses-Alpes eussent été entourés d'une barrière de douanes, cela les eût rendus plus riches et eût même empêché leurs habitants d'émigrer à Lyon ou à Paris ?

2 Beaucoup d'éminents économistes, qui ne font point profession de protectionnisme, ont adhéré à la doctrine de la protection-tutelle, à commencer par J.-B. Say et Stuart Mill. Voir aussi en ce sens, Taussig, Some aspects of the tariff question, p. 21-23.
} 
le lait de la pure doctrine libre-échangiste de leur mère-patrie et pourtant n'ont pas hésité à élever, comme d'instinct, un rempart protectionniste contre la mère-patrie elle-même.

On invoquait notamment l'exemple des États-Unis. L'industrie américaine aurait-elle grandi si vite si elle avait eu à lutter dès ses débuts contre les manufactures anglaises et n'aurait-elle pas été écrasée dans l'œuf par sa puissante rivale?

Très bien : mais aujourd'hui voici que les États-Unis ont brillamment fait leur évolution économique et sont devenus un des premiers pays manufacturiers du monde. Aujourd'hui que les voilà grands et forts, ont-ils renoncé à l'abri du rempart qui a protégé leur enfance ? Nullement. Ils continuent à être protectionnistes tout en repoussant du pied, comme outrageant, l'argument de la «protection-tutelle ». Ils déclarent maintenant, par un argument inverse, qu'un pays avancé, en civilisation, riche et payant à ses ouvriers de hauts salaires, doit se protéger contre les États à civilisation arriérée et à bas salaires : c'est de notre Europe qu'il s'agit. De même, disent les économistes américains, que l'Europe et l'Asie abaissent notre civilisation et notre standard of life par l'envoi de leurs émigrants pauvres et faméliques, blancs ou jaunes, de même font-ils en nous envoyant leurs produits à bas prix, et il faut défendre notre état de civilisation et nos hauts salaires à la fois contre l'invasion des travailleurs pauvres et contre l'invasion des marchandises qui sont le produit d'un travail pauvre ${ }^{1}$.

Alors que conclure et qui trompe-t-on ici ? À qui la protection est-elle nécessaire ? Est-ce aux jeunes contre les vieux ou aux vieux contre les jeunes? Est-ce aux faibles contre les forts ou aux forts contre les faibles ? Et que penser d'un argument qui peut servir indifféremment à deux thèses contradictoires ?

\section{§ 2. L'indépendance économique.}

$\underline{\text { Retour à la table des matières }}$

En admettant même qu'aucun pays ne succombât dans cette lutte internationale et que chacun réussît à trouver quelques branches de production où il conserverait sa supériorité et où il ferait refluer toutes ses forces productives, serait-ce là un résultat désirable ? — L'école libre-échangiste l'affirme parce qu'elle ne voit là qu'une vaste application de la loi de la division du travail ; elle se plaît à considérer le monde comme un immense bazar avisé en autant de rayons ou d'ateliers qu'il y a de pays, où chaque nation ne fera qu'une seule chose, celle qu'elle est prédéterminée à faire le mieux, et où par conséquent se trouvera réalisée la

Cette thèse, d'un nationalisme vraiment féroce, est exposée d'une façon savante dans Patten (Les fondements économiques de la protection, traduction française): il oppose les sociétés «à forme dynamique » (progressive) comme les États-Unis, à celles «à forme statique » (stationnaire) comme celles d'Europe. 
meilleure utilisation possible des forces productives de notre planète et de l'humanité. La France ne fera que des vins fins, des chapeaux de dames et des soieries, l'Angleterre des machines et des cotonnades, la Chine du thé, l'Australie de la laine, la Russie du blé, la Suisse des fromages ou des horloges, et la Grèce des raisins secs !

Mais semblable idéal, en admettant qu'il pût être réalisé, entraînerait la dégradation de tous les pays et, par voie de conséquence, du genre humain luimême qui n'a pas d'existence propre en dehors des nations qui le constituent. Si, en effet, il a été reconnu que, même pour les individus, la spécialisation dans un même travail est funeste à leur développement physique, intellectuel et moral, que dire quand il s'agit de tout un peuple ! Un pays où, en poussant le système à l'extrême, tous les hommes feraient le même métier, ne serait plus qu'une masse amorphe, sans organisation. La biologie nous enseigne que le développement d'un être organisé et son rang sur l'échelle de la vie sont en raison de la variété et de la multiplicité de ses fonctions et de la différenciation des organes qui y pourvoient. Il en est exactement de même d'un peuple ; s'il veut s'élever à une vie intense et riche, il doit s'efforcer de multiplier chez lui toutes les formes d'activité sociale, toutes ses énergies, et veiller par conséquent à ce que la concurrence étrangère ne vienne pas les détruire l'une après l'autre ${ }^{1}$.

D'autre part, la spécialisation à outrance serait une grosse imprudence au point de vue économique, parce qu'elle aggraverait trop les risques et serait trop en contradiction avec ce dicton de sagesse pratique — on ne doit pas mettre tous ses œufs dans le même panier.

C’est entendu: la diversité des tâches, de même que celle des conditions sociales, est nécessaire au progrès. Et même nous admettons volontiers qu'il ne faut pas se laisser aller, comme les libre-échangistes y sont peut-être trop enclins, à accepter l'idée fataliste d'une division naturelle du travail entre les peuples, déterminée par les conditions physiques du sol et du sous-sol ou par de prétendues aptitudes innées des habitants. Il faut reconnaître au contraire qu'en dehors de certains cas de localisation d'industries, imposés par la force des choses (Vol. I, p. 286) ce qu'on appelle les supériorités naturelles d'un pays ne sont généralement que des supériorités acquises qui ont eu pour point de départ des initiatives heureuses, souvent même des causes fortuites, mais qui se sont peu à peu

C'est en ce sens que le ministre du Commerce, M. Dupuy, disait au Sénat (11 mars 1910) : « Le tarif douanier est une des conditions d'indépendance de la patrie ».

C'est ce que répète un catéchisme allemand contenant «les Dix Commandements » du consommateur, dont l'un dit: "N'oublie pas que lorsque tu achètes un produit étranger, tu diminues d'autant la force de ta patrie ».

Récemment (26 janvier 1918), dans la réunion mensuelle de la Fédération des Industriels et Commerçants, l'orateur désigné disait: «Nous devons proclamer que, sans l'indépendance économique, on ne peut pas concevoir l'indépendance politique » (applaudissement). Il est vrai qu'immédiatement après il protestait contre un «nationalisme étroit » et déclarait que «la politique économique du vase clos est néfaste pour la nation ». 
enracinées par la pratique et propagées par l'exemple. On peut dire, si l'on veut, que la France a une supériorité naturelle pour la production des grands vins ou l'Allemagne pour la fabrication des teintures parce que dérivées de la houille, mais on ne voit guère quelle nécessité naturelle, quel décret providentiel, auraient conféré aux midinettes parisiennes la spécialité des chapeaux de dames ou aux brasseurs de Munich celle de la bière - et moins encore pour la fabrication des cotonnades ou des draps ici ou là. Il n'est jamais trop tard pour un pays, même quand il s'agit d'un pays aussi vieux que la France, pour tenter des voies nouvelles et essayer de faire aussi bien que les autres. Reste à savoir seulement si l'établissement des droits de douane est le meilleur moyen d'arriver à ce résultat. Ce n'est pas bien sûr (voir ci-dessus, p. 39).

En tout cas, il faut prendre garde que s'il est dangereux pour un pays de se spécialiser dans une seule tâche, comme un ouvrier d'atelier, ce ne serait pas une politique moins absurde que de prétendre tout faire et, pour mieux atteindre ce but, de prendre pour règle de se passer de l'étranger « à tout prix », ce qui veut dire même en s'infligeant des efforts inutiles et des sacrifices indéfinis. Or il est à craindre que la guerre actuelle n'ait pour effet de pousser dans cette voie tous les pays, belligérants ou même neutres, par la hantise du blocus et des privations qu'ils ont eu à subir. Déjà l'Angleterre se prépare à faire l'œuvre inverse de celle qu'elle avait faite il y a un demi-siècle, c'est-à-dire à remettre en culture les terres à blé qu'elle avait converties en pâturages. Et ce n'est pas seulement la production des aliments et des matières premières que chaque pays va s'efforcer de se réserver mais aussi toutes les industries que les Anglais appellent industries-clefs (keyindustries), c'est-à-dire celles indispensables au fonctionnement d'autres industries, comme, par exemple, celle des teintures dont l'Allemagne avait eu jusqu'à présent le quasi-monopole. En outre, étant donné le caractère d'intégration des guerres modernes qui mobilisent pour leurs besoins, non pas seulement tous les hommes mais tous les produits, il n'est plus guère d'industries dont on puisse dire qu'elle soit inutile à la défense nationale, et on se voit entraîné ainsi à tout protéger pour garantir l'indépendance nationale.

Il y aurait peut-être une leçon toute différente à tirer de la guerre actuelle : c'est, tout au contraire, l'aisance relative avec laquelle les pays considérés comme les plus dépendants de l'étranger ont réussi à se suffire à eux-mêmes et finalement l'impuissance du blocus, tant d'un côté que de l'autre, à obtenir la décision attendue ${ }^{1}$. Et, en tout cas, pour éviter le retour de telles privations, la liberté des

Avant la guerre on exagérait beaucoup les chiffres relatifs à la dépendance de l'étranger, notamment en ce qui concernait l'Angleterre et l'Allemagne. Elle n'était pourtant pas si redoutable, car les statistiques commerciales (pour l'année 1913), en ce qui concerne l'importation des produits alimentaires donnent. 6.546 millions de francs pour l'Angleterre et un peu moins de 4 milliards de francs pour l'Allemagne, ce qui représente par habitant 146 francs pour le premier de ces deux pays ( 0,40 par jour) et 60 francs ( 0,17 par jour) pour le second. $\mathrm{Si}$ l'on eût mieux considéré ces chiffres, on aurait pensé que la suppression de ces importations ne serait pas telle qu'elle dût entraîner la famine ni même des privations intolérables et on se serait 
mers serait un moyen plus sûr que de vains et onéreux efforts pour dresser entre les pays des cloisons étanches, ce qui serait une façon de prolonger indéfiniment après la guerre le régime du blocus ${ }^{1}$.

\section{§ 3. L'argument du travail national.}

\section{Retour à la table des matières}

C'est le nœud de la question. Pour les libre-échangistes, comme nous l'avons dit déjà (p. 22), l'échange international n'a pas d'autre but que l'échange individuel, à savoir économiser à chacun des contractants une part du travail qu'il devrait fournir pour se procurer l'objet acquis s'il devait le produire directement. Cet avantage est nécessairement et par définition même réciproque, car s'il faisait défaut du côté de l'une des parties, celle-ci se refuserait à l'échange n'y ayant plus d'intérêt. Cela ne veut pas dire que l'avantage soit le même des deux côtés ; il sera même généralement plus grand d'un côté que de l'autre, mais c'est précisément pour le co-échangiste le moins bien doué en capacité productive qu'il sera le plus grand puisque c’est précisément pour celui-là que la part de travail économisé sera la plus forte ${ }^{2}$.

Mais les protectionnistes se placent à un point de vue tout différent. Ce que les libre-échangistes appellent travail économisé ils l'appellent travail supprimé, et par là préjudice infligé à l'industrie nationale. Et ils nient que le pays qui se trouve dans une situation inférieure soit celui qui se trouve le plus avantagé par l'échange international. Tout au contraire le pays pauvre se trouvera obligé, pour acquérir le produit du pays industriellement supérieur, de céder des produits qui représenteront un travail très supérieur au travail fourni par celui-ci. Il est donc absolument inexact que le commerce international ait pour effet d'enrichir les deux parties, mais il serait bien plus vrai d'appliquer ici le vieux dicton que le dommage de l'un fait le profit de l'autre. Peut-on soutenir que le commerce entre l'Angleterre et le Portugal, qui dure depuis un siècle et demi, ait enrichi également les deux pays et plus spécialement le Portugal ?

épargné, de part et d'autre, des illusions qui ont eu l'effet de prolonger indéfiniment la guerre. La disette, là où elle a sévi, a été la conséquence moins de la cessation des importations que du manque de main-d'œuvre et de moyens de transport.

1 L'idéal du philosophe allemand Fichte, tel qu'il a été exposé dans son livre L'État commercial isolé (1800), était celui-ci : l'État produisant uniquement ce qu'il consomme et consommant uniquement ce qu'il produit et, pour mieux assurer son isolement, suppression de toute monnaie métallique remplacée par une monnaie de papier nationale, et même la porte fermée à tous les touristes «qui, en quête de distractions, vont promener d'un pays à l'autre leur oisiveté et leur ennui ». Cet État-Robinson, comme il faudrait l'appeler, est une caricature, mais instructive, de l'idéal autonomiste.

2 C'est l'argument développé à satiété, mais sous des aspects divers et ingénieux, par Bastiat, dans ses Sophismes économiques. 
Il faut reconnaître que l'argument des protectionnistes peut trouver un appui dans la doctrine des valeurs internationales que nous avons résumées ci-dessus (p. 24, note). L'argument des libre-échangistes avait pour fondement ce principe que la valeur échangée est toujours déterminée par le coût de production des deux objets échangés : or si cela est vrai de l'échange individuel, on ne croît plus que ce soit vrai pour l'échange entre deux pays : on enseigne que la valeur des objets échangés est déterminée par le besoin qu'en ressent celui des deux pays qui peut le moins s'en passer et qui par là se trouve à la discrétion de l'autre.

Mais même étant admise l'inégalité des avantages pour les pays coéchangistes, il n'en résulte pas que l'établissement d'un droit protecteur puisse avoir pour effet de rétablir l'égalité et de compenser l'infériorité du pays désavantagé ${ }^{1}$.

Quant à l'argument du travail supprimé, il est incontestable, mais nous avons déjà fait remarquer à propos des inventions mécaniques (I, p. 136) que c'est là un résultat inévitable du progrès économique sous n'importe quelle forme ; en effet, on ne saurait économiser une certaine quantité de travail sans rendre inutile une certaine catégorie de travailleurs. Le commerce des soies avec la Chine est un avantage pour les consommateurs français, puisqu'il leur permet de se procurer des soies avec moins de dépenses et moins de travail; mais les agriculteurs et travailleurs des Cévennes qui vivaient de cette industrie se trouvent en quelque sorte expropriés.

Il est bien vrai, comme nous l'avons expliqué déjà (p. 8), que toute importation nouvelle tend à déterminer automatiquement une contre-exportation et que les soies de Chine seront payées, par exemple, avec des articles de Paris qu'il faudra produire à cet effet. Mais il ne faut pas oublier que les soies importées de Chine représentent évidemment une valeur moindre que les soies françaises qu'elles ont remplacées dans la consommation : sans cela elles n'auraient pu se substituer à elles sur le marché. Elles représentent par exemple une valeur de 100 millions seulement tandis que la production séricicole française représentait une valeur de 120 millions. Donc, pour faire face à cette importation par une contre-exportation équivalente, il suffira que l'industrie parisienne envoie à la Chine (ou ailleurs) pour 100 millions de francs d'articles de Paris. Le résultat final sera donc bien une diminution de 20 millions de francs pour la production indigène, représentant une diminution de travail correspondante.

N'y aurait-il d'ailleurs d'autre effet produit qu'un déplacement de travail celui-ci saute aux yeux - il n'en constituerait pas moins un préjudice grave pour certaines classes de la population. Il est clair que les fabricants de soie des Cévennes, ne pouvant pas convertir leurs filatures en fabriques d'articles de Paris,

1 C'est seulement si l'on croit que le droit protecteur est toujours supporté par le pays exportateur qu'alors on pourra voir là une surcharge imposée au pays économiquement supérieur et qui compensera l'inégalité. 
devront perdre les capitaux engagés dans leurs usines sous la forme de capitaux fixes ; et comme les fileuses qu'ils employaient ne peuvent pas non plus aller faire de la bimbeloterie pour les Chinois, il n'est pas sûr qu'elles trouvent un autre métier. C'est donc la ruine pour les premiers, le chômage pour les seconds.

Tous ces inconvénients sont incontestables, mais, d'autre part, il ne faut pas oublier l'avantage pour les consommateurs résultant de la baisse des prix. Et d'autre part, même au point de vue des producteurs, on peut faire valoir certaines circonstances rassurantes. On peut dire que le commerce international, par ses conséquences indirectes, pourra augmenter la quantité de travail qu'il avait commencé par diminuer, et cela de deux façons différentes :

Parce que l'abaissement des prix, résultant du libre-échange lui-même, entraînera un accroissement de consommation et par conséquent un accroissement de production. Par exemple, la baisse des soies fera que nous en consommerons davantage. En admettant même que cette demande accrue ne porte que sur les soies de Chine et non sur les soies françaises, il faudra néanmoins, pour payer cette importation grossissante, une exportation grossissante aussi d'articles de Paris, représentant non plus seulement 100 millions de francs comme tout à l'heure, mais peut-être 120 millions de francs comme auparavant ;

Parce que l'abaissement des prix, en diminuant les dépenses des consommateurs sur un article déterminé, peut leur permettre de reporter l'économie ainsi réalisée sur d'autres dépenses, ou de la placer. Par exemple, tout ce qui sera enlevé à l'industrie des soieries pourra aller par une autre voie, sous forme d'épargnes au de dépenses nouvelles, alimenter d'autres industries, et il est probable qu'en définitive la quantité de travail national employé restera la même. C'est la même réponse que celle déjà discutée à propos des machines (I, pp. 132137) : toute économie bénéficie au producteur aussi bien qu'au consommateur, quoiqu'elle puisse porter préjudice à des intérêts particuliers.

\section{§ 4. L'argument de la balance du commerce.}

$\underline{\text { Retour à la table des matières }}$

Nous avons expliqué déjà (p. 12) pourquoi il faut abandonner la vieille idée encore souvent ressassée dans des journaux importants ${ }^{1}$ - qu'un pays marche à sa ruine quand il importe plus qu'il n'exporte. Mais la question n'est que déplacée, car, remplaçant alors les mots «balance du commerce » par ceux de "balance des comptes », nous devons la formuler ainsi : un pays ne risque-t-il pas de se ruiner quand, tout compte fait, il a plus à payer à l'étranger qu'à en recevoir ?

1 C'est ainsi que dans un des journaux à plus grand tirage, naguère un député faisait le compte que de 1880 à 1912 l’Allemagne avait importé pour 34 milliards de francs de plus que ce qu'elle avait exporté, et s'était par conséquent appauvrie d'une valeur égale ! 
À cette question les économistes de l'école classique répondaient hardiment : non ! Et ils donnaient, à l'appui de leur dire, une très élégante démonstration, en s'appuyant sur la loi que nous avons exposée ci-dessus, à savoir que la balance des comptes tend à se régler d'elle-même, que s'il y a excès d’importation et sortie du numéraire, la baisse du prix ou la hausse du change tend à enrayer les importations et à faire refluer le numéraire, et que, d'ailleurs, il importe peu à un pays d'avoir plus ou moins de numéraire (voir ci-dessus, p. 6).

Néanmoins aujourd'hui on n'est pas si affirmatif et on admet plutôt que c'est une situation fâcheuse pour un pays que d'avoir — nous ne disons plus une balance du commerce défavorable, ce qui, en effet, ne, signifie rien - mais une balance des comptes qui le constitue débiteur de l'étranger.

En effet, ce n'est pas une situation favorable ni normale pour un pays, pas plus que pour un individu, d'être toujours en posture de débiteur ${ }^{1}$. C'est la marque d'un état d'infériorité et de dépendance ; c'est la preuve qu'on n'arrive pas à équilibrer son actif et son passif, et quand il s'agit d'un pays c'est la preuve — je ne dirai pas qu'il ne réussit pas à vivre de ses propres ressources, ce qui ne serait pas un mal mais qu'il ne réussit pas à payer par son travail ce qu'il doit à l'étranger.

D'ailleurs, tôt ou tard, quand un pays est débiteur, il lui faut payer, ce qu'il ne pourra faire qu'en puisant dans les réserves monétaires et spécialement dans les encaisses des banques. Or, il n'est pas indifférent pour un pays, quoi qu'on en dise, d'avoir peu ou beaucoup de monnaie (I, p. 435), et s'il est vrai que la diminution en quantité de la monnaie porte son remède en elle-même, parce que cette diminution en quantité détermine une hausse de valeur de la monnaie qui se traduit par une baisse générale des prix — cette baisse générale des prix doit être considérée ellemême comme un mal parce qu'elle entraîne une baisse des profits et des salaires, et comme un refroidissement général du milieu économique : elle décourage la production (voir ce que nous avons dit des Variations de prix, I, p. 365).

Et si, pour remplacer le numéraire qui s'en va, le pays émet du papier-monnaie, le voilà sur la pente qui le conduit à la banqueroute. Et le pire sera si le pays, n'ayant pas d'argent pour payer le solde débiteur, emprunte pour s'acquitter, comme ces fils de famille qui font renouveler à chaque échéance les billets qu'ils ont souscrits ! Alors il marche à la banqueroute. Telle a été l'histoire de plus d'un État.

C'est dans le même sens que le vieux Caton disait: Patrem familias vendacem, non emacem, esse oportet (De Agricultura). La loi de Moïse dit (Deutéronome, XV, 6) : "Mets soigneusement en pratique le commandement que je te prescris aujourd'hui. Tu prêteras à beaucoup de nations et tu n'emprunteras point : ainsi tu domineras sur beaucoup de nations et elles ne domineront point sur toi ». Il est vrai qu'il s'agit là du prêt et non de la vente, mais, disent les protectionnistes, cela revient au même, car le pays vendeur finit tôt ou tard par devenir le pays créditeur. 
En résumé, nous dirons qu'il n'y a aucun danger pour un pays à avoir une balance du commerce défavorable — c'est le cas des pays les plus avancés ${ }^{1}$ mais il est fâcheux pour un pays d'avoir, de façon permanente, une balance des comptes défavorable.

Ce n'est donc pas sans raison que les banques et les gens d'affaires se préoccupent de la balance entre les exportations et les importations et consultent avec anxiété le signe qui la révèle, à savoir le cours du change. Sans doute, les exportations ne sont pas le seul article qui figure dans cette balance, côté crédit, mais c'est de beaucoup le plus important et c'est pourquoi leur augmentation ou diminution ne saurait être envisagée avec la dédaigneuse indifférence que montrent les libre-échangistes.

\section{§ 5. Le grief de cherté.}

\section{$\underline{\text { Retour à la table des matières }}$}

Le protectionnisme n'accepte pas cette imputation qu'il est nécessairement la cherté et le libre-échange le bon marché. Il ne considère nullement comme démontré que le droit de douane entraîne nécessairement une hausse des prix que le consommateur aura à payer. Car d'abord il peut très bien se faire que tout ou partie du droit de douane soit supporté par le vendeur étranger : il sera bien forcé de s’y résigner s'il veut conserver sa clientèle, car il n'ignore pas qu'une hausse de prix aurait nécessairement pour effet de la réduire.

D'autre part, si le droit protecteur a pour résultat, comme on l'espère, de développer l'industrie protégée, en ce cas la concurrence à l'intérieur suffira pour ramener les prix à l'ancien niveau, par conséquent l'extension de l'industrie nationale n'aura infligé aucun préjudice au consommateur.

Il y a une part de vérité dans ces deux arguments.

En effet, il peut arriver que le producteur étranger supporte les droits dans certains cas qui ont été signalés par Stuart Mill. Toute élévation du prix entraîne

\begin{tabular}{|c|c|c|c|c|}
\hline $\mathrm{IC}$ & Importations & Exportations & Écarts & p. cent \\
\hline Angleterre & 19.394 & 16.014 & -3.380 & -21 \\
\hline Allemagne & 13.400 & 12.600 & -800 & -6 \\
\hline France & 8.421 & 6.880 & -1.541 & -22 \\
\hline Belgique & 5.050 & 3.716 & -1.834 & -33 \\
\hline États-Unis & 9.200 & 12.500 & +3.300 & +36 \\
\hline
\end{tabular}

La quatrième colonne indique en tant p. 100 le déficit ou l'excédent de l'exportation sur l'importation, celle-ci étant représentée par 100.

On voit que de ces cinq grands pays commerçants les États-Unis sont les seuls où l'on trouve un excédent. 
une réduction dans la consommation. Le producteur étranger aura donc à se demander s'il n'est pas de son intérêt de consentir un sacrifice en abaissant le prix de ses articles d'une somme égale au montant du droit afin de conserver sa clientèle en lui maintenant ses anciens prix. Le droit qui frappe ses produits le met dans cette fâcheuse alternative ou de restreindre le chiffre de ses ventes ou de faire un sacrifice sur le prix. Il n'est pas impossible que, tout compte fait, son intérêt l'engage à choisir le second parti, c'est-à-dire à prendre à sa charge tout ou partie du droit. C'est ainsi que beaucoup de fabricants français, pendant la guerre commerciale franco-suisse de 1893 à 1895, pour ne pas perdre leur clientèle suisse, avaient pris à leur charge tout ou partie des droits établis par le nouveau tarif. Seulement, pour que les producteurs étrangers se résignent à cette extrémité, il faut deux conditions préalables : - la première, que le prix de revient le leur permette ; la seconde, qu'ils ne trouvent pas le moyen d'écouler leurs produits sur un autre marché.

Il peut arriver aussi que la concurrence intérieure, en se développant, ait pour résultat d'enrayer la hausse. On peut même aller jusqu'à imaginer que, sous l'abri confortable de la barrière de douane, la production se développe au point de dégénérer en surproduction — c'est ce qui est arrivé pour la production des vins en France - et d'entraîner un avilissement du prix. Mais, dans ce cas, où est l'avantage des droits protecteurs ? Est-ce un bien que la France soit inondée de vin et de blé français ait lieu de l'être par le vin et le blé étrangers ? Je pense, au contraire, que la surproduction provoquée ainsi à l'intérieur est pire que celle qui vient de l'étranger, car contre celle-ci il est facile de se défendre, tout simplement en n'achetant plus dès qu'on a assez, tandis que, quand la surproduction est à l'intérieur, le refus d'acheter, à un moment donné, entraîne la ruine des producteurs nationaux. Un des grands avantages du libre-échange est la stabilité des prix ${ }^{1}$.

Mais ce sont là des cas exceptionnels et ce qu'il faut remarquer c'est que lorsqu'ils se réalisent ils sont tout à fait contraires aux intentions des protectionnistes : ceux-ci ne sont donc pas fondés à les invoquer en faveur de leur système. Il est bien évident que lorsque des industriels ou des agriculteurs réclament auprès des pouvoirs publics des droits protecteurs c'est parce qu'ils estiment que leurs prix de vente sont insuffisants ou parce qu'ils craignent de les voir baisser et, par conséquent, les droits réclamés n'ont d'autre but que de déterminer cette hausse ou, ce qui revient au même, d'empêcher la baisse prévue.

Un des inconvénients, en effet, du régime commercial à cloisons, qui est le régime protectionniste, c'est que, enfermé dans chaque compartiment, le niveau des prix est soumis à de brusques oscillations tandis que par le libre-échange il s'établit un nivellement général. De même autrefois quand il y avait en France des douanes entre provinces, le prix du blé variait dans des proportions invraisemblables; et même encore après l'abolition des douanes, la difficulté de transport suffisait pour déterminer des variations du simple au double et plus encore - 10 fr. 14 l'hectolitre dans la Meurthe et 28 fr. 57 dans le Gard, en 1805 (voir Schelle, op. cit.). Aujourd'hui, tout obstacle étant supprimé, les différences d'un département à l'autre ne dépassent pas 2 ou 3 francs. 
Et si on venait leur dire : Nous vous accordons le droit demandé, mais nous vous avertissons qu'il ne fera pas monter les prix — nul doute que les intéressés ne répondissent : s'il doit en être ainsi, gardez vos droits protecteurs, nous n'en avons que faire !

La hausse du prix est donc, sinon toujours le résultat, du moins toujours le but du protectionnisme. Il faut reconnaître seulement que la hausse n'est pas toujours ni même généralement égale au montant du droit ; le droit ne joue pas en plein, comme on dit. Il est clair que si la récolte du blé a été abondante en France, le prix du blé baissera et le droit de douane de 7 francs le quintal n'aura pas pour effet de le faire monter, puisque le blé étranger ne sera pas nécessaire sur le marché ; et par conséquent, ou bien l'importation cessera, ou bien l'importateur se résignera à le vendre au cours du marché intérieur en prenant à sa charge le droit de douane.

Mais, malheureusement, c'est précisément dans les années de mauvaise récolte que le droit joue en plein parce qu'en ce cas on ne peut se passer du blé étranger et l'importateur en profite pour faire payer le maximum. Cela est si vrai que dans les temps de disette le législateur suspend le droit ${ }^{1}$. Et c'est ce qui est arrivé dans de bien autres proportions dès le début de la guerre actuelle où tous les États se sont empressés de décréter la libre entrée des céréales et autres denrées, afin d'enrayer si possible la hausse des prix. Comment, en présence de tels faits, pourrait-on soutenir de bonne foi que les droits dé douane n'ont pas d'effet sur les prix ${ }^{2}$ ?

1 C'est précisément ce qui est arrivé en 1898 où le prix du blé dépassa 32 francs le quintal et où le droit de douane dut être suspendu, M. Méline, par une ironie du sort, se trouvant en ce moment président du Conseil des ministres.

2 S'il fallait une preuve de plus, on pourrait rappeler le système ancien de l'échelle mobile qui faisait varier le montant du droit en raison inverse du prix du blé, jusqu'à le réduire à zéro quand le prix atteignait un certain prix. Quelle signification aurait pu avoir un tel système, qui a été considéré en son temps comme un chef-d'œuvre, si le droit de douane n'avait aucune relation nécessaire avec les prix ?

D'ailleurs, si c'est l'étranger qui paie les droits de douane, pourquoi exonérer les matières premières importées, comme on ne manque pas de le faire pourtant, même sous les régimes les plus protectionnistes?

Les tableaux des prix comparés dans les pays libre-échangistes et protectionnistes confirment absolument ces données du bon sens. Pour le produit-type, le blé, on trouvera dans le petit livre de M. Schelle, Le Bilan du Protectionnisme en France, la liste du prix annuel du blé (le quintal), de 1891 à 1911 à Paris, à Londres et à Bruxelles. Voici la moyenne des prix depuis 1894, date à laquelle le droit d'entrée a été porté pour la France à 7 francs (et déduction faite de l'année 1898 pendant laquelle il a été supprimé), jusqu'à 1911.
Paris 22,84 fr.
Londres $\quad 17,97 \mathrm{fr}$.
Bruxelles $17,67 \mathrm{fr}$.

La différence de prix est donc à peu près de 5 francs entre la capitale de la France et celle des deux pays libre-échangistes.

Mêmes constatations quand, au lieu du prix du blé, on prend l'ensemble du prix, c'est-à-dire le coût de la vie pour une famille ouvrière. 
On peut admettre aussi que la répercussion du prix du blé étranger sur le blé indigène ne se réalise qu'incomplètement si la quantité importée ne représente qu'une faible fraction de la production nationale. En effet, quoique ce soit une loi économique, que pour tous les produits similaires sur un même marché il n'y ait qu'un prix unique (vol. I, p. 343) et que, par conséquent, en théorie, il suffirait qu'un seul hectolitre de blé étranger importé (étant supposé qu'on ne peut s'en passer) fût vendu 30 fr. pour que les 100 millions d'hectolitres de blé indigène fussent tous vendus au même prix, en fait cette égalisation ne se réalisera pas. Même en ce qui concerne le blé indigène il y a des différences de prix assez notables d'une région à l'autre parce que le nivellement des prix ne peut se faire dans les mêmes conditions que le nivellement d'un liquide ; à plus forte raison donc peut-il y avoir des différences de prix entre le blé indigène et le blé étranger si l'importation est faible: une loi économique n'est jamais qu'approximative mais le protectionnisme n'est pas fondé à se prévaloir de ces anomalies.

Les sociétés de consommation, qui sont assez bien qualifiées pour représenter les intérêts des consommateurs et pour connaître leurs besoins, ne s'y sont pas trompées - et dans tous les pays, même en France, elles ont fait campagne pour l'abolition ou la réduction des droits protecteurs. Leur intervention active n'a certainement pas peu contribué, en Angleterre, à l'échec des tariff reformers (programme Chamberlain) en 1903.

Pour se défendre contre le grief de faire renchérir la vie et d'infliger par là à tous les habitants une surtaxe sous la forme d'impôt de consommation, les protectionnistes n'ont qu'un argument solide, c'est de dire : tant pis ! il le faut. C'est un sacrifice commandé par la sécurité du pays. Chaque peuple s'évertue à se créer, au prix des plus lourds sacrifices, des forteresses, des flottes de guerre, des fabriques d'armes. Eh bien ! les industries indispensables à la sécurité d'un pays ne sont pas seulement telle ou telle fabrique d'armes ou de biscuits, c'est la houille sans laquelle les trains ne pourraient marcher, ni par conséquent la mobilisation s'effectuer ; c'est le fer, ce sont les chevaux, c'est le blé, la viande, le drap, le, cuir, tout ce qui est nécessaire pour entretenir et faire vivre des millions d'hommes. Je ne sais quel économiste américain faisait le compte qu'une certaine filature avait coûté plus cher à son pays qu'un croiseur cuirassé. Voilà qui était franc ! Oui, mieux vaut déclarer hardiment que les droits protecteurs et les guerres de tarifs valent ce que valent la paix armée et la guerre à coups de canon, qu'ils ne sont pas moins onéreux, mais non moins nécessaires à l'existence d'un peuple qui réclame sa place au soleil. Mais les protectionnistes n'aiment pas à faire cet aveu et préfèrent leurrer le pays par la perspective de gains imaginaires.

\section{$\S$ 6. Les droits compensateurs. - Le dumping.}

$\underline{\text { Retour à la table des matières }}$ 
Entre l'ancien protectionnisme, encore imprégné de mercantilisme et s'appuyant surtout sur l'argument de la balance du commerce, et le libreéchangisme absolu, à la Bastiat ou à la mode de Manchester, qui déclare qu'un pays doit laisser ses portes ouvertes toutes grandes alors même que tous les autres pays lui fermeraient les leurs, il s'est formé un néo-protectionnisme qui estime que la politique d'un pays, en ce qui concerne ses relations commerciales avec les autres pays, ne peut être unilatérale et doit nécessairement se régler sur la politique de ceux-ci.

Les économistes de l'école libérale ne se préoccupaient guère de la réciprocité. Sans doute, disent-ils, il est très désirable que la porte soit grande ouverte de la part de chacune des parties, mais si elle est fermée ou simplement entre-bâillée chez l'un des pays, ce n'est pas une raison pour que nous fermions la nôtre. Mieux vaut encore qu'il y en ait une d'ouverte que toutes les deux fermées ! Si, par exemple, l'Europe frappe de droits les produits américains, elle infligera un préjudice aux États-Unis, mais elle en infligera un aussi à elle-même, et le mal que nous pouvons faire à notre voisin ne saurait être considéré comme une compensation pour celui que nous nous faisons à nous-mêmes.

Les néo-protectionnistes disent : nous ne voulons pas exclure la concurrence étrangère, mais nous voulons que cette concurrence soit loyale. Le commerce n'est pas une guerre, soit ! mais c'est une affaire où chaque partie doit jouer franc jeu fair trade comme disent les Anglais, en l'opposant au free trade. Si donc un pays étranger exclut nos produits, nous devons exclure les siens. Il faut que le traitement soit réciproque.

Et il ne suffit pas de regarder au régime douanier de l'étranger, il faut regarder aux conditions de sa production agricole ou industrielle. Si elles sont tellement plus favorables que, même sans recourir à des primes ou dumping, il se trouve en situation de vendre ses produits à des prix très inférieurs aux nôtres, en ce cas la concurrence n'est plus loyale et il faut rétablir l'égalité par des droits équivalents à la différence entre le prix de revient des produits étrangers et le prix des nôtres ; c'est ce qu'on appelle les droits compensateurs. Si tel pays étranger, disons par exemple, l'Amérique - à raison des ressources naturelles d'une terre encore vierge, ou parce qu'il n'a pas à supporter dans son budget les conséquences d'un lourd passé historique - peut produire du blé à 18 francs le quintal, tandis que l'agriculteur français ne peut le produire qu'à 25 francs en moyenne, il est juste qu'un droit compensateur de 7 francs à l'importation vienne rétablir l'égalité des charges, de même qu'on le fait dans les courses de chevaux quand les jockeys n'ont pas le même poids.

Ainsi présenté, le néo-protectionnisme semble parfaitement équitable. Et pourtant quand on demande de rétablir l'égalité dans la concurrence par des droits compensateurs, encore faudrait-il savoir de quel côté est l'infériorité, de quel côté penche la balance ? Nous disons en France que cette compensation doit être faite 
contre les Américains, parce qu'ils ont plus de ressources naturelles, un sol non épuisé encore par vingt siècles de culture et un budget moins lourd. Mais les Américains disent que la compensation doit exister contre nous, parce que les salaires inférieurs payés à nos ouvriers, les journées plus longues qui leur sont imposées, la moindre valeur de l'argent en Europe, sont autant de conditions qui nous permettent de produire à des prix très inférieurs aux leurs.

Il est même à remarquer que sous son apparence modérée, le système compensateur devrait aboutir logiquement à l'établissement de droits prohibitifs. En effet, aussi longtemps qu'un produit étranger continue à entrer, c'est qu'il y trouve bénéfice ; c'est qu'il a été produit plus économiquement là-bas qu'ici ; c'est donc la preuve que le droit compensateur n'a pas suffi pour supprimer complètement l'inégalité : il faut donc la relever jusqu'à ce que la cessation de tout courant d'importation ait prouvé que l'équilibre est complètement rétabli. L'existence d'un courant suppose évidemment une différence de niveau : si l'on veut arrêter le courant dans une rivière, il faut donc remonter le barrage jusqu'à ce qu'il n'y ait plus d'écoulement d'amont en aval. Pour voir jusqu'où mènerait l'application de ce système, il n'y a qu'à l'appliquer par hypothèse, au commerce intérieur. Tout commerçant qui verrait un concurrent lui enlever des clients se dirait: "Ce confrère doit avoir sur moi une supériorité quelconque dans la fabrication et dans la vente (et assurément il ne se tromperait pas) : peut-être est-il mieux placé, ou a-t-il quelque secret de fabrication, ou a-t-il moins d'impôts à payer ${ }^{1}$, ou paie-t-il moins ses ouvriers. Il est juste de frapper ses produits d'un droit différentiel tel qu'ils ne puissent pas les vendre à un prix inférieur au mien ${ }^{2} »$ !

En somme, supprimer les différences de situation entre échangistes, ce serait supprimer la raison d'être de tout échange.

On ne saurait donc voir dans les droits compensateurs une atténuation au système protectionniste si on veut en faire un instrument de nivellement entre les pays échangistes - mais on peut mieux les justifier lorsqu'on les propose comme une arme défensive contre une politique agressive de l'étranger, au cas où celui-ci

1 Cette thèse que le libre-échange n'est juste qu'entre pays qui se trouvent dans des conditions égales comme charge d'impôts et comme taux des salaires a une apparence de logique frappante et a trouvé de l'écho dans les milieux ouvriers. Pourtant si l'on admet, comme nous croyons l'avoir démontré (p. 55), que les droits de douane retombent le plus souvent sur les nationaux sous la forme d'une élévation des prix, alors on pourra apprécier l'ironie de cette soi-disant compensation qui, sous prétexte d'égaliser la lutte, met double charge sur les épaules des contribuables qui sont déjà le plus lourdement chargés et de la classe ouvrière qui est la moins bien payée.

2 Ce n'est pas une comparaison purement imaginaire, car telle est précisément la réclamation formulée sans cesse par les commerçants des villes contre les Grands Magasins et les sociétés coopératives de consommation, réclamations qui ont trouvé généralement bon accueil auprès des Chambres législatives: aussi les Grands Magasins, sinon les coopératives, ont-ils été frappés de surtaxes qu'on pourrait qualifier de même de droits compensateurs. 
voudrait forcer notre porte en donnant des primes d'exportation à ses fabricants ou en pratiquant le système du dumping.

Il a été souvent question du dumping ${ }^{1}$ avant la guerre et plus que jamais on s'en préoccupe pour après la guerre, parce qu'on voit là une arme de guerre économique spéciale à l'Allemagne et qui paraît aussi redoutable que les gaz asphyxiants. Le mot anglais qui sert à désigner ce procédé indique pourtant qu'il n'est pas d'invention allemande - mais il est vrai que les Allemands ont su en user mieux que tout autre pays grâce à l'organisation savante de leurs Cartels (Vol. I, p. 287). Ces associations de producteurs, quand elles ont acquis un quasi-monopole sur le marché, ont intérêt à ne pas déprécier les prix par une production surabondante et, pour l'éviter, elles trouvent avantage à déverser au dehors, fût-ce même à perte, le trop-plein de leur production. Elles indemnisent d'ailleurs, par une caisse d'assurances, ceux de leurs membres qui sont chargés de cette liquidation ${ }^{2}$.

Mais le dumping est-il une arme si redoutable qu'on le croit ? Il semble que les nationaux devraient être les seuls à s'en plaindre et que les étrangers qui en bénéficient, en payant en produits au-dessous du cours, n'aient qu'à s'en féliciter non seulement ceux qui les achètent pour leur consommation, mais plus encore ceux qui les achètent comme matières premières pour leur industrie. On dit que le dumping a pour but de tuer l'industrie nationale et que, dès que celle-ci est morte, les prix sont relevés. Mais je ne sais si on pourrait citer beaucoup d'exemples de cette tactique ${ }^{3}$, tandis qu'en sens inverse on peut citer des cas assez nombreux d'industriels achetant la marchandise allemande dumped et, avec cette matière première, fabriquant un produit qui, réimporté sur le marché allemand, venait faire une concurrence victorieuse au produit allemand ! Il faut bien croire d'ailleurs que l'opération n'est pas si avantageuse pour l'exportation qu'on le croit, car elle commençait à être assez discréditée en Allemagne.

Quant à ce qu'on dit de la déloyauté du procédé, il n'y a guère lieu de s'en émouvoir, car il est d'une pratique courante dans le commerce intérieur. Ne voyons-nous pas tous les jours des magasins annoncer par d'énormes enseignes: Liquidation à perte ! Et il paraît que c'est par ce moyen que les marchands anglais se créent une clientèle aux Indes; quand ils veulent faire pénétrer un nouveau produit, ils commencent par le vendre à perte et relèvent peu à peu les prix au fur et à mesure que le client y prend goût : c'est ce qu'on pourrait appeler la méthode

Littéralement le mot veut dire entasser, amonceler, mais au sens commercial ce serait plutôt : se débarrasser, déblayer.

2 On cite, entre beaucoup d'autres cas, celui des poutres en fer (fers à T) dont le prix courant en Allemagne était de 130 marks la tonne et qui étaient vendus seulement 100 à 110 marks en Angleterre ou dans l'Amérique du Sud et même 75 marks en Italie ! Voir, pour plus de détails, le livre de M. Hauser, Les méthodes allemandes d'expansion économique.

3 On cite cependant le cas d'industries métallurgiques en Écosse qui auraient été tuées par le dumping allemand. 
d'entraînement appliquée à l'exportation. Et c'est dans le commerce intérieur surtout qu'on peut trouver maints exemples de ventes à bas prix faites en vue de tuer la concurrence ; l'histoire des Trusts et même celle des magasins à succursales en fournissent à profusion (I, p. 294).

On a réclamé maintes fois des droits anti-dumping, c'est-à-dire établis de façon à annuler la baisse des prix résultant du dumping (ce qui suppose donc que le droit aura pour effet de relever le prix et réfute une fois de plus les dénégations des protectionnistes sur ce point) et cette mesure a été appliquée notamment par le Canada ${ }^{1}$. Elle ne peut guère l'être que dans les pays où les droits sont établis ad valorem et même en ce cas il n'est pas facile de calculer quelle est la différence entre le prix du produit dumped au pays de provenance et le prix à l'importation. Et c'est tout de même une politique bizarre que de dire à l'Allemagne, par exemple : Vous nous vendez tel produit meilleur marché qu'à vos nationaux ; nous allons prendre des mesures pour empêcher cette inégalité et pour vous obliger à vendre chez nous aussi cher que chez vous !

Ce n'est pas seulement contre le dumping que l'on réclame des droits protecteurs ou, comme on dit, des pénalisations, mais aussi contre les primes accordées à la production ou à l'exportation et qui ne sont en effet que des espèces de dumping officiel (voir ci-après, p. 80).

À un degré au-dessus des droits compensateurs se placent les mesures dites de rétorsion quand un pays s'estime injustement traité, par exemple lorsque ses produits se trouvent soumis à des droits dans le pays $\mathrm{X}$ plus élevés que ceux qui sont accordés aux autres pays. On répond en frappant les produits du pays $\mathrm{X}$ de majorations égales : c'est le système des représailles; coup pour coup. À s'en tenir au point de vue économique, cette guerre de tarifs et cette surenchère de mauvais traitements sont évidemment absurdes, puisque nous croyons démontré que toute mesure semblable porte non moins préjudice au pays qui l'édicte qu'à celui contre qui elle est dirigée. Néanmoins, elle peut se justifier au point de vue politique si elle a pour résultat de forcer l'adversaire à changer ses procédés ${ }^{2}$.

\section{§ 7. L'argument fiscal.}

$\underline{\text { Retour à la table des matières }}$

Les protectionnistes ont enfin un argument qui, bien qu'emprunté à un ordre de faits tout à fait en dehors du protectionnisme, ne laisse pas que d'avoir une grande force : c'est l'argument fiscal. Le droit de douane est un impôt, mais qui, disent-ils, est payé par l'étranger et par conséquent a cette vertu miraculeuse de n'infliger

1 La Conférence économique entre les gouvernements alliés de l'Entente, tenue à Paris en juin 1916, a pris la décision « de défendre leur commerce et leur industrie contre une agression économique résultant du dumping ou de tout autre procédé de concurrence déloyale ».

2 De ces guerres de tarifs on pourrait citer bien des exemples, notamment entre la France et l'Italie en 1887-1897 et entre la France et la Suisse de 1892 à 1895. 
aucune charge au contribuable ${ }^{1}$. La meilleure preuve de ses avantages au point de vue fiscal c'est que même les États libre-échangistes y ont recours sur la plus grande échelle : c'est plus de 900 millions de francs que l'Angleterre retire de ses douanes, notablement plus que la France pourtant protectionniste. Au lendemain de la guerre, quand les ex-belligérants devront s'évertuer à combler leurs énormes déficits, ils seront bien heureux d'utiliser cette ressource et on peut croire que loin de diminuer les droits de douane, même ceux portant sur les produits des pays amis et alliés, ils s'empresseront de les augmenter.

En effet, les douanes ont toujours été et resteront sans doute une riche source pour le Trésor, mais nous avons déjà fait remarquer qu'il ne faut pas se faire l'illusion de croire que ces droits diffèrent des autres impôts en ce qu'ils seraient payés par l'étranger, sinon dans des circonstances exceptionnelles que nous avons indiquées ci-dessus. Ce serait vraiment trop commode si un pays pouvait se procurer ainsi l'argent dont il a besoin en le prenant dans la poche de l'étranger. Et d'ailleurs, en admettant même que tel fût le cas, comme ce ne serait pas un secret magique, il est clair que chaque État s'empresserait d'en user et chacun faisant payer ses impôts par ses voisins, aucun ne s'en trouverait mieux !

Les libre-échangistes ne critiquent le droit de douane en tant que droit fiscal, mais ils disent que, si l'on se place à ce point de vue, le droit sera d'autant plus avantageux qu'il sera mieux dégorgé de tout venin protectionniste et que par conséquent les protectionnistes sont très mal venus à se prévaloir de l'argument fiscal en faveur de leur cause. En effet, si le droit de douane est établi avec une intention protectionniste, il doit avoir pour but de réduire l'importation, sinon de la supprimer totalement, et par là de réduire au minimum la matière imposable ${ }^{2}$. Au contraire, si le droit est établi avec la seule préoccupation de procurer au Trésor le rendement maximum, il devra rester assez modéré pour ne pas décourager l'importation et il sera avantageux de le réduire peu à peu, comme on fait par exemple pour les tarifs postaux où l'expérience montre qu'une réduction dans le port des lettres provoque ordinairement un accroissement de recettes.

\footnotetext{
M. Méline, le leader protectionniste, disait à la tribune de la Chambre (séance du 28 février 1898) : «C'est l'étranger qui paie les droits de douane ».

À la suite de la guerre civile aux États-Unis, M. Lawrence, contrôleur du Trésor aux États-Unis, disait : " Par notre tarif douanier, nous informerons le manufacturier étranger qu'il peut écouler ses produits chez nous, mais qu'il lui faut payer ce privilège. Il est ainsi forcé de réduire ses prix et ses profits et de contribuer à la formation de ce revenu qui nous permet d'acquitter notre dette publique et de servir des pensions à nos soldats mutilés ou blessés pendant la guerre civile. Ceci est de la justice distributive, puisque de la sorte nous forçons l'Angleterre et la France de prendre leur part des dépenses d'une rébellion qu'elles avaient méchamment encouragée » (Cité par l'Économiste français, 1882, $1^{\mathrm{er}}$ volume, p. 411).

2 Le président des États-Unis, Mac-Kinley, en présentant son fameux tarif des douanes, le déclarait très franchement : "L'objet de ce tarif n'est pas d'augmenter notre revenu fiscal, mais au contraire de le réduire et finalement de le faire disparaître du jour où les droits auront atteint un niveau suffisant pour atteindre leur but ».
} 
Tel est le cas, dit-on, pour l'Angleterre. Ses droits de douane n'ont aucun caractère protectionniste - la preuve c'est qu'ils ne frappent que des denrées exotiques (vins, thé, café, sucre, raisins de Corinthe, etc.) — et c'est pourquoi ils sont si fructueux ${ }^{1}$. Après la guerre, s'ils veulent tirer beaucoup d'argent des douanes, tous les États devront suivre la même méthode.

On ne saurait contester l'exactitude théorique de cette distinction entre le droit protecteur et le droit fiscal ; mais il faut reconnaître que dans la pratique les deux caractères sont plus ou moins superposés. Même pour l'Angleterre, toujours citée comme exemple, on ne peut contester que les droits sur les vins ou les eaux-de-vie n'aient pour résultat de protéger les brasseurs comme les fabricants de gin ou de whisky. Étant donnée la loi de substitution (Vol. I, p. 22) et sa conséquence qui est la possibilité de remplacer presque tout produit par quelque succédané, il en résulte qu'un droit mis à l'importation d'un produit même exotique doit réagir sur quelque industrie indigène - par exemple en France les droits sur le manioc ou les noix d'arachide bénéficient aux cultivateurs de colza ou aux fabricants de pâtes alimentaires.

\section{IV \\ Le régime des traités.}

$\underline{\text { Retour à la table des matières }}$

Nous devons prendre pour but d'établir entre les nations les mêmes rapports de justice qu'entre les individus. Nous devons donc haïr les systèmes protectionnistes en tant qu'ils ont pour but de réaliser pour chaque, peuple le « chacun pour soi, chacun chez soi ", parce que les buts visés par chaque pays se trouvent antagonistes, chacun prenant pour but de pénétrer chez le voisin et d'empêcher le voisin d'entrer chez lui. Mais le libre-échange répond-il mieux à l'idée de coopération? Il est permis d'en douter. Lorsque nous avons étudié le commerce intérieur, nous avons dû constater que, quoique né sous les auspices favorables de la liberté du travail et de la liberté des échanges, il a abouti trop souvent à la lutte pour la vie entre producteurs, au renchérissement des denrées ou à la détérioration de la qualité pour les consommateurs, à ce point qu'il a fallu remplacer peu à peu le régime de libre concurrence commerciale par le régime des ententes commerciales et des associations coopératives. Il y a donc tout lieu de craindre que ce même régime de libre concurrence étendu au commerce international n'aboutisse aux mêmes résultats. En somme, le libre-échangisme, tel qu'il s'exprime dans la formule " laisser-faire, laisser-passer », n'est aussi, tout comme le protectionnisme absolu, qu'une des faces de la lutte pour le profit. Entre les nations comme entre les

1 Environ 900 millions de francs contre 742 millions en France (en 1913). 
individus, nous devons chercher à établir des rapports qui ne soient pas compétitifs ni même purement échangistes, mais coopératifs.

Quel est donc le régime entre peuples qui se rapproche le plus de celui de l'association entre individus ? C'est celui des traités de commerce, soit qu'ils constituent simplement des contrats synallagmatiques entre deux pays, soit, bien mieux encore, quand ils constituent une union commerciale entre plusieurs pays. Là est l'avenir. Et en fait telle est bien la tendance actuelle. Par les freins qu'ils imposent aux prétentions excessives, par la réciprocité d'intérêts qu'ils établissent, par là solidarité qu'ils finissent par créer entre les nations contractantes, les traités de commerce paraissent la politique la plus sage qu'on puisse pratiquer. Cependant, nous allons voir qu'en France la politique douanière depuis 1892 a été inspirée par la haine des traités de commerce.

Pour les libre-échangistes, le régime des traités de commerce offre les avantages suivants :

$1^{\circ}$ D'assurer la fixité des tarifs pendant une longue période de temps (généralement dix ans), ce qui est très favorable aux opérations commerciales. Il est vrai que, par contre, ils lient les pays contractants et leur ôtent la possibilité de modifier leurs tarifs suivant les circonstances, mais ce lien doit être considéré comme un bien, non comme un mal, puisque, grâce à lui, les fabricants peuvent calculer et établir leurs prix pour une période assez longue. Le principal grief des fabricants étrangers, et surtout anglais, contre notre régime commercial, c'est précisément que par suite de la faculté que le gouvernement se réserve de modifier les droits à son gré, ils ne peuvent compter sur le lendemain (voir ci-après, p. 69).

Mais, en sens inverse, c'est précisément cette fixité qui constitue le grief que faisaient valoir nos producteurs en France contre le régime des traités. Ils ne veulent pas être liés afin de pouvoir élever les droits toutes les fois qu'ils croiront en avoir besoin. Aussi la France a-t-elle, pour leur donner satisfaction, remplacé le régime des traités de commerce à échéance fixe par celui d'accords commerciaux toujours résiliables au gré de chacune des parties, comme ces baux à loyer ou à ferme qui peuvent être résiliés à volonté, en prévenant seulement trois mois ou six mois à l'avance. Comme on peut le penser, l'incertitude créée par un tel régime n'est guère faite pour encourager à traiter. Cela est si vrai que, malgré les protestations de nos industriels, le gouvernement, pour pouvoir négocier avec les autres pays, a été obligé, dans bien des cas, de consolider les droits, c'est-à-dire de prendre l'engagement de ne pas les modifier — par exemple vis-à-vis de la Russie pour les droits sur les blés.

$2^{\circ}$ D'établir une solidarité entre tous les pays, en dehors même des deux parties contractantes, par la clause dite « de la nation la plus favorisée », qu'il est d'usage d'insérer dans tous les traités et en vertu de laquelle toute concession faite par un pays à un autre se trouve de plein droit étendue à tous ceux avec lesquels il a déjà 
traité. Cette clause est fortement antipathique aux protectionnistes, précisément parce qu'en entr'ouvrant la porte pour l'un, elle se trouve entr'ouverte pour tous. Mais ce qui a le plus contribué à la rendre impopulaire c'est que l'Allemagne en bénéficiait de droit en vertu de l'article de Francfort, en sorte que nous ne pouvions accorder une concession à un pays ami sans que l'Allemagne en profitât. Il est vrai que la clause était réciproque, mais elle jouait plus rarement à notre profit par suite de circonstances que nous expliquerons plus loin. Aussi les protectionnistes demandent-ils que cette clause, qui était devenue de style, n'ait plus de place dans les traités futurs, même dans ceux conclus avec les pays amis. Pourtant, même parmi eux, on hésite, car cette clause est aussi une sauvegarde pour les anciens contractants contre les concessions faites aux nouveaux venus ${ }^{1}$.

$3^{\circ}$ De conduire graduellement vers un régime de plus en plus libéral, par les concessions réciproques que les parties contractantes s'arrachent réciproquement à chaque renouvellement, tandis que l'expérience prouve que le système protectionniste, une fois installé dans un pays, tend à s'aggraver et à se généraliser, chaque industrie venant réclamer, l'une après l'autre, sa part.

$4^{\circ}$ Et finalement de fortifier les bons rapports entre les peuples et de diminuer les risques de guerre. Un traité de commerce entre deux pays vaut presque une alliance.

D'autre part, les protectionnistes modérés acceptent les traités de commerce parce qu'ils permettent de donner satisfaction à certaines réclamations du protectionnisme :

$1^{\circ}$ Les traités de commerce ne sont pas inconciliables avec l'établissement d'un tarif général et de droits protecteurs ; au contraire, ils le supposent, à l'état virtuel tout au moins, car tout traité est un contrat synallagmatique, tout contrat implique l'échange de certains avantages. Or, quel avantage un pays qui n'aurait point de droits à l'importation pourrait-il offrir en échange de ceux qu'il réclamerait ? Menacerait-il de fermer sa porte? Mais encore faut-il qu'il ait d'abord installé une porte et des verrous! S'il y a « entrée libre », un traité n'a plus de raison d'être. C'est pour cette raison que l'Angleterre peut difficilement conclure des traités et c'est afin de se ménager cette faculté de négocier qu'elle inclinait naguère vers l'établissement de droits. Depuis la guerre elle a d'autres motifs que nous verrons plus loin.

$2^{\circ}$ Les traités donnent satisfaction au principe de la réciprocité (ci-dessus, p. 58) - ce que les Anglais appellent le fair trade par opposition au free trade c'est-à-dire la porte ouverte aux pays qui ouvrent la leur et fermée à ceux qui la

Au jour où nous écrivons (avril 1917), le gouvernement vient de décider de dénoncer tous les accords commerciaux (sans distinction de pays) contenant la clause de la nation la plus favorisée, afin d'avoir les mains libres dès la fin de la guerre. 
ferment. Tout contrat implique en effet les mêmes droits pour les parties contractantes.

$3^{\circ}$ Les traités permettent de ménager les situations acquises, de sauvegarder les industries dont la ruine entraînerait une trop grande perturbation, soit au point de vue politique et social, soit au point de vue économique. Si la France juge, par exemple, que l'industrie de la marine marchande au point de vue de la défense nationale, ou celle de la viticulture à raison de l'énormité du capital engagé et de l'abondance des salaires qu'elle distribue, doivent être maintenues à tout prix, les traités de commerce permettront de le faire.

$4^{\circ}$ Les traités permettent certaines différenciations de droits pour tenir compte de la situation respective de chaque pays et des industries qui, pour chacun d'eux, paraissent plus ou moins menacées par leur concurrence, tandis que le tarif général des douanes est nécessairement uniforme et ne peut établir des droits différents selon le pays de provenance — ou du moins ce serait alors une mesure de guerre.

Il est vrai que cette différenciation des droits se trouve souvent annulée par la clause de la nation la plus favorisée dont nous venons de parler. Pas nécessairement pourtant, car la clause de la nation la plus favorisée ne s'étend qu'aux produits identiques : or dans la différenciation on peut préciser le produit favorisé par une indication nominative ou tout au moins par une définition assez étroitement ajustée pour que d'autres, même similaires, ne puissent bénéficier de cette faveur ${ }^{1}$. C'est ce qu'on appelle la spécialisation et l'Allemagne y a eu souvent recours pour éluder la clause du traité de Francfort. En France on s'est plaint amèrement de ce procédé qu'on trouve déloyal, mais on ne voit pas bien, s'il est si habile et si efficace qu'on le dit, pourquoi la France n'en usait pas, vis-à-vis des produits allemands.

Exemple : pour accorder au bétail de la Suisse une faveur que l'Allemagne ne voulait pas accorder au bétail français et pour tourner la clause du traité de Francfort, il a été dit dans le traité germano-suisse que pourraient bénéficier des tarifs réduits seulement " les taureaux élevés à une altitude de plus de 300 mètres et faisant un estivage à une altitude au-dessus de 800 mètres ». Ou bien une réduction est accordée aux chevaux de race flamande », ce qui naturellement ne s'applique pas aux chevaux de race française. Ou bien encore, pour favoriser l'Italie, le vin de Marsala forme un numéro spécial.

Dans je ne sais combien de publications françaises on a cité comme venant du premier ministre allemand, M. de Bulow, cette déclaration: "La force de notre nouveau tarif c'est qu'il comprend 946 articles et est par conséquent très spécialisé, ce qui veut dire que sur tel article nous pouvons faire des concessions à l'Autriche, à la Russie, à l'Italie, sans que ces concessions s'appliquent à la France. Entre l'article français et l'article analogue, russe, italien, autrichien, on trouvera aisément des différences, très petites en réalité, mais suffisantes pour qu'on puisse appliquer deux paragraphes différents ». Comme on peut bien le penser, une déclaration sous une forme aussi crue n'a jamais été faite officiellement ; la phrase est, paraît-il, de M. Luzzatti dans un commentaire d'un discours d'un ministre allemand (voir Schelle, op. cit.), mais elle n'en exprime pas moins bien le système. 
Tels sont les avantages du régime des traités de commerce et qui doivent suffire pour réconcilier protectionnistes et libre-échangistes. Ils seraient plus grands encore s'ils s'étendaient sous forme d'Unions commerciales, c'est-à-dire s'ils s'élevaient de la forme du contrat bilatéral à celle du contrat d'association entre plusieurs États, de la forme simplement contractuelle à celle coopérative. Déjà avant la guerre de nombreux projets d'Unions douanières avaient éclos, soit Union latine entre la France, l'Italie et l'Espagne, soit entre les États des deux Amériques, soit même, avant la guerre, entre l'Europe Occidentale et Centrale, réunissant la France et l'Allemagne ${ }^{1}$. Et il semble bien que la guerre actuelle aura pour résultat de réaliser quelques grandes Unions commerciales, soit celle entre les pays de l'Entente, c'est-à-dire anglo-latine, déjà amorcées par les ententes organisées au cours de la guerre en vue du ravitaillement, soit celle dans l'autre camp qui a déjà fait grand bruit sous le nom de Mittel-Europa.

Ces Unions comportent d'ailleurs tous les degrés, depuis la simple réciprocité de traitement sous la forme de droits préférentiels jusqu'à la suppression totale des ligues de douanes entre les États associés, ce qui constitue le régime dit du Zollverein, en souvenir de celui qui prépara l'unification de l'Allemagne.

\section{V}

\section{La législation douanière.}

$\underline{\text { Retour à la table des matières }}$

Nous avons dit que le régime commercial de la France, tel qu'il résulte de la loi organique du 11 janvier 1892, avait été créé surtout en haine des traités de commerce de 1860 (voir p. 30). Aussi voici ses traits caractéristiques ${ }^{2}$ :

$1^{\circ}$ Il établit un tarif autonome, c'est-à-dire des droits qui sont fixés par une loi et ne peuvent être modifiés que par une loi nouvelle ${ }^{3}$. Le pays, au lieu d'avoir les mains liées par un traité, par un contrat synallagmatique, se réserve le droit de

\footnotetext{
Voir les articles publiés à ce sujet par M. Peez dans la Revue d'Économie politique de 18911892.

Voir Nogaro et Moye, Les régimes douaniers.

3 Cependant dans certains cas d'urgence le Gouvernement peut, par de simples décrets, établir certains droits. Notamment il peut édicter des surtaxes du double droit sur les marchandises - et des droits compensateurs contre les primes à l'exportation et le dumping.

Il peut notamment, quand il s'agit de denrées alimentaires, décréter l'application anticipée des droits dont il propose la création ou le relèvement, parce que, dès qu'on prévoit l'établissement du droit nouveau, le commerce se hâte d'acheter et d'échapper par là, au moins pour un certain temps, au paiement de ces droits. Aussi appelle-t-on cette mesure de sauvegarde le cadenas. L'utilité de cette mesure est d'ailleurs très contestable, car il est peu probable que les gros fabricants ne soient pas avertis; et si même ils sont surpris, ce ne sera pas un bien car il s'ensuivra une brusque hausse du prix qui pourra être désastreuse.
} 
modifier les tarifs quand il le jugera bon et seulement alors ${ }^{1}$. En conséquence, le tarif des douanes est promulgué en forme de loi, énumérant en détail chaque catégorie de marchandises avec le droit spécifique correspondant.

$2^{\circ}$ Cependant l'antipathie pour les traités de commerce n'est pas allée jusqu'à se refuser à négocier avec aucun pays, car cet isolement pourrait avoir de graves inconvénients. On admet donc, sinon des traités, du moins des accords commerciaux qui, au lieu d'être conclus pour une période de temps déterminée, seront toujours révocables au gré de l'une des deux parties, la France ne pouvant refuser à l'autre partie le droit qu'elle réclame pour elle-même. Ainsi l'autonomie du tarif reste sauvegardée.

$3^{\circ}$ Mais s'il n'y avait qu'un seul tarif pour chaque produit, ces accords commerciaux seraient impossibles, car à quoi bon négocier et marchander là où il n'y a qu'un prix fixe ? Aussi le système de la loi de 1892 comporte-t-il non un seul, mais deux tarifs pour chaque article ${ }^{2}$.

L'un, dit tarif minimum, qui est établi d'après la différence entre le prix de revient du produit indigène qu'il s'agit de protéger et le produit similaire étranger. Le droit est soi-disant calculé de façon à rétablir exactement l'équilibre entre les deux produits et permettre la concurrence à conditions égales. Notons en passant que cette évaluation est impossible. Car nous savons (I, p. 345) que si sur un marché quelconque il ne peut y avoir qu'un même prix pour tous les produits similaires, par contre il y a autant de prix de revient différents qu'il y a d'unités. C'est de là, comme nous le verrons plus loin, que naît « la rente ». Il n'y a pas deux fabriques, pas plus que deux terres à blé ou deux vignobles, pour lesquelles le coût de production soit le même. Il n'y a donc pas un coût de production français et un étranger : il y en a mille de l'un et mille de l'autre.

L'autre, dit tarif maximum ou tarif général, plus élevé (généralement de 50 p. 100), destiné seulement à servir d'arme entre les mains du négociateur pour obtenir des concessions de l'autre partie et la frapper si elle ne cède pas. Le négociateur pourra dire : Si vous ne diminuez pas les droits sur tel ou tel article, ou si vous ne m'accordez pas le traitement de la nation la plus favorisée, alors je vous appliquerai le tarif général.

Dans la plupart des pays, il y aussi un tarif général et les négociateurs ont toujours pour but d'obtenir un tarif conventionnel plus doux. Seulement, dans les autres pays, les concessions possibles ne sont pas déterminées à l'avance, tandis que ce qui caractérise le système français, c'est que le tarif minimum y est

1 En fait, il a usé et abusé de cette faculté puisque de 1892 à 1913 il y a eu plus de 40 lois modifiant le tarif des douanes, sans compter quelques centaines de modifications de détail faisant passer une marchandise d'une catégorie dans une autre.

2 Cependant il y a certains articles pour lesquels il n'y a qu'un tarif, à vrai dire maximum plutôt que minimum, notamment pour le blé. 
intangible, il est tabou ; c'est la limite sacrée qu'on ne doit pas franchir puisque, par définition, c'est le minimum de protection que puisse supporter l'industrie spécifiée sans périr.

Or cette innovation de la loi française, quoique imitée par d'autres pays, ne nous paraît pas de nature à rendre les négociations plus avantageuses. Si dans une vente l'acheteur savait à l'avance quel est l'unique et dernier prix auquel le vendeur peut descendre, tandis que le vendeur ignorerait le prix auquel l'acheteur peut monter, la situation du vendeur ne serait-elle pas défavorable ? C'est comme si le négociateur français ne pouvait faire mouvoir ses pions que sur deux cases seulement de l'échiquier, tandis que son adversaire en aurait cent : il perdrait la partie assurément. Car remarquez que notre double tarif ne comporte pas de degré intermédiaire.

Aussi la France ne paraît pas avoir été très heureuse dans ses négociations. Elle a été obligée tantôt d'accorder tout ce que demandait l'étranger, tantôt de recourir à des guerres de tarifs, qui ont été fâcheuses au point de vue économique et même au point de vue politique, comme avec l'Italie et la Suisse. Et finalement elle a été obligée de faire d'assez sérieuses brèches dans son mur d'airain par les concessions suivantes :

a) En abaissant le tarif minimum soi-disant intangible, quand elle a reconnu qu'il n'y avait pas d'autre moyen d'obtenir des concessions de l'autre partie. C'est ainsi qu'elle a dû abaisser 9 articles du tarif minimum pour traiter avec la Russie et 54 avec la Suisse. Les protestations ont été vives : néanmoins la Chambre et le Sénat, mis au pied du mur, se sont résignés à voter ces réductions, puisqu'une loi était indispensable.

b) En s'engageant à ne pas modifier les droits sur certains articles spécifiés. On comprend, en effet, que les pays à qui nous avons accordé, au prix de nombreuses concessions de leur part, notre tarif minimum, disent: Mais à quoi nous servira cette concession si vous la retirez demain en modifiant la loi ? Nous jouerons alors le rôle de dupe ${ }^{1}$. - Et pour leur donner cette satisfaction très légitime, le Gouvernement a pris sur lui, dans divers cas, de consolider les droits, comme on dit, c'est-à-dire de s'engager à ne pas les modifier tant que l'accord durera. Notamment la Russie, dans la convention de 1905, a exigé et obtenu la consolidation des droits sur les grains et les pétroles. Elle y avait un grand intérêt. La consolidation ne supprime pas la faculté de dénoncer l'accord : seulement, il faudra dénoncer l'accord tout entier — et on comprend que ce soit une garantie. Néanmoins les autonomistes français ont protesté âprement contre cette nouvelle

Et cette appréhension est parfaitement fondée, car avant même la refonte générale du tarif en 1910, plusieurs fois déjà le Parlement avait voté des relèvements au tarif minimum (de 1892 à 1907, il y a eu 40 articles relevés, notamment sur le blé, le vin, la viande, etc., et 5 seulement abaissés). 
concession ${ }^{1}$ et le Gouvernement se félicitait dernièrement d'avoir pu l'éviter dans l'accord avec le Canada.

Voici quelle était, à la veille de la guerre, la situation en ce qui concerne les relations commerciales de la France avec l'étranger. Il faut distinguer quatre cas :

$1^{\circ}$ Il n'y avait qu'un seul pays, l'Allemagne, avec lequel la France était liée par un véritable traité et même par un traité qui, à la différence des traités de commerce ordinaires, ne comportait aucune limitation de durée et ne pouvait être dissous que d'un commun accord — ou par une nouvelle guerre. C'est parce que ce traité faisait partie intégrante du traité politique de Francfort qui a clôturé la guerre de 1870-1871. C'était seulement un des articles, le fameux article 11, qui stipulait que les relations commerciales entre les deux pays auraient dorénavant « pour base le régime du traitement réciproque sur le pied de la nation la plus favorisée ». Cette clause d'ailleurs ne fut point imposée par le vainqueur, comme on n'a cessé de le répéter à tort dans presque tous les livres français, mais au contraire elle fut demandée par le négociateur français, M. Pouyer-Quertier ${ }^{2}$.

$2^{\circ}$ Vis-à-vis de tous les pays d'Europe ${ }^{3}$ et d'un certain nombre de pays hors d'Europe, il y a des conventions par lesquelles la France accorde son tarif minimum en bloc et bénéficie du traitement de la nation la plus favorisée — ou, s'il s'agit de pays libre-échangistes, alors la même faveur existe sans convention formelle. C'est le cas de l'Angleterre, de la Belgique et de la Hollande.

$3^{\circ}$ Vis-à-vis d'un assez grand nombre de pays hors d'Europe, le tarif minimum n'est accordé que pour certains articles, moyennant des concessions spécifiées aussi. C'est le cas, notamment, pour les États-Unis ${ }^{4}$, la Chine, le Brésil.

$4^{\circ}$ Enfin, il y a un petit nombre de pays auxquels le tarif maximum est appliqué — Pérou, Chili, Bolivie, colonies anglaises, etc.

Le régime de la loi de 1892 a été modifié en 1910, dans le sens d'un protectionnisme renforcé. On a, sur un grand nombre d'articles, surélevé le tarif minimum de façon à pouvoir tenir la dragée haute aux autres pays quand il s'agira

1 La Société des Agriculteurs de France dit : «Considérant que cette convention nous enlève la liberté de nos tarifs... qu'elle remet en question tout le régime économique inauguré en 1892, qu'elle porte une atteinte des plus graves aux intérêts de l'agriculture française... proteste énergiquement contre cette convention, demande que la ratification en soit refusée ».

2 Cette clause ne s'appliquait pas à toutes les conventions que pourrait conclure la France ou l'Allemagne avec n'importe quel pays, mais était limitée aux conventions conclues avec l'un des six pays plus proches voisins, Belgique, Hollande, Russie, Autriche, Suisse et Angleterre. Ultérieurement, l'Italie s'y est trouvée aussi comprise, car par suite de la triple alliance elle avait droit vis-à-vis de l'Allemagne au même traitement que l'Autriche.

3 Le Portugal, qui seul était resté en dehors, a été admis au bénéfice du tarif minimum en 1911. C'est un des pays où les droits sont le plus élevés.

4 Lors de l'accord de 1910, les États-Unis réclamaient le bénéfice de notre tarif minimum sous peine de nous appliquer leur tarif maximum qui est prohibitif. On a fini par transiger. 
de traiter. On a donné comme raison que d'autres pays avaient procédé déjà de la sorte : notamment l'Espagne et même la Suisse.

Voyons sommairement comment sont établis les droits de douane. Il y a deux modes différents :

$1^{\circ}$ Le droit peut être établi proportionnellement à la valeur des marchandises, en tant pour cent : c'est le droit dit ad valorem, c'est le mode généralement adopté dans les pays libre-échangistes. Il a pour grand avantage la simplicité. Tout le tarif des douanes peut tenir en une page. Mais si ce régime offre la même simplicité que l'impôt sur le revenu, il en a aussi le même inconvénient qui est la presque impossibilité d'éviter la fraude, à moins de recourir à des mesures très vexatoires. En effet, il ne laisse à l'administration des douanes que le choix entre deux abus : ou accepter les yeux fermés les déclarations de valeurs des importateurs; ou exercer un contrôle qui dégénère fatalement en une véritable inquisition. Aux États-Unis où, malgré le régime ultra-protectionniste, les droits sont établis ad valorem, l'administration des douanes s'est rendue célèbre par ses vexations ${ }^{1}$. Il faut, dit la loi américaine, que la valeur déclarée corresponde exactement aux prix du gros, tels qu'ils sont cotés dans le pays exportateur, et que les factures soient contrôlées par le consul dans le pays d'exportation. Toute différence en moins comporte le paiement d'un quadruple droit, et en outre parfois la confiscation de la marchandise. L'administration des douanes entretient à l'étranger des agents d'information qui pratiquent une sorte d'espionnage sur les maisons d'exportation. Et comme ce contrôle des déclarations est insuffisant malgré sa rigueur, on en arrive à la taxation d'office faite par des commissions d'experts, en sorte que l'on ne peut jamais savoir ce qu'on sera exposé à payer.

Il y a, il est vrai, comme correctif au droit ad valorem, un moyen de contrôle ingénieux et point inquisitorial, c'est le droit de préemption, la faculté pour l'administration des douanes de se rendre acquéreur de l'objet au prix déclaré. Mais ce droit ne peut guère agir qu'à l'état de menace, car il serait impossible de l'appliquer couramment : l'administration des douanes ne peut se transformer en hôtel des ventes.

$2^{\circ}$ Le droit peut être fixé d'avance d'après la nature de la marchandise — un droit pour chaque article, comme les prix de vente dans un magasin : c'est ce qu'on appelle les droits spécifiques. C'est un système très compliqué puisqu'il faut, pour

\footnotetext{
Les querelles entre la douane américaine et les fabricants de porcelaine de Limoges durent depuis des années. L'administration des douanes américaines a un office à Paris qui est chargé de vérifier l'exactitude des déclarations en faisant une enquête chez l'expéditeur et en lui demandant communication de ses livres ou factures. S'il s'y refuse, il s'expose à voir à l'avenir ses expéditions retenues en douane. C'est pour les articles de luxe, diamants, toilettes de dame, dentelles, que naturellement la rigueur est la plus grande.
} 
serrer d'un peu près la valeur de l'objet, multiplier les catégories ${ }^{1}$ : il faut cataloguer et détailler des milliers d'articles, en sorte qu'il faut de gros volumes pour contenir le tarif et ce n'est pas une petite affaire de s'y reconnaître — d'autant plus que, malgré ces énumérations, le législateur ne peut tout prévoir. On cite bien des cas amusants, comme celui des momies d'Égypte, qui ont mis parfois dans l'embarras les employés des douanes !

Néanmoins ce système a le grand avantage de supprimer à peu près la fraude ${ }^{2}$. Et d'autre part, à raison même de sa complication, il se prête mieux aux marchandages dans les négociations pour les traités de commerce et à des différenciations de droit selon la nature de l'industrie. Aussi est-il adopté en France depuis 1881 (sous le régime libre-échangiste depuis 1860 les droits étaient ad valorem) et dans la plupart des pays.

Les droits protecteurs ne frappent jamais tous les produits importés : il y a des distinctions à faire. Si l'on veut se conformer à l'esprit du système protectionniste, il y a certaines catégories qui sembleraient devoir être exemptées ${ }^{3}$ :

a) Les produits qui n'ont point de similaires dans le pays et pour lesquels, par conséquent, il n'y a point d'industrie nationale à protéger : tels, toutes les denrées exotiques.

Cependant il est à remarquer que ces produits sont précisément ceux qui sont le plus lourdement taxés ${ }^{4}$, mais ils sont frappés au point de vue fiscal, en tant qu'articles de luxe, quoique cette présomption soit souvent bien mal fondée : par exemple pour le café, dont la valeur réelle était tombée avant la guerre à 80

1 C'est ainsi que pour les tissus, il faut spécifier combien de fils ils comptent au centimètre carré, car le droit varie selon la finesse des tissus ; - comment ils sont teints, si c'est à une couleur, ou deux ou trois, etc. ; s'ils sont piqués, gaufrés, brillantés, etc.

2 Nous disons « à peu près parce qu'on peut tout de même trouver moyen parfois de faire passer un objet de catégorie dans une autre moins taxée.

3 On distingue, c'est d'ailleurs la classification officielle de l'administration des douanes : $-1^{\circ}$ les produits alimentaires $;-2^{\circ}$ les matières premières $;-3^{\circ}$ les produits fabriqués. Et on considère comme la norme d'un état progressif quand les importations de la $1^{\text {re }}$ et de la $3^{\mathrm{e}}$ catégories diminuent tandis que celles de la $2^{\mathrm{e}}$ catégorie augmentent. C'est le point de vue colbertiste.

Voici, par exemple, la répartition des importations entre ces trois catégories pour quelques pays (en 1913 pour la France, en 1912 pour les autres pays) :

\begin{tabular}{|c|c|c|c|c|c|c|}
\hline \multirow[b]{2}{*}{$\begin{array}{l}\text { Produits } \\
\text { alimentaires }\end{array}$} & \multicolumn{2}{|c|}{ France } & \multicolumn{2}{|c|}{ Angleterre } & \multicolumn{2}{|c|}{ Allemagne } \\
\hline & 1.817 & $21 \%$ & 6.546 & $41 \%$ & 3.958 & $30 \%$ \\
\hline Matières premières & 4.946 & $59 \%$ & 6.277 & $39 \%$ & 7.266 & $55 \%$ \\
\hline Produits fabriqués & $\frac{1.658}{8.421}$ & $\underline{20 \%}$ & $\frac{3.143}{15066}$ & $\underline{20 \%}$ & $\underline{1.986}$ & $\underline{15 \%}$ \\
\hline & 8.421 & $100 \%$ & 15.966 & $100 \%$ & 13.200 & $100 \%$ \\
\hline
\end{tabular}

4 Ces produits exotiques ne sont guère qu'au nombre de cinq : café, thé, cacao, poivre et pétrole mais ils paient environ 250 millions de droits pour une valeur totale de 250 à 300 millions, soit environ 100 p. 100. 
centimes le kilo et qui pourtant paie 2 fr. 20 de droits ! C’est précisément de ces produits exotiques que l'Angleterre tire la plus grosse part de ses 900 millions de droits de douane. Mais de plus, ils sont souvent frappés même au point de vue protecteur, sous prétexte qu'ils font, en tant que succédanés, une concurrence indirecte à des produits indigènes. Ainsi en France on frappe le pétrole ou les noix d'arachides parce qu'ils font concurrence aux huiles de colza ou d'olives, ou le manioc parce qu'il fait concurrence à la fécule de pommes de terre ! De même, en Angleterre, les brasseurs réclament une majoration des droits sur les vins.

b) Les produits qui servent de matières premières à d'autres industries et pour lesquels, par conséquent, tout droit se répercuterait en une aggravation du coût de production. Ces industries se trouveraient donc placées en situation d'infériorité vis-à-vis des industries étrangères et on irait ainsi à l'encontre du but visé par le protectionnisme ${ }^{1}$.

c) Enfin il semble qu'on devrait exempter aussi les denrées alimentaires afin de ne pas augmenter le coût de la vie pour le peuple. Mais nous savons (p. 53) que les protectionnistes nient que les droits de douane aient cette conséquence et, en sens contraire, ils affirment la nécessité de protéger avant tout l'industrie nourricière de la population. Aussi les denrées alimentaires sont-elles rarement exemptes de droit, mais généralement elles bénéficient de droits plus modérés que les produits industriels ${ }^{2}$.

Il n'est pas facile de se prononcer sur les résultats de ce régime, malgré plus de vingt années d'expérience. Les protectionnistes déclarent que l'expérience est décisive en leur faveur puisque la balance du commerce est devenue moins défavorable et que la production agricole de la France a beaucoup augmenté. Mais les libre-échangistes répondent que la balance du commerce importe peu, que les progrès de l'industrie et de l'agriculture sont inférieurs en France, à ceux de beaucoup d'autres pays, et que d'ailleurs le peu qu'on peut inscrire au compte de l'agriculture tient à de tout autres causes que les droits de douane, notamment au

1 Pourtant la houille qui est, sinon matière première, du moins matière instrumentale et si nécessaire à l'industrie, est frappée d'un droit modique en apparence $1 \mathrm{fr}$. 20 le quintal, mais qui n'en représente pas moins environ 8 p. 100 du prix de la houille (prix avant la guerre, bien entendu) et grève l'industrie française d'une assez lourde charge, quelque 25 millions de francs. Il y a aussi des droits sur les bois et sur le plomb, mais au total les droits sur les matières premières importées ne sont que de 45 millions, soit moins de 1 p. 100 de la valeur totale.

Sur les produits industriels, le total des droits est de 335 millions, ce qui représente 20 p. 100.

2 En France, nous rappelons que le blé est taxé à 7 francs le quintal ; le prix du blé avant la guerre étant de 17 à 18 francs sur le marché libre (ci-dessus, p. 57), ce droit représente une taxe énorme de 40 p. 100. L'Italie et l'Espagne sont les deux seuls pays qui frappent le blé de droits aussi élevés (7,50 et 8 francs). En Allemagne, il est de 6,87.

Il y a aussi des droits protecteurs sur la viande, poisson, légumes secs, fromages, œufs, fruits, vins et bière - mais ils sont plus modérés.

Au total, les droits sur les denrées alimentaires s'élèvent à 407 millions, ce qui, sur une valeur totale de 1.817 millions (en 1913), représenterait plus de 22 p. 100. Mais si l'on décompte les droits frappant les produits exotiques comme droits fiscaux, la proportion s'abaisse à 10 p. 1.00. 
développement des syndicats agricoles et à la propagation des engrais chimiques, et enfin que le prix du blé, le coût de la vie et celui des matières premières sont plus élevés en France que dans les pays libre-échangistes (voir p. 56) ${ }^{1}$.

\section{VI}

\section{Les primes à la production.}

$\underline{\text { Retour à la table des matières }}$

Puisque les droits protecteurs ont tant d'inconvénients, n'y aurait-il pas quelque autre système possible pour remplacer les droits de douane, ce qu'on pourrait appeler la protection sans droits protecteurs ? - Oui. Il y en a même beaucoup plus qu'on ne croit et nous ne pouvons que les énumérer sommairement ${ }^{2}$.

D'abord il ne faut pas oublier une forme de protectionnisme très intéressante, s'exerçant non plus sous forme de lois ou règlements, mais par l'initiative privée, celle exercée par les consommateurs eux-mêmes, soit sous forme de boycottage des produits étrangers, soit sous forme de propagande en faveur des produits nationaux ou de ceux d'un pays ami. Déjà, avant la guerre, il y avait eu des manifestations assez dramatiques de cette intervention du consommateur dans les relations internationales ; il est à prévoir qu'après la guerre elle va prendre une extension formidable. Mais nous aurons à y revenir au livre de la Consommation ${ }^{3}$.

En outre, il faut indiquer :

$1^{\circ} \quad$ Les tarifs différentiels des chemins de fer pour décourager l'importation ou favoriser l'exportation de certains produits; l'Allemagne et l'Autriche ont annoncé leur résolution de s'opposer à toute mesure semblable et de faire de cette exclusion une des conditions du traité de paix ;

1 En défendant le régime des droits protecteurs, M. Méline disait : « Il a provoqué dans toute la France l'augmentation des ensemencements de blé et l'élévation des rendements » (cité par Schelle, Le bilan du protectionnisme). Or la statistique ne justifie nullement cette affirmation, tout au moins en ce qui concerne l'étendue des terres cultivées. En 1894, date à laquelle le droit sur les blés fut porté à 7 francs (il était auparavant de 5 francs), la superficie cultivée en froment était de 7 millions d'hectares ; en 1913, elle était tombée à 6.542.000, soit une diminution de 450.000 hectares.

Comme rendement par hectare, il a passé dans le même intervalle de 17,5 hectolitres à 18,7, faible accroissement, très inférieur à celui des autres pays.

2 Le seul traité, à notre connaissance, où les modes de protection autres que les droits de douane se trouvent méthodiquement classés et analysés est celui de M. Grunzel, Economic Protectionism, de la Bibliothèque Carnegie, 1916.

3 Il faudrait citer encore, parmi les mesures de protection, les marques de fabrique à l'effet d'exclure les marchandises usurpant ou portant de fausses marques, et les mesures de police sanitaire contre le bétail, dont on a joué maintes fois dans le sens protectionniste. 
$2^{\circ}$ Les garanties d'intérêt pour les capitaux qui consentent à s'engager dans quelque nouvelle entreprise industrielle, mesures souvent employées au Mexique et dans divers États de l'Amérique du Sud ;

$3^{\circ}$ Certaines exemptions ou réductions d'impôts accordées aux industries nouvelles qu'on veut acclimater: il y en a de fréquents exemples en Hongrie, Roumanie, etc. ${ }^{1}$;

$4^{\circ}$ Mais le système le plus connu est celui des primes à la production, c'est-àdire d'une somme d'argent allouée par l'État au producteur sous certaines conditions.

Ce mode de protection paraît très supérieur, au point de vue théorique du moins, à celui sous forme de droits de douane. En effet, il ne donne lieu à presque aucun des griefs que l'on fait valoir contre les droits de douane.

a) Les primes n'apportent aucune entrave au commerce extérieur et permettent le plein développement des importations puisqu'elles laissent libre entrée aux produits étrangers ;

b) Il est facile de les payer à qui de droit, tandis que les droits de douane exigent une administration coûteuse et créent toute une puissante et démoralisante industrie qui s'appelle la contrebande ;

c) Elles ne portent aucun préjudice aux consommateurs, puisqu'elles ne relèvent pas le prix des produits ;

d) Elles ne gênent en rien la production, puisqu'elles ne renchérissent pas le prix des matières premières et ne relèvent pas le coût de production. Au contraire ! elles peuvent être graduées de façon à stimuler les progrès de l'industrie protégée.

C'est ainsi que les primes accordées à la marine marchande sont plus ou moins importantes suivant que le navire est à voiles ou à vapeur, en bois ou en fer, et suivant la vitesse. C'est ainsi que les primes accordées par la loi de 1891 aux filatures de soie sont en raison du degré de perfectionnement de leur outillage. De même celles pour le sucre qui ont contribué à perfectionner non seulement la production du sucre, mais la culture des betteraves.

En Roumanie, la loi accorde aux industries nouvelles des concessions gratuites de terrain, des exemptions de droits de douane ou remboursements pour leurs matières premières ou outillages, des dégrèvements d'impôts, etc. Mais en échange elles doivent employer (après un délai de 5 ans) trois quarts d'ouvriers du pays, recevoir des apprentis en tel nombre que l'administration le jugera utile, etc. 
Malheureusement tous ces avantages ont pour contre-partie un vice rédhibitoire, c'est que les primes constituent une dépense pour le budget de l'État, tandis qu'au contraire les droits de douane constituent une recette. Or, les États, étant généralement obérés, sont naturellement plus disposés à toucher de l'argent qu'à en donner !

Et pourtant au point de vue théorique et même, pourrait-on dire, moral, c est précisément dans cet inconvénient apparent que nous verrions la vraie supériorité du système des primes, celle de la franchise : ce mode de protection n'est pas hypocrite. Il ne se donne pas pour autre chose que ce qu'il est, à savoir un sacrifice imposé au pays par une raison d'utilité publique. Le public sait qu'il paie cette protection et il sait exactement le prix dont il la paie, tandis que les droits de douane entretiennent dans le pays une illusion fâcheuse en lui faisant prendre pour un gain ce qui en réalité est une charge.

Mais il y a d'autres griefs contre les primes, c'est la difficulté de les attribuer à telle industrie plutôt qu'à telle autre sans faire du favoritisme. La prime sera souvent presque nominative, faite pour le producteur plus que pour le produit. L'avantage résultant du droit de douane est, au contraire, presque anonyme : on ne sait pas exactement qui en profite, tandis qu'on voit l'industriel qui va toucher sa prime et on sait combien il touche. Et c'est ce qui fait qu'un semblable système ne sera jamais populaire. Il étale sous un jour trop cru les sacrifices qu'il demande à tous et les privilèges qu'il accorde à quelques-uns, et choque par là le sentiment d'égalité. Ajoutons qu'il exige, dans le discernement des mérites, une impartialité qu'on ne peut guère attendre d'un gouvernement quelconque.

Enfin l'attribution de primes, surtout s'il s'agit de prime à l'exportation, risque de provoquer de la part des pays étrangers l'établissement de droits compensateurs qui annuleront l'effet des primes. En effet, la prime accordée à l'exportation permet au producteur de vendre meilleur marché aux étrangers qu'à ses concitoyens et constitue ainsi une sorte de dumping officiel.

Ainsi un gouvernement ne se décide à recourir aux primes que lorsqu'il ne peut faire autrement, lorsqu'il doit renoncer aux droits protecteurs pour quelque raison péremptoire : - soit parce qu'il porterait préjudice par là à une autre industrie nationale : c'est ainsi qu'il n'a alloué des primes aux producteurs de soie que parce que les fabricants de soieries de Lyon ont énergiquement protesté contre l'établissement de droits sur leur matière première ; — soit parce qu'il s'exposerait à des représailles de la part des pays étrangers : c'est pour cela qu'il a dû recourir aux primes pour protéger la marine marchande.

Ces primes en France constituent une assez lourde charge pour le budget : environ 13 millions de francs pour les producteurs de cocons, de lin et de chanvre, d'huile, et pour la filature de soie, auxquels il faut ajouter 70 millions pour la marine marchande (voir ci-après, p. 93). On ne cesse de les remanier et de les 
augmenter, et pourtant elles ne donnent aucun résultat encourageant. Deux des principales industries primées, la sériciculture et la filature de soie, sont en pleine décadence: il est vrai qu'on en conclut non que les primes devraient être supprimées, mais qu'elles doivent être augmentées ! Quant à la marine marchande qui absorbe le plus gros des primes, les résultats ne sont guère plus satisfaisants, mais ceci mérite un chapitre spécial.

Nous n'avons parlé jusqu'à présent que des primes à la production, c'est-à-dire sans considérer si l'industrie protégée travaille pour l'intérieur ou pour l'extérieur. Mais il peut y avoir aussi des primes spéciales pour l'exportation. Elles étaient même assez usitées autrefois, mais de nos jours il n'y en a plus guère car ces primes à l'exportation ont le double inconvénient :

$1^{\circ}$ De permettre de vendre les produits primés à plus bas prix aux étrangers qu'aux nationaux, et elles risquent même, au cas où elles stimuleraient trop l'exportation, de raréfier le produit sur le marché national et par là d'en augmenter le prix ;

$2^{\circ}$ De provoquer de la part des pays importateurs des majorations de droits qui annuleraient l'effet des primes, en sorte que l'État aurait dépensé son argent en pure perte.

En somme, la prime à l'exportation agit à la façon du dumping si discrédité ; car elle a pour résultat de faire vendre le produit sur le marché international audessous du cours ${ }^{1}$.

Il y a un cas célèbre de prime à l'exportation, mais qui, quoique tout récent, n'a plus qu'un intérêt historique : c'est le sucre. L'Allemagne, l'Autriche et même la France, ayant forcé leur production bien au delà de leurs besoins, afin d'écouler l'excédent au dehors, se sont mises à donner des primes d'exportation sur le sucre. L'Angleterre, qui était la principale importatrice, a pu profiter de la baisse des prix causée à la fois par la prime et par la concurrence que les trois pays producteurs se faisaient entre eux, et recevoir ainsi du sucre à des prix si dérisoires qu'on a pu l'employer comme aliment pour les chevaux à la place d'avoine et comme matériaux pour construction à la place de plâtre ! Et les industries de confitures, chocolaterie et bonbons, ont pu travailler dans des conditions si avantageuses qu'elles ont pu réexporter en Allemagne avec de gros bénéfices leurs produits faits avec le sucre allemand !

L'Angleterre s'accommodait fort de ce régime, mais non ses colonies qui ne pouvaient plus vendre leur sucre de canne. Celles-ci demandèrent et finirent par obtenir que ce régime prît fin. Pour leur complaire, l'Angleterre convoqua la Conférence dite de Bruxelles en 1907 et, par la menace de frapper les sucres importés de droits égaux au montant du prix, elle obtint des trois pays ci-dessus nommés l'abolition du système des primes. Ce qui est assez amusant c'est que peu d'années après (en 1912) elle s'en repentit et déclara qu'elle renonçait à pénaliser le sucre, ne voulant plus se pénaliser elle-même. Mais il était trop tard. Les autres pays ne voulurent plus revenir aux primes : c'est que la législation sur les sucres est des plus compliquées qui soient et elle ne se prête pas au rôle de girouette. Au reste, la guerre est survenue avant que la question du sucre eût reçu une solution définitive.

Il n'y a donc plus en France que quelques rares primes à l'exportation (notamment sur les morues et autres poissons secs) ; mais il faut remarquer que les admissions temporaires peuvent dans certains cas jouer comme primes à l'exportation (ci-après, p. 82). 


\section{VII}

\section{De quelques atténuations au régime protectionniste.}

$\underline{\text { Retour à la table des matières }}$

On peut en indiquer quatre qui, d'ailleurs, ont un but commun éviter que les droits de douane ne portent préjudice au commerce d'exportation et de réexportation.

$1^{\circ}$ Le moyen le plus simple est, au cas où une marchandise importée vient à être réexportée, de rembourser à la sortie les droits payés à l'entrée ; procédé généralement désigné sous le nom anglais de drawback. C'est un système de moins en moins employé ${ }^{1}$ — le fisc n'aime jamais à rembourser — et ou lui préfère le système suivant.

$2^{\circ}$ Le système dit de l'admission temporaire consiste à exempter de droits les matières premières destinées à la réexportation, lorsque, sous forme de Produits manufacturés, elles auront à disputer aux marchandises étrangères le marché international. C'est ce qu'on appelle l'admission temporaire. Afin d'éviter des fraudes trop faciles, on fait souscrire à l'importateur un engagement de payer les droits sous peine d'amendes sévères — avec caution, d'où le nom d'acquit-àcaution - si, dans un certain délai, il n'a pas justifié de la réexportation de ces matières premières transformées. ${ }^{2}$

Ce système n'est pas d'une application commode si l'on exige que les matières réexportées soient les mêmes que celles importées ; la vérification de leur identité implique des mesures vexatoires pour l'industriel. Et d'autre part si l'on se contente, comme on le fait généralement, de l'équivalence, c'est-à-dire que la quantité réexportée soit égale à la quantité importée, alors on ouvre la porte à des

1 Cependant il y a encore en France quelques cas de drawback, notamment pour le coton employé à la fabrication de tissus exportés, et pour le sel employé pour les morues et poissons secs ; mais dans ce dernier cas, il ne s'agit pas de rembourser un droit payé à l'importation (le sel ayant été généralement produit en France), mais de rembourser l'impôt intérieur perçu sur le sel.

2 Le régime des acquits-à-caution s'applique à un assez grand nombre de matières premières : blés destinés à la mouture, fers et autres métaux, fils de soie, huiles, cacao, au total, représentant une valeur d'un peu plus de 200 millions de francs.

Il ne faut pas confondre l'admission temporaire avec l'entrepôt, lorsqu'on autorise certaines marchandises à stationner provisoirement en magasin (voir ci-après). Moins encore faut-il la confondre avec le transit, lorsque des marchandises étrangères ne font que traverser la France en wagons fermés et scellés. Les marchandises qui passent par l'entrepôt ou en transit représentent des valeurs énormes, plusieurs milliards. Ce sont ces marchandises qui sont représentées par la différence entre les chiffres du commerce général et du commerce spécial (ci-dessus, p. 2). 
spéculations qui ont pour résultat d'éluder la loi. Voici un minotier de Marseille qui importe des blés russes, mais comme il ne travaille que pour l'intérieur et non pour l'exportation, il n'a aucun titre à réclamer l'admission temporaire ; il paie donc le droit à l'importation qui n'est pas mince, 7 francs les 100 kilos. Mais il s'avise qu'il y a à Lille un minotier qui se trouve dans la situation inverse de la sienne, c'est-à-dire qui veut exporter de la farine en Belgique parce qu'il en a trop. Le Marseillais dit au Lillois : « Je vais me faire exempter du droit en disant que je travaille pour l'exportation. Pour cela j'aurai à signer un acquit-à-caution : mais, quand vous exporterez votre farine, je vous enverrai l'engagement, et c'est vous qui le ferez acquitter ». Il va sans dire que le minotier de Lille ne lui rendra pas ce service gratis. Ils partageront, selon l'offre et la demande, le bénéfice de 7 francs par 100 kilos ${ }^{1}$.

Nous ne voyons pas grand mal à ce trafic, mais au point de vue fiscal, comme au point de vue protectionniste, il a quelques inconvénients.

Au point de vue fiscal, l'État ne perd ni plus ni moins que si l'opération était sincère, mais la faveur accordée se trouve faussée, car elle n'avait d'autre but que de favoriser l'exportation : or dans l'espèce l'exportation aurait eu lieu quand même : l'exemption est donc un sacrifice inutile imposé au Trésor, c'est-à-dire au contribuable.

Au point de vue protectionniste, on peut voir là un danger à la fois pour les producteurs de blé et les consommateurs de pains. Pourquoi ? Parce que à Marseille l'importation des blés étrangers se trouve artificiellement encouragée par une forte réduction du droit (il est clair que si l'importateur peut vendre son acquit, disons 5 francs, le droit d'entrée sera réduit pour lui à 2 francs), d'où baisse possible du blé français au détriment des agriculteurs méridionaux ; - et parce que dans le Nord, au contraire, c'est l'exportation du blé français qui se trouve encouragée par une prime de 2 francs ( 7 francs moins les 5 francs payés pour l'acquit), d'où hausse possible du blé au détriment des consommateurs des villes ouvrières de la région.

On a essayé, tant bien que mal, de remédier à ces abus, soit en exigeant que la matière transformée ressorte par la porte par laquelle elle est entrée (c'est ce qu'on appelle le régime des zones), soit en faisant escorter la matière à l'usine où elle doit se transformer. Mais alors il faut un contrôle vexatoire et coûteux.

En Allemagne le régime des acquits-à-caution est remplacé par celui des bons à l'importation : mais, malgré leur nom, ce sont plutôt des primes à l'exportation. En effet, c'est aux exportateurs de céréales que le bon est délivré sous forme d'un

Dans la pratique, ce marché se fait sous la forme de vente d'acquits-à-caution. Selon la loi de l'offre et de la demande leur cours varie, c'est-à-dire que, selon que les exportateurs qui veulent les acheter ou les importateurs qui veulent les vendre sont plus ou moins nombreux, ils retiennent une plus ou moins grosse part de la valeur du titre. 
certificat qui sera accepté par la Douane pour l'acquittement des droits d'importation (soit celle des céréales, soit celle d'autres marchandises nominativement désignées). C'est donc bien une prime à l'exportation ; seulement, au lieu d'être payée en argent, elle l'est en une sorte de papier-monnaie qui subit un agio variable selon l'offre et la demande.

$3^{\circ}$ L'entrepôt est, comme son nom l'indique, simplement un magasin où les marchandises importées restent en dépôt jusqu'à ce que leur sort ait été décidé : si elles sont réexpédiées à l'étranger, elles ne paieront aucun droit ; si, au contraire, elles finissent par rester dans le pays, alors elles paieront les droits. Cette période d'attente suspensive peut se prolonger assez longtemps, jusqu'à cinq ans. Les marchandises ne peuvent y faire l'objet de transformation industrielle, mais seulement de toutes manipulations commerciales ayant pour but la conservation ou l'amélioration des produits, telles que mélanges, coupages, etc.

L'entrepôt, à la différence du port franc que nous allons voir, peut être établi à l'intérieur du pays.

Exceptionnellement, pour certaines marchandises, on n'exige pas l'emmagasinage dans les locaux spéciaux de l'administration des douanes, mais on admet qu'elles soient laissées à la garde du commerçant importateur dans ses propres magasins, avec engagement sous caution : c'est ce qu'on appelle l'entrepôt fictif par opposition à l'entrepôt réel ${ }^{1}$.

$4^{\circ}$ On appelle ports francs ceux où les marchandises débarquées peuvent être manipulées et même transformées librement, sans avoir à payer aucun droit de douane $^{2}$. Autrefois c'était toute la ville qui était ainsi mise hors l'enceinte des douanes : Hambourg de tout temps, Marseille à diverses périodes de son histoire. Aujourd'hui c'est le port seulement ou même une portion du Port qui constitue la zone franche. Elle est séparée matériellement du reste de la ville par des murs ou des grilles pour empêcher la contrebande. Elle jouit d'une véritable exterritorialité douanière ${ }^{3}$. Dans l'intérieur de cette enceinte il n'est permis à personne d'habiter ni

1 Ces manipulations commerciales ne sont possibles que depuis une loi nouvelle (1917) : jusqu'alors il ne pouvait être touché aux marchandises dans l'entrepôt. Cette loi a été inspirée surtout par le désir de prévenir la mesure plus radicale des ports francs.

2 Les trois grands ports de l'Allemagne, Hambourg, Brème et Stettin, sont des ports francs. Copenhague a été fait port franc en 1894. En France, Bordeaux, La Rochelle, Marseille (avec certaines réserves) et Alger surtout, demandent la franchise : il est à craindre même que tous les ports ne la demandent ! - En tout cas, après la guerre, il est probable que plusieurs grands ports en Europe deviendront ports francs : Salonique, Constantza, Trieste, etc.

3 Ces ports francs sont dans la même situation que les zones franches de Savoie et du pays de Gex qui, quoique appartenant à la France, se trouvent en dehors de la ligne des douanes, ainsi que savent les nombreux voyageurs pour Évian ou Thonon. Cette zone franche a naturellement Genève comme centre d'attraction et excite par là une vive jalousie de la part des villes françaises de Savoie : elle aura bien du mal à se défendre après la guerre. 
de consommer, mais les commerçants peuvent y faire ce qu'ils veulent et même les industriels y installer des fabriques ${ }^{1}$.

Non seulement la franchise du port donne à la ville à laquelle elle est conférée un grand développement — nul doute que la ville de Hambourg ne lui doive pour une grande part sa merveilleuse fortune ${ }^{2}$ - mais de plus elle sert de correctif utile au régime protectionniste. Les marchandises qui courent à travers les mers, se heurtant partout aux barrières des douanes, trouvent là des îlots de liberté où elles se posent, et elles y affluent de tous les points du monde. Sans doute, elles ne peuvent pénétrer dans l'intérieur, mais c'est déjà beaucoup qu'elles puissent attendre là le moment propice, chercher leur voie, s'échanger les unes contre les autres, ou se transformer pour repartir dans une direction nouvelle. Colbert, que les protectionnistes ne récuseront pas, avait créé, comme complément à son célèbre système, cinq ports francs: Marseille, Saint-Jean-de-Luz, Bayonne, Lorient, Dunkerque. Or, jamais la marine française ne fut plus prospère. Et il est vraiment inouï que, dans l'état de détresse de notre marine marchande, on n'ait pas cherché là un moyen de salut. D'autant plus que les chantiers de construction des navires pourraient être installés dans la zone franche et ne seraient plus paralysés, comme ils prétendent l'être, par les droits de douanes sur les fers et autres matériaux de construction. Les primes à la construction navale deviendraient superflues. On y a bien pensé : il y a même plusieurs projets de loi, mais ils dorment depuis des années dans les cartons du Parlement.

Il est vrai que, comme toute réforme, celle-ci a suscité des objections :

$1^{\circ}$ Elle serait inutile, dit-on, puisque les marchandises destinées à être réexportées trouvent déjà dans le régime des entrepôts ou des admissions temporaires les facilités nécessaires : elles n'ont pas à payer de droits (voir ci-après Politique commerciale).

Il est vrai : mais quant à l'entrepôt, les marchandises qui y entrent ont néanmoins à subir autant et plus de formalités que si elles payaient ; elles sont toujours sous l'œil du douanier, tandis que dans le port franc ce fâcheux personnage ne pénètre pas. De plus, le port franc est un marché : l'entrepôt n'est qu'un dépôt, c'est tout différent. Quant à l'admission temporaire c'est simplement une faveur accordée à une industrie déterminée et qui n'a pas d'influence sur le mouvement du commerce international.

C'est ainsi que dans l'enceinte de la zone franche de Hambourg il y a une centaine d'industries diverses employant plus de 100.000 ouvriers.

Voir La question des zones et ports francs, par Daniel Bellet, Revue d'Économie politique, maijuin 1917.

2 On dira peut-être que l'Angleterre n'a pas de ports francs ? Eh ! sans doute, l'Angleterre entière étant « île franche». Et on peut en dire autant des ports belges, comme Anvers, les droits de douane en Belgique étant insignifiants. 
$2^{\circ}$ Elle serait dangereuse, parce que ces ports francs serviraient de lieux d'asile à des industriels étrangers qui en useraient pour concurrencer les industries nationales, sinon sur le marché intérieur, du moins sur les marchés étrangers, et qui s'adonneraient à de louches opérations en vue de fabriquer des produits frelatés et de les exporter comme produits français d'origine.

Mais il faut répondre que la création d'établissements dans ces zones peut être soumise à une autorisation administrative, et que si les Français abandonnent ces zones à des concurrents étrangers ils n'auront qu'à s'en prendre à eux-mêmes. Et quant aux falsifications et contrefaçons, se feraient-elles moins hors de France que dans les ports français ? Ce que l'industrie française doit craindre n'est-ce pas de voir ses bons produits se vendre sous des marques étrangères plutôt que de voir des produits étrangers se vendre sous des marques françaises ? Ceci au contraire serait pour elle une excellente réclame.

$3^{\circ}$ Elle serait impossible, parce que lorsque les marchandises étrangères, après avoir été débarquées dans le port franc, voudraient entrer à l'intérieur, on ne pourrait plus reconnaître leur origine et par conséquent on ne saurait plus si on doit leur appliquer le tarif maximum ou minimum. Si c'est le tarif minimum, en ce cas toutes les marchandises frappées du tarif maximum s'empresseront de passer par cette porte dérobée, en sorte que le tarif maximum sera aboli en fait. Si c'est le tarif maximum, alors toutes les marchandises jouissant du tarif minimum se garderont comme d'un piège de s'arrêter dans la zone franche d'où elles ne pourraient plus sortir qu'en payant ce tarif maximum.

Mais ce dilemme n'a de prise que pour les marchandises destinées à l'intérieur du pays : or ce n'est pas pour celles-là qu'est fait le port franc, c'est surtout pour les marchandises destinées à être réexportées. Dès lors, peu leur importe le tarif maximum ou minimum. Si pourtant on croit désirable que le marché intérieur ne soit pas fermé aux marchandises manipulées dans la zone franche, eh bien ! en ce cas, on trouvera bien le moyen de vérifier leur provenance et de, leur appliquer les droits correspondants.

En somme, l'hostilité contre les ports francs tient surtout à ce qu'ils fourniraient, par leur seule existence et surtout par leur succès, un trop dangereux exemple contre le protectionnisme. Du jour, en effet, où il serait constaté que la suppression des douanes fait la fortune d'un port, on ne peut manquer de se demander pourquoi elle ne ferait pas celle du pays tout entier. 


\section{VIII}

\section{De la protection de la marine marchande.}

$\underline{\text { Retour à la table des matières }}$

Nous avons parlé déjà de la marine comme moyen de transport (I, p. 411-417) et, tout en constatant son importance, nous avons montré par des chiffres que le développement commercial des divers pays n'était nullement en fonction de l'importance de leur marine marchande. Un pays peut avoir tout intérêt, au point de vue économique, à recourir pour ses transports maritimes à d'autres pays qui se trouvent maritimement mieux situés ${ }^{1}$.

Nous avons constaté aussi que dans la statistique de la marine marchande la France n'a pu maintenir sa flotte au deuxième rang qu'elle occupait autrefois et s'est vu dépasser successivement par quatre autres pays, en sorte qu'elle n'était plus, avant la guerre, qu'au cinquième rang, serrée de près par le Japon. Et pourtant, comme nous allons le voir, elle a essayé de tous les systèmes protectionnistes et même de la liberté ! Et pourtant l'État n'a pas ménagé ses faveurs, ni ses sacrifices. Et pourtant la nature elle-même semblait encourager cette ambition de la France, car où trouver un autre pays en Europe, peut-être même dans le monde, qui se trouve plus heureusement situé, à l'extrémité occidentale de l'Europe et de l'ancien monde, face au Nouveau Monde, avec 3.000 kilomètres de côtes, découpés de golfes et de rades, sur les mers les plus fréquentées du globe, depuis la mer du Nord jusqu'à la Méditerranée, et, en outre, un empire colonial réparti entre tous les Océans ? Ce ne sera certainement pas la Russie, ni l'Autriche, qui n'ont d'ouvertures que sur des mers fermées, qui n'ont de fenêtres que sur la cour, ni l'Allemagne embouteillée dans la mer du Nord et qui en gémit, ni la Norvège qui est tout en côtes et en golfes, il est vrai, mais dont la façade regarde la mer polaire. L'Italie, si heureusement située dans là mer latine, est loin de l'Océan - et l'Angleterre elle-même serait dans une situation excentrique si elle n'avait pris soin de se réserver quelques pied-à-terre sur toutes les routes maritimes.

Il semble donc que je ne sais quel mauvais sort jeté sur la marine française ait rendu inutiles ces beaux dons et on pourrait se demander s'il ne serait pas d'une politique sage pour la France de ne pas s'obstiner dans une voie où elle n'a trouvé que des déceptions et de ne pas rouler indéfiniment ce rocher de Sisyphe.

«Une nation sans marine est comme un oiseau sans ailes ». Le mot est joli et a été souvent répété en France (quoiqu'il ait, croit-on, pour premier auteur un député allemand), mais il ne signifie rien, car s'il est vrai qu'un oiseau sans ailes ne serait pas, " un oiseau », puisque le mot d'oiseau par sa définition même implique un animal ailé, il n'en résulte nullement qu'une nation sans marine ne fût pas « une nation » et ne pût être même une nation libre comme la Suisse. 
Mais si ce doute pouvait se poser avant la guerre, il ne sera plus guère possible de s'y arrêter après. En effet le courant qui déjà poussait chaque pays vers la mer va prendre une force irrésistible — la Suisse elle-même veut avoir sa marine — et cela pour des raisons évidentes.

D'abord parce que l'argument que nous avons vu déjà en ce qui concerne les industries vitales, la nécessité d'assurer l'indépendance économique du pays, semble se poser ici plus frappant que partout ailleurs - quoique pourtant si cette indépendance devait aller jusqu'à dispenser le pays de rien demander au dehors, il est clair qu'une marine marchande deviendrait inutile. Puis, parce que le taux énorme du fret, qui va durer longtemps après la guerre, imposera à la France un tribut énorme à payer aux marines étrangères (il se chiffrait par centaines de millions avant la guerre et se chiffrera par milliards après ${ }^{1}$ ) si elle ne réussit à s'en libérer en faisant elle-même ses transports par ses propres moyens. Enfin il y a l'argument militaire. Avant la guerre, la marine marchande et la marine de guerre évoluaient dans des voies de plus en plus divergentes, en sorte qu'il semblait que celle-ci n'eût aucun besoin de celle-là. Mais une des surprises de cette guerre c'est que tandis que les puissants cuirassés restaient majestueusement condamnés au repos, ce sont les navires marchands et de plus humbles encore, chalutiers et bateaux de pêche, qui ont mené la guerre sur mer. On n'oubliera plus les services rendus par ces loups de mer et on n'osera plus risquer d'en laisser perdre la race.

Malheureusement, après la guerre la marine marchande française se trouvera dans un état d'infériorité bien pire qu'avant. Sans doute, presque tous les États, non seulement belligérants mais même neutres, auront perdu une portion notable de leur flotte ${ }^{2}$ — sauf les États Unis - mais du moins ces pertes auront-elles été en partie compensées par une grande activité des chantiers de construction, surtout en Angleterre et en Allemagne, tandis qu'en France les constructions navales ont dû être presque totalement arrêtées faute de main-d'œuvre et de matériaux et, en outre,

1 Le fret payé pour le transport par voie de mer de 40 millions de tonnes (30 millions à l'importation, 10 millions à l'exportation) qui entrent ou sortent de France, était évalué à 600 millions, dont 183 millions seulement touchés par les armateurs français et 417 millions par les armateurs étrangers. Or le fret depuis la guerre a augmenté dans la proportion de 800 à $1.000 \mathrm{p}$. 100 ! ce qui veut dire que pour un même chiffre du tonnage, importé et exporté, et en supposant que le fret ne baissât pas après la guerre (et il ne baissera pas de longtemps, étant données les destructions et l'usure de la flotte existante), ce serait 4 milliards par an que la France aurait à payer ! - Toutefois il faut penser que si la France veut construire les navires nécessaires ils lui coûteront aussi dix fois plus qu'avant.

2 La diminution du tonnage à la fin de cette quatrième année de guerre peut être évaluée à un cinquième pour la flotte totale du monde (10 millions de tonnes sur 50), toute compensation faite du tonnage détruit (plus de 15 millions de tonnes) et du tonnage construit.

Les États-Unis vont prendre après la guerre le second rang, après l'Angleterre, dépassant de beaucoup tous les pays avec un tonnage (de haute mer) probablement de 5 à 6 millions de tonnes. 
la flotte restante aura été usée à fond ${ }^{1}$. Et la difficulté sera grande après la cessation des hostilités, soit pour construire, soit pour acheter de nouveaux bateaux, car le taux invraisemblable auquel est monté le prix des navires, soit comme construction, soit comme location, ne cessera pas de sitôt ${ }^{2}$.

Que faudra-t-il donc faire pour recommencer l'effort séculaire? Mais auparavant voyons ce qui avait été fait avant la guerre.

On a commencé par les droits protecteurs et même on peut dire que c'est la protection de la marine marchande qui a été le point de départ de tout le système protectionniste. Le fameux Act de navigation de Cromwell (1651) était fait pour protéger la marine anglaise et pour enlever à la Hollande l'empire des mers. À cet effet il réservait à la marine anglaise le monopole exclusif de toute importation de marchandises venant des pays d'outre-mer (Amérique, Afrique, Asie, Russie et Turquie) et quant à celles de provenance d'Europe, elles n'étaient admises que sous le pavillon de leur propre nation, non sous le pavillon d'un intermédiaire. On admet généralement, quoiqu'il se soit trouvé quelques contradicteurs, que ce régime si brutal n'a pas été sans efficacité pour le développement de la puissance maritime anglaise. Le système non moins célèbre de Colbert, la grande Ordonnance de 1681, qui protégeait aussi la marine marchande, était plus modéré. Sans analyser ici ce régime qui n'a plus qu'un intérêt historique, rappelons seulement que la protection de la marine marchande s'exerçait sous forme :- $-a$ ) de majorations des droits sur les marchandises importées (surtaxes du pavillon); - b) de droits frappant les navires eux-mêmes quand ces navires étaient étrangers (droits de navigation) $;-c$ ) d'un monopole réservé au pavillon français pour le commerce avec les colonies.

1 Le gouvernement allemand a déjà décidé de rembourser aux constructeurs ou armateurs toute la majoration des dépenses nécessaires pour remplacer les navires perdus, du moins pour ceux qui seront construits à bref délai.

Les dépenses prévues pour la reconstitution de la flotte allemande sont évaluées à 1.500 millions de marks (près de 2 milliards de francs) : pour la France on a parlé de crédits de 6 à 700 millions.

La diminution du tonnage mondial paraît devoir être moindre que celle indiquée, à raison de l'activité prodigieuse des chantiers américains. D'après le Shipping Board de New-York, le total du tonnage coulé jusqu'au $1^{\mathrm{er}}$ septembre 1918 a été de 21.405 .000 tonnes et celui du tonnage construit de 14.247.000 tonnes, laissant donc un déficit de 7.158 .000 tonnes à ce jour.

2 En ce moment (mars 1918), le gouvernement français vient de louer au Brésil 30 navires jaugeant en tout 150.000 à 200.000 tonnes, au prix de 110 millions (pour 15 mois), ce qui représente environ 3.700.000 francs par navire (7 à 8.000 francs par jour) et 600 francs par tonne.

Le fret a, suivant les cas, quintuplé, décuplé, vingtuplé, par exemple :

\begin{tabular}{|c|c|c|c|}
\hline & (la tonne) & 1914 & 1917 \\
\hline De Cardif : & à Rouen & 11 fr. " & 51 fr. » \\
\hline " & à Gênes & 10 fr. " & 212 fr. " \\
\hline " & à Alger & 11 fr. 50 & 185 fr. " \\
\hline » & à Rio-Janeiro & 21 fr. " & 156 fr. » \\
\hline
\end{tabular}

La curieuse inégalité de ces prix, ne correspondant aucunement aux inégalités de distance, s'explique par la différence des risques sur les voies de parcours. 
Mais toutes ces mesures ont été abrogées en 1866, à la suite des fameux traités libre-échangistes avec l'Angleterre ${ }^{1}$. Durant les années suivantes la marine vécut donc sous le régime de la liberté : elle s'accrut certainement — on était à l'époque critique de la transformation des navires à voiles en bateaux à vapeur - mais non dans des proportions très encourageantes.

Aussi en 1881, date du retour au protectionnisme, on ne pouvait manquer de revenir aussi au régime protecteur pour la marine. Seulement on n'osa pas revenir à l'ancien système des droits protecteurs proprement dits (surtaxes de pavillon ou de navigation) parce qu'on craignit de provoquer des représailles de la part des autres pays et on eut l'idée de recourir au système que l'on emploie toutes les fois qu'on ne peut ou qu'on ne veut établir de droits protecteurs et qu'on veut tout de même soutenir une industrie, au système des primes (ci-dessus, p. 77). C'est ce qu'on fait depuis 1881.

Ce n'est pas seulement une industrie qu'il s'agissait de protéger, mais deux : celle de la construction des navires et celle du transport, de l'armement, comme on dit, ce qui complique beaucoup le problème, car les intérêts de l'une et de l'autre sont opposés en ce sens que les armateurs ont intérêt à ce que les navires leur coûtent le moins possible. Aussi, depuis vingt-sept ans, quatre régimes ont-ils été successivement essayés : loi du 29 janvier 1881, loi du 30 janvier 1893, loi du 7 avril 1902, loi du 19 avril 1906 !

En ce qui concerne la construction, on accorde des primes calculées de façon à compenser la différence entre le coût de production en France et à l'étranger, prenant l'Angleterre surtout pour terme de comparaison. Mais un tel calcul est nécessairement très arbitraire. La loi la plus récente, celle de 1906, accordait une

Cependant il y a encore aujourd'hui :

$1^{\circ}$ le monopole du cabotage entre les ports de France et d'Algérie ;

$2^{\circ}$ celui de la pêche côtière ;

$3^{\circ}$ les surtaxes d'entrepôt, majoration des droits de douanes, très modique, sur les marchandises d'outre-mer quand elles ont fait escale dans des ports étrangers - par exemple quand, au lieu d'apporter directement le café ou le caoutchouc du Brésil au Havre, les navires ont passé par Anvers - et alors même qu'elles sont importées sous pavillon français.

Le monopole du cabotage, qui ne devrait exister tout au plus qu'entre ports du territoire français, a été étendu abusivement au transport entre la France et l'Algérie et a mis par là l'Algérie dans une véritable servitude économique. Les trois Compagnies qui ont accaparé ce transport et qui, en outre, touchent des subventions de l'État pour le service postal, font payer des tarifs exorbitants et n'ont, sauf quelques échantillons récents, qu'une flotte misérable. Et le pire c'est que sitôt qu'il y a grève des matelots ou des déchargeurs de Marseille, ce qui est arrivé souvent déjà, l'Algérie se trouve absolument privée de toute communication avec la France, puisqu'elle ne peut recourir aux navires étrangers. Une loi récente a permis, il est vrai, au gouvernement de suspendre en ce cas le monopole du pavillon français, mais il n'en avait jamais fait usage jusqu'à la guerre actuelle où l'abrogation du monopole s'est imposée par suite de la pénurie des moyens de transports. 
prime de 145 francs par tonne pour les navires à vapeur ${ }^{1}$, ce qui paraîtrait alors exagéré, puisque cette prime représente plus de la moitié du coût de la tonne en Angleterre : or les intéressés eux-mêmes admettaient que la différence de coût entre les deux pays ne dépassait pas 20 p. 100.

Qu'on accorde aux constructeurs une prime à titre de compensation, soit, mais pourquoi celle aux armateurs ? Est-ce parce qu'ils doivent payer leurs navires plus cher que les armateurs étrangers ? Mais ils devraient, au contraire, les payer moins, car, puisque les constructeurs français touchent une prime considérable, il semble que le moins qu'ils pussent faire ce serait de construire et livrer des bateaux dans des conditions au moins égales à celles des constructeurs anglais ou américains ? Hélas ! il n'en est rien : ils les font payer 50 p. 100 plus cher et avec un délai deux ou trois fois plus long ${ }^{2}$ ! Leur excuse c'est que, étant trop nombreux, ils n'ont que peu de commandes et sont écrasés par les frais généraux. — Mais s'ils ont peu de commandes c'est parce qu'ils vendent trop cher, et ainsi ils tourneront éternellement dans un cercle vicieux ${ }^{3}$ !

Toutefois ce n'est pas sur le prix de revient des navires qu'est fondée la prime de navigation, mais sur la nécessité de compenser le désavantage qui résulterait pour les armateurs des charges sociales et des privilèges des inscrits maritimes : aussi leur donne-t-on le nom justificatif de compensations d'armement. Elles sont établies d'après le nombre de jours durant lesquels le navire a été équipé et sous la condition qu'il aura effectué réellement un parcours minimum et aura transporté réellement un minimum de marchandises. Ceci a été introduit par la loi de 1906 pour empêcher les incroyables abus du régime précédent qui accordait la prime uniquement en raison du chemin parcouru, ce qui fait qu'on voyait de ces navires se promener à travers les mers sans rien transporter, simplement pour toucher la prime - aussi les appelait-on «les cueilleurs de primes ${ }^{4}$. Ces primes sont encore énormes. Un navire de 6.000 tonnes pouvait toucher plus de 60.000 francs

1 Il y a en outre une prime pour la machine (par 100 kil.) Un navire à vapeur de 3.000 tonnes reçoit ainsi 435.000 francs pour la coque et plus de 100.000 francs environ pour la machine, soit un joli cadeau de 50.000 francs ! Il est vrai que tous ces chiffres sont peu de chose maintenant à côté du prix du fret ou de celui de la location des navires (ci-dessus, p. 88).

La prime n'est que de 95 francs par tonne pour les navires à voile en fer. Pour les voiliers en bois, la prime est seulement de 40 francs.

Il est vrai que cette prime n'est pas promise à perpétuité : elle devait décroître d'année en année afin de stimuler les constructeurs français et ne pas les laisser s'endormir sur l'oreiller.

2 Déclaration des administrateurs des chantiers de la Loire, reproduite dans un rapport de $\mathbf{M}$. Charles Roux sur le budget de commerce de 1898.

3 Il y a en France une centaine de cales de constructions qui coûtent fort cher et dont plus de la moitié sont toujours vides. De plus, les chantiers français ne travaillant que sur commande, ont chaque fois à exécuter des modèles différents, tandis que les chantiers anglais fabriquent des navires « à la confection », comme la Belle Jardinière fait des costumes.

$4 \quad$ Il y a des Compagnies maritimes qui ont pu distribuer des dividendes rien qu'avec les primes. Il y en eut d'autres qui refusaient du fret parce que le temps employé au chargement et déchargement eût été du temps perdu pour le compte de la prime. 
par an pendant douze ans ${ }^{1}$ ! Du moins ces primes ayant pour but de compenser l'infériorité des armateurs français vis-à-vis des étrangers, on pourrait croire qu'elles ont pour résultat de permettre à nos armateurs d'offrir à nos commerçants des prix de transport aussi bon marché que les étrangers ? Point du tout ! le même phénomène que nous avons constaté pour les constructeurs se reproduit ici. Le fret, comme on l'appelle, était beaucoup plus cher en France qu'à l'étranger, à telles enseignes que des centaines de millions de francs de marchandises françaises allaient s'embarquer à Anvers, Rotterdam ou à Londres, pour trouver de meilleures conditions $^{2}$. Et les armateurs français se plaignaient de manquer de fret ! c'est le même cercle vicieux que nous avons signalé pour les constructeurs.

Afin de stimuler les armateurs à marcher avec le progrès, la prime est majorée jusqu'à 30 p. 100 pour les navires dépassant 46 nœuds : inversement elle est réduite de 17 p. 100 pour ceux ne dépassant pas 10 nœuds et supprimée complètement pour ceux ne dépassant pas 9 nœuds ${ }^{3}$.

Et afin que les armateurs ne soient pas livrés absolument à la discrétion des constructeurs français, la loi leur permet non seulement d'acheter des navires à l'étranger, mais de bénéficier sur ces navires de toute la prime de navigation, pourvu qu'ils les fassent franciser (et que ces navires ne soient pas vieux de plus de deux ans, ce qui est un peu rigoureux) ${ }^{4}$.

Il n'y a pas seulement les primes de construction et de navigation : il y a aussi les subventions allouées à de grandes lignes maritimes à la condition qu'elles feront un service régulier entre certains points déterminés et se chargeront du transport des postes et de quelques autres transports d'État. Ici la subvention peut être considérée comme le prix d'un service rendu, car il est en effet très utile pour un pays, au point de vue politique comme au point de vue commercial, d'avoir des moyens de transport réguliers sur les grandes routes du monde, ne fût-ce qu'avec

1 La prime (ou compensation) par tonne par jour d'armement (ce n'est plus tout à fait la même chose que par jour de navigation) est de 4 centimes pour les vapeurs jusqu'à 3.000 tonnes, de 3 centimes entre 3 et 6.000 tonnes, de 2 centimes pour les navires d'un tonnage supérieur. La prime ne peut être touchée pour un même navire que pendant douze ans.

Anvers expédiait, année moyenne, pour 400 millions de francs de marchandises françaises.

3 Le nœud représente un mille marin (1.852 mètres), ce qui veut dire qu'autant de nœuds par minute auront été comptés sur la corde qui, en se déroulant, sert de mesure à la vitesse du navire, autant de milles seront parcourus dans une heure. D'ailleurs, aujourd'hui, on ne mesure plus la vitesse du navire à la corde, mais le nom est resté. Ainsi, quand on dit d'un navire qu'il fait 10 ou 16 nœuds, cela veut dire qu'il fait 18 1/2 ou 30 kilomètres à l'heure.

4 Sous le régime de la loi de 1881 les armateurs ne touchaient qu'une demi-prime pour les navires achetés à l'étranger, et, sous le régime de la loi de 1893, ils n'en touchaient aucune, ce qui fait que les armateurs étaient obligés de faire construire leur navires en France et de subir toutes les conditions des constructeurs français.

Il y a pourtant un droit pour la francisation des navires étrangers, mais il est peu de chose, 2 francs par tonne. 
ses colonies ${ }^{1}$. C'est à peu près comme les subventions aux chemins de fer. Aussi ces subventions sont pratiquées dans la plupart des pays ${ }^{2}$. Toutefois, les lignes subventionnées de la France lui coûtent relativement plus cher qu'aux autres pays parce que, ayant peu de trafic, elles ne peuvent fonctionner que moyennant de gros dédommagements et si elles coûtent cher à l'État, les Compagnies maritimes assurent que les charges qui leur sont imposées en retour sont écrasantes ${ }^{3}$. On ne voit pas cependant pourquoi, s'il en est ainsi, elles ne les déclinent pas et ne préfèrent pas la liberté sans subventions.

Tout cela était donc ingénieusement combiné. Le législateur de 1906 avait fait tous ses efforts pour éviter les erreurs des lois précédentes; aussi faut-il reconnaître qu'il y avait eu un progrès assez notable dans les années qui ont précédé la guerre. La flotte de commerce française, qui durant toute la seconde moitié du XIX ${ }^{\mathrm{e}}$ siècle était restée à peu près stationnaire au chiffre de 1 million de tonneaux et plutôt au-dessous, a commencé à augmenter depuis 1900 et a atteint, à la veille de la guerre, 2.300.000 tonnes brut, 1.629 .000 tonnes net ${ }^{4}$. Mais il est douteux que cet accroissement soit dû au régime législatif, car la date de 1900, qui marque le commencement du relèvement, ne coïncide avec la mise en vigueur d'aucune des lois qui se sont succédé pour la protection de la marine, et, d'autre part, l'accroissement a été bien plus grand dans les pays qui n'ont, pas usé de primes ${ }^{5}$. En tout cas, le résultat obtenu n'a guère été en raison des sacrifices énormes effectués, car depuis 1881 plus de 600 millions de francs ont été jetés à la

1 Les trois grandes Compagnies de navigation subventionnées (Messageries Maritimes, Compagnie Transatlantique, Chargeurs Réunis), représentent près de 800.000 tonnes, soit plus du tiers du total de notre flotte marchande. Sans elles, nombre de pays ne verraient jamais notre pavillon.

2 L'Angleterre elle-même donne 21 millions de francs, l'Italie plus de 17, la République Argentine plus de 15 millions, et une douzaine d'autres pays de 1 à 10 millions. L'Allemagne n'alloue qu'une dizaine de millions de francs de primes directes, mais beaucoup plus sous forme de réduction de tarifs sur les matériaux pour les chantiers navals.

3 Les Compagnies chargées du service avec l'Algérie se plaignent notamment, non sans raison, semble-t-il, du nombre abusif de fonctionnaires ou soi-disant tels qu'on les oblige à transporter à prix réduit : en 1913, sur 220.000 voyageurs, il y en a eu 141.672 voyageant par « réquisition », à prix réduit, donc les $2 / 3$ !

Au total donc, voici quelles étaient les charges que s'impose l'État en France pour sa marine (en 1913) :

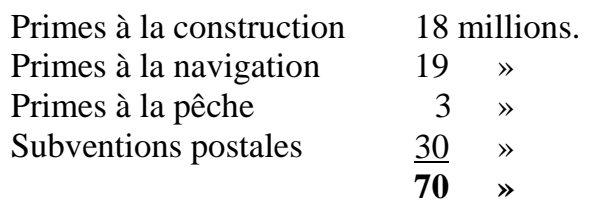

Le tonnage net est, comme on le voit par la comparaison de ces deux chiffres, inférieur de $30 \mathrm{p}$. 100 environ au tonnage brut ; la réduction est moindre pour les voiliers, mais plus forte pour les vapeurs, parce que les machines et soutes à charbon prennent beaucoup de place.

5 Dira-t-on que s'ils ont été perdus pour le Trésor, ils ne l'ont pas été pour ceux qui les ont touchés ? - Mais si, puisque les Compagnies maritimes et armateurs ont fait généralement moins de profits que toute autre entreprise. 
mer, sans réussir à empêcher notre marine de descendre du deuxième au cinquième rang ${ }^{1}$.

C'est pourquoi le système des primes paraît assez discrédité. Mais alors par quoi le remplacer ? Au cours de la guerre l'État a réquisitionné la totalité de la flotte de commerce. Il est possible que cette mesure extrême, quoique dictée seulement par les circonstances, tende à se transformer après la guerre en nationalisation de la marine -marchande et qu'on cherche dans cette voie la solution. Toutefois, même en supposant que l'État prenne le monopole de la construction des navires et en retienne la propriété, on ne le voit guère assumant le monopole de la navigation : le commerce maritime est autrement compliqué que l'exploitation d'un réseau de chemins de fer ${ }^{2}$.

Comme solutions plus modérées on a proposé soit le rétablissement des surtaxes de pavillon abolies en 1866 (ci-dessus, p. 89) ; — soit le rétablissement des droits de port qui ont été appliqués de 1866 à 1872, mais très majorés et emportant des taux différentiels selon que les navires viendraient de pays amis ou des autres : ils auraient d'ailleurs l'avantage de fournir les ressources nécessaires pour mettre nos ports à la hauteur de ceux de l'étranger (ci-dessus) ${ }^{3}$; — soit enfin, quoique cette solution se présente comme précisément l'inverse de la précédente,

1 Prenons les chiffres des principales marines marchandes à partir de 1881, puisque c'est à cette date que le régime protecteur de la marine marchande en France a commencé (Annuaire Statistique de la France, 1917, p. 202). Ces chiffres sont ceux du tonnage net : en millions de tonnes.

\begin{tabular}{|c|c|c|c|c|c|c|}
\hline & Allemagne & États-Unis & Angleterre & France & Italie & Norvège \\
\hline 1881 & 1.194 & 3.615 & 5.912 & 914 & 989 & 1.520 \\
\hline 1914 & 3.320 & 7.929 & 12.106 & 1.629 & 1.282 & 1.784 \\
\hline Accroissement & $179 \%$ & $119 \%$ & $105 \%$ & $78 \%$ & $30 \%$ & $17 \%$ \\
\hline
\end{tabular}

On voit que, comme progrès réalisé, la France n'est pas au dernier rang, mais a été néanmoins de beaucoup devancée. Ces chiffres ne donnent d'ailleurs qu'une mesure incomplète des progrès réalisés, car y sont compris à la fois les voiliers et les vapeurs. Or, c'est l'accroissement de ces derniers qui est le plus important, puisqu'une tonne de bateau à vapeur est estimée valoir 3 tonnes de voilier comme moyen de transport. Si donc on ne comptait que les vapeurs, on verrait que l'accroissement du tonnage pour l'Angleterre, les États-Unis et surtout l'Allemagne, par rapport à celui de la France, est encore bien supérieur aux chiffres ci-dessus indiqués : pour l'Allemagne, le tonnage à vapeur a presque décuplé au cours de ces 33 ans.

À noter que, pour les États-Unis, les chiffres sont exagérés parce qu'ils comprennent la navigation intérieure : voir la correction, Vol. I, p. 413, ainsi que les chiffres pour tous les autres pays mais en tonnage brut.

2 Le Contrôleur de la marine marchande a avisé les armateurs (mars 1918) que dorénavant ils exploiteraient pour le compte de l'État, celui-ci leur garantissant seulement l'intérêt du capital, une rémunération et le remplacement des navires perdus.

3 La surtaxe du pavillon est simplement une majoration de droits de douane pour les marchandises effectivement débarquées. Les droits de quai frappent le navire proportionnellement à son tonnage : ils sont donc énormes pour les grands navires et par là écartent les navires qui n'auraient à charger ou à débarquer qu'une petite partie de leur cargaison - ce qui était le cas des grands navires allemands faisant escale dans nos ports de la Manche. 
l'ouverture de ports francs (voir ci-dessus, p. 83). Mais cette dernière solution, qui nous paraîtrait la meilleure, est celle qui a le moins de chance de se réaliser.

Pour trouver le remède approprié, il importerait préalablement de découvrir la cause du mal, c'est-à-dire quelles sont les raisons de l'infériorité chronique de la marine marchande française. Or on ne peut pas dire qu'on y ait tout à fait réussi. Le diagnostic reste encore très incertain.

Voici cependant les principales explications qu'on a données :

$1^{\circ}$ Insuffisance du fret, c'est-à-dire des catégories de marchandises qui sont propres à alimenter un transport maritime régulier, telles par exemple que le charbon pour l'Angleterre, le coton ou le blé pour les États-Unis. Il est certain que ce ne sont pas des articles de Paris ou des chapeaux de dames qui peuvent nourrir une flotte de transport. Mais si la France n'exporte pas beaucoup de matières lourdes (il y en a pourtant quelques-unes : notamment les vins en fûts), du moins elle en importe et, somme toute, son mouvement maritime, entrées et sorties, se chiffre par 40 millions de tonnes ${ }^{1}$. Ce serait suffisant assurément pour remplir beaucoup plus que les 2.400.000 tonnes de notre flotte. Or on reste loin de compte, car elle ne transporte qu'un peu plus de moitié (56 p. 100) à l'exportation et un peu plus du quart (28 p. 100) à l'importation ${ }^{2}$;

$2^{\circ}$ Situation géographiquement désavantageuse de la France, malgré les apparences contraires. En effet, la France se trouvant à l'extrême occident de l'Europe, du jour où le méridien économique s'est déplacé vers l'Europe centrale, les ports français ont cessé d'être des terminus, comme Hambourg, Anvers ou Rotterdam, mais sont devenus des stations de passage où les navires font seulement escale ${ }^{3}$. Il est commode pour les navires étrangers d'y toucher en passant pour compléter leur chargement ou en débarquer une partie - mais pour le gros de leur chargement ils préfèrent aller à Anvers, Rotterdam ou Hambourg. Ces ports ont pour hinterland des régions où la richesse du sous-sol, la densité de la population et l'activité industrielle sont tout autres que celles des régions avoisinant Le Havre, Cherbourg, Brest ou Nantes. Peut-être pourra-t-on remédier dans une certaine mesure à cet inconvénient en créant des routes plus directes des ports français de l'Atlantique et de la Manche vers l'Europe centrale, mais la guerre actuelle n'est pas faite pour faciliter leur réalisation.

1 Oui, mais il faut considérer que tout navire fait nécessairement le va-et-vient et, pour qu'il puisse le faire avec profit, il faut qu'il puisse trouver des marchandises à transporter au retour comme à l'aller, ou vice versa. S'il doit faire l'un des deux voyages à vide, sur lest, comme on dit, cela devient très onéreux. Si donc les navires français devaient aller vides en Amérique, aux Indes ou en Australie, pour en rapporter le blé ou la laine que nous importons, ils feraient une mauvaise affaire.

Ces chiffres doivent être considérés comme rectifiant ceux donnés Vol, I, p. 415.

3 Nos ports sont bien placés pour les voyageurs qui préfèrent toujours réduire au minimum le trajet par mer : mais encore faudrait-il leur offrir des bateaux plus confortables - et puis ce n'est pas un fret très rémunérateur. 
$3^{\circ}$ Une autre cause d'infériorité, au dire des armateurs, serait la législation française qui leur imposerait des charges onéreuses que les autres pays n'ont pas à supporter, notamment : - $a$ ) celle résultant du régime dit de l'inscription maritime qui fait de la profession de marin un monopole pour les habitants des rivages de la mer, se traduisant par plus d'exigences, des salaires plus élevés, plus de dépenses de nourriture, et moins de travail, d'où nécessité d'avoir plus d'hommes à bord ; b) obligation de composer l'équipage avec trois quarts au moins de marins français ; $-c$ ) charges sociales, telles que l'obligation du rapatriement des marins lorsque, pour cause de maladie ou toute autre (sauf désertion), ils se trouvent débarqués à l'étranger, et l'obligation récente du repos hebdomadaire qui vient de provoquer des grèves violentes.

Il est certain que l'inscription maritime est une institution tout à fait surannée et de nature à préjudicier au progrès de notre marine, mais en ce qui concerne les charges sociales imposées aux armateurs en faveur des équipages, il ne semble pas qu'elles soient exagérées et il n'est pas démontré qu'elles soient moindres dans les autres pays ${ }^{1}$.

L'inscription maritime date de Colbert et a été complétée par des lois postérieures. Tous les jeunes gens des régions du littoral doivent un certain temps de service à bord des navires de la flotte de guerre - et, comme compensation, ils jouissent de divers privilèges dont les plus importants sont :

a) le privilège de recrutement à bord des navires de commerce - sauf un quart au plus restant disponible pour les étrangers ;

b) le droit à une pension de retraite dont le montant varie selon le nombre d'années de navigation et de grade.

Ce monopole des inscrits maritimes a provoqué en ces derniers temps de vives protestations parce que les marins syndiqués de Marseille en ont profité pour arrêter plusieurs fois la navigation entre la France et l'Algérie et forcer ainsi les armateurs à satisfaire à leurs réclamations.

En outre, il devient de plus en plus ridicule au fur et à mesure que les travaux à faire - soit à bord des navires de guerre (mécaniciens et chauffeurs), soit à bord des steamers pour voyageurs (garçons de service et de table, télégraphistes sans fil, etc.) - perdent tout contact avec la profession de marin-pêcheur. Aussi a-t-il été question de l'abolir et il semble en effet que celte survivance n'ait plus de raison d'être, mais les privilèges sont difficiles à déraciner.

En ce qui concerne l'obligation de composer l'équipage avec majorité de nationaux, cette règle se retrouve en Espagne (4/5), en Italie (2/3), en Grèce et Russie (3/4), etc. En Allemagne, elle ne s'applique qu'aux navires des Compagnies subventionnées mais n'y laisse point de place aux étrangers. En Angleterre, il est vrai, elle n'existe pas en droit (sinon pour les officiers), mais en fait la proportion des étrangers est bien intérieure à celle autorisée par la loi française.

D'ailleurs, les armateurs anglais et allemands se plaignent de leur côté de subir d'autres charges qui leur seraient spéciales. 


\section{IX}

\section{Le commerce colonial ${ }^{1}$.}

$\underline{\text { Retour à la table des matières }}$

La question des relations commerciales entre les métropoles et leurs colonies a constitué pendant des siècles un des chapitres les plus importants de l'histoire économique et même de l'histoire générale, puisque, la guerre de l'indépendance américaine, par exemple, n'a été qu'un des épisodes de cette histoire. On pensait alors que les colonies n'avaient pas d'autre raison d'être que de procurer des bénéfices à la métropole en lui achetant, le plus cher possible, ses produits manufacturés et en lui vendant, au plus bas prix, les denrées coloniales ${ }^{2}$. À cette fin avait été élaboré tout un système compliqué, dit pacte colonial, qui peut se résumer en ces cinq articles :

$1^{\circ}$ les colonies ne devaient acheter qu'à la métropole ;

$2^{\circ}$ les colonies ne devaient vendre qu'à la métropole ;

$3^{\circ}$ les colonies ne devaient pas avoir de manufactures — pour ne pas être tentées de consommer leurs propres produits ;

$4^{\circ}$ les colonies ne pouvaient recevoir et expédier de marchandises que sous le pavillon de la métropole ;

$5^{\circ}$ et, comme contre-partie aux clauses léonines de ce soi-disant pacte, la métropole s'engageait à recevoir en franchise, ou avec des réductions de droits, les produits coloniaux.

Ce qui est surprenant, c'est que toutes les colonies n'aient pas été tuées par ce régime. Au reste, beaucoup le furent. Et si les autres, comme celles des deux Amériques, ne le furent pas c'est parce qu'elles surent se révolter à temps !

Voir ci-dessus, I, p. 141-146, L'émigration et la colonisation.

Montesquieu lui-même déclarait que : « l'objet de ces colonies est de faire le commerce à de » meilleures conditions qu'on ne le fait avec les peuples voisins avec lesquels tous les avantages

" sont réciproques. On a établi que la métropole pourrait seule négocier avec les colonies, et » cela avec grande raison parce que le but de l'établissement a été l'extension du commerce, » non la fondation d'une» ville ou d'un nouvel empire » (Esprit des Lois, liv. XXI, ch. 21).

Ainsi ce grand esprit ne voyait la colonisation que par ce petit côté. 
Aujourd'hui cette célèbre question n'a pas encore perdu toute importance. Les rapports entre les métropoles et les colonies peuvent se classer sous trois catégories :

$1^{\circ}$ Système de l'autonomie. - La colonie établit son régime de douanes à son gré : c'est le système anglais. Elle peut frapper les produits de la métropole comme ceux des pays étrangers, ou au contraire leur accorder un traitement de faveur. Les principales colonies anglaises, celles de l'Australasie et le Canada, ont donné une preuve de cette indépendance en adoptant, contre toutes les traditions maternelles, un système ultra-projectionniste. Cependant depuis quelque temps, sous l'influence de l'idée impérialiste, plusieurs d'entre elles ont consenti des réductions de droits d'un quart ou même d'un tiers pour les produits métropolitains - quoique sans espoir de réciprocité, puisque l'Angleterre n'ayant pas de droits protecteurs ne peut faire de différenciations entre les importations qu'elle reçoit.

Mais dès avant la guerre (1903-1906), une campagne avait été engagée pour resserrer les liens entre les diverses parties de l'Empire en accordant aux produits coloniaux la préférence sur les produits étrangers, et, à cet effet, en frappant ces derniers de droits différentiels. Cette campagne, inspirée par M. Chamberlain, échoua : les tariff reformers ne purent ébranler la fidélité des Anglais pour le free trade. Mais le loyalisme des colonies anglaises pendant la guerre et les sacrifices immenses d'hommes et d'argent qu'elles se sont imposées pour la défense de l'Empire ont déjà redonné à ce mouvement une impulsion irrésistible et il est à prévoir qu'après la guerre il entraînera une modification radicale dans le régime commercial de l'Angleterre : il est à prévoir que l'île-franche va être obligée d'établir une barrière des droits comportant une échelle à trois ou quatre degrés selon la provenance des produits — coloniaux, alliés, neutres, ou ex-ennemis.

Pour la France, quelques colonies seulement - toutes celles de l'Afrique Occidentale et Centrale (sauf le Gabon), celles de Taïti dans le Pacifique, en Asie les cinq villes de l'Inde — jouissent de l'autonomie commerciale.

Il va sans dire que dans ce système la métropole conserve vis-à-vis de ses colonies la même indépendance que celle qu'elle leur reconnaît. Elle peut donc taxer leurs produits au même titre que les produits étrangers, mais plus généralement elle leur accorde un traitement de faveur ${ }^{1}$.

En principe, les produits des colonies autonomes jouissent en France du tarif minimum et même d'un certain nombre d'exemptions totales. C'est le cas pour la plupart des produits qui viennent de la Tunisie. Cependant, comme ces produits, étant à peu près les mêmes que ceux de France (vins, blés, huiles d'olive, etc.), font une dangereuse concurrence aux produits similaires de la métropole, on a essayé de concilier les intérêts des colons tunisiens et ceux des agriculteurs français en fixant chaque année une limite à la quantité de chaque catégorie qui pourrait être importée. Et les viticulteurs français voudraient imposer cette même limitation aux vins d'Algérie. 
Ce régime de l'autonomie commerciale est certainement l'idéal désirable, pour tous ceux du moins qui pensent que les colonies sont faites pour leurs habitants et non pour les commerçants de la métropole. Mais cette opinion est généralement considérée comme une duperie sentimentale ${ }^{1}$, et en fait l'autonomie n'est guère tolérée que là où l'on ne peut faire autrement — notamment parce que, comme en Afrique, les colonies françaises et anglaises étant enclavées les unes dans les autres, l'établissement d'un cordon douanier serait impossible.

$2^{\circ}$ Système de l'assimilation. - La colonie est considérée comme faisant partie de la métropole et par conséquent comme enfermée dans la même ligne des douanes. En conséquence, les produits de la métropole y entrent en franchise, tandis que ceux de l'étranger y sont soumis aux mêmes droits qu'à l'entrée dans la métropole. C'est le système appliqué à la plupart des colonies françaises. Il est déplorable. En admettant, en effet, qu'il puisse se justifier pour des colonies voisines comme l'Algérie, il est vraiment insensé de forcer des colonies qui sont à l'autre bout du monde - l'Indo-Chine, la Réunion, les Antilles, la Guyane, Madagascar, le Gabon, et jusqu'à la Nouvelle-Calédonie et à nos antipodes — à s'approvisionner de marchandises françaises et à repousser par des droits exorbitants les produits étrangers qui sont à leur porte: ceux d'Amérique, d'Australie ou de Chine. Cette servitude ne peut avoir d'autre effet que de renchérir la vie dans ces colonies, de les isoler artificiellement du milieu où elles pourraient puiser la sève et, en fin de compte, de diminuer leur capacité d'achat ${ }^{2}$.

Il faut noter aussi qu'en excluant les produits étrangers, ce régime a rendu les gouvernements étrangers très hostiles à l'extension de l'empire colonial français. Les graves conflits à propos du Maroc n'ont pas eu d'autre cause. La dénonciation successive des traités de commerce que la Tunisie avait conclus avec les pays étrangers et la fermeture graduelle de cette colonie avaient donné à craindre que ce système de "tunisification », comme on l'a appelé, ne fût appliqué par la France

\footnotetext{
« Faut-il laisser les colonies exercer librement leur activité dans toutes les voies où il leur plaira de la diriger et leur donner la facilité de nous infliger une concurrence désastreuse ? La réponse ne saurait être douteuse ». Cette phrase d'un rapport à la Chambre, que nous empruntons à $\mathrm{M}$. Schelle (livre déjà cité), est exactement pareille à celles qui furent prononcées par le ministre anglais il y a cent cinquante ans et qui déterminèrent la guerre et la séparation des États-Unis.

2 Et ce régime a aussi ce résultat fâcheux, en supprimant par des tarifs quasi prohibitifs l'importation des marchandises étrangères, de supprimer avec elles les droits de douane qui forment le plus clair de leur budget, résultat paradoxal mais certain.

Au reste, l'absurdité de ce système est si évidente que la loi du 11 janvier 1892, qui l'a institué, a permis aux colonies de demander des dérogations sous forme de réductions de droits sur les produits étrangers qui leur sont le plus utiles. Mais ces dérogations doivent être autorisées par le Conseil d'État et ne sont que rarement accordées. - Pourtant un décret de 1911 a autorisé l'entrée en franchise des produits alimentaires.

Un projet de loi déposé, avant la guerre attribuait aux colonies assimilées la faculté de modifier leur tarif douanier selon leurs besoins. Et même deux de ces colonies, la Nouvelle-Calédonie et le Gabon devaient passer dans la catégorie autonome. Espérons que la guerre aura pour effet de fortifier cette résolution quoiqu'elle eût provoqué déjà des protestations chez certains industriels français.
} 
dans toutes ses possessions nouvelles. Au contraire, les colonies anglaises restant ouvertes à tous, l'œuvre colonisatrice de ce pays provoque beaucoup moins de défiances. Ce système de l'assimilation, sous couleur de solidarité entre tous les membres d'un même corps, est une survivance pure et simple de l'égoïste système colonial. Au reste, les industriels français ne se gênent, pas pour dire, sans avoir lu Montesquieu, que « le but de la colonisation est de procurer des débouchés et non la fondation d'un nouvel empire ».

Ce système de l'assimilation est même pire que l'ancien pacte colonial en ce qu'il n'offre pas, comme celui-ci, à la colonie la compensation de la réciprocité par la libre entrée de tous les produits coloniaux dans la métropole. Il est vrai qu'en principe ceux-ci ne sont pas frappés de droits protecteurs, mais en fait tout ce qu'on appelle denrées coloniales, sucre, café, cacao, épices, etc., est frappé de droits sinon protecteurs, du moins fiscaux très élevés, sans doute parce que denrées plus ou moins de luxe ! C'est à grand' peine que nos colonies ont pu obtenir quelques réductions, généralement de moitié (mais insignifiantes pour le sucre) ${ }^{1}$.

Et un autre abus c'est que lorsque les colonies veulent mettre des droits sur l'importation, lesquels constituent une importante ressource pour leur budget, la métropole les oblige à les supprimer en ce qui concerne les produits métropolitains importés, afin de ne pas les faire renchérir.

$3^{\circ}$ Système de la porte ouverte. - La colonie doit rester ouverte aux importations de tous les pays en vertu de conventions internationales. Ce n'est point à dire que la colonie ne puisse établir des droits de douane, mais ces droits doivent avoir un caractère purement fiscal, ne comporter aucune différence de traitement entre la métropole et les autres pays, et généralement ne pas dépasser 10 p. 100 de la valeur. - Ce régime, inconnu autrefois, tend à se propager parce qu'il est imposé parfois au pays colonisateur par les autres pays comme le prix qu'ils mettent à la reconnaissance de sa conquête. Tel a été le cas pour les vastes colonies belges et françaises du Congo, en vertu de la convention de Berlin en 1885, et pour le protectorat français au Maroc par l'acte d'Algésiras et le traité franco-allemand de 1912.

Quoique ce système paraisse très dur au pays colonisateur, qui doit supporter tous les frais de la colonisation et ne peut s'en réserver le profit, il faut souhaiter qu'il devienne la règle générale, car d'abord, par la concurrence qu'il ouvre entre les nations, il est une garantie pour les indigènes de la colonie nouvelle, et de plus, en se généralisant, il adoucirait beaucoup les conflits internationaux. On peut

On voulait établir un droit sur le manioc. On a fait grâce provisoirement à celui des colonies, mais le président de la Commission des douanes à la Chambre les a averties : "Ce qu'il faut, c'est que vous nous apportiez ce qui nous manque ; ce qu'il ne faut pas c'est que, comme le fait actuellement le manioc étranger, vous fassiez concurrence à notre pomme de terre, à notre maïs, à notre orge, à notre betterave ». C'est le pur système colonial du XVIII siècle. 
penser qu'après la guerre il pourrait apporter une solution au terrible problème de l'attribution des possessions coloniales entre belligérants.

Si le système de l'assimilation, appliqué à la plus grande partie de notre empire colonial, a réussi à réduire beaucoup le commerce des colonies avec l'étranger, il n'a pu pourtant l'éliminer parce que la force des choses s'y oppose. Le commerce des colonies françaises avait fait de grands progrès avant la guerre. Après avoir lentement atteint le chiffre de 1 milliard de francs en 1907, il s'était rapidement élevé à 3.300 milliards en 1913, faisant plus que tripler en six ans, chiffre d'autant plus honorable que sur les 40 ou 50 millions d'habitants de ce vaste empire, il n'y a que très peu de colons français ou même européens et qu'on ne saurait donc établir une comparaison avec les colonies anglaises.

La part de la France dans ce commerce total était d'un peu plus de moitié, avec des différences considérables selon les colonies, tenant non seulement aux diversités des régimes douaniers indiquées ci-dessus, mais aussi nécessairement au plus ou moins d'éloignement de la métropole ${ }^{1}$.

Après la guerre, il faut s'attendre à un grand accroissement du commerce colonial, en France, parce qu'on y verra un moyen de s'affranchir de l'étranger pour un grand nombre de matières premières et produits exotiques. En Angleterre, une autre raison s'ajoutera à celle-là : c'est le désir de resserrer les liens que la guerre entre les diverses parties de l'Empire a si fortement noués - et on sera sans doute amené à accorder un régime de faveur aux produits coloniaux, ce qui impliquera nécessairement l'établissement de droits sur les importations étrangères non coloniales.

\begin{tabular}{|c|c|c|c|c|}
\hline \multicolumn{2}{|c|}{$\begin{array}{c}\text { Commerce total } \\
\text { des colonies } \\
\text { (en 1913) }\end{array}$} & $\begin{array}{l}\text { Commerce } \\
\text { avec la } \\
\text { métropole }\end{array}$ & \multicolumn{2}{|c|}{$\begin{array}{c}\text { Part du } \\
\text { commerce } \\
\text { métropolitain. }\end{array}$} \\
\hline Algérie & 1.292 & 884 & \multicolumn{2}{|c|}{67 p. 100} \\
\hline Tunisie & 323 & 181 & 56 & $»$ \\
\hline Maroc & 237 & 99 & 42 & $»$ \\
\hline \multicolumn{5}{|l|}{ Afrique (y compris } \\
\hline $\begin{array}{l}\text { Madagascar et île de la } \\
\text { Réunion) }\end{array}$ & 569 & 254 & 45 & " \\
\hline Indo-Chine (y compris Inde) & 705 & 224 & 32 & $»$ \\
\hline Amérique & 125 & 90 & 72 & $»$ \\
\hline \multirow[t]{2}{*}{ Océanie } & $\underline{54}$ & $\underline{25}$ & $\underline{47}$ & $\Perp$ \\
\hline & $3.3 \overline{05}$ & $1 . \overline{757}$ & $\overline{53}$ & $\overline{\prime \prime}$ \\
\hline
\end{tabular}

Voir Annuaire Statistique de la France, 1917, pp. 249-251, 153*-155*. 


\section{$\mathbf{X}$ \\ Le commerce international pendant la guerre.}

\section{$\underline{\text { Retour à la table des matières }}$}

Les perturbations causées par la guerre dans le commerce international ont été énormes, mais elles n'ont été autres que celles qui pouvaient être prévues, si ce n'est que les proportions ont dépassé toute attente et n'ont fait que confirmer les lois économiques que nous avons exposées dans les chapitres précédents. Voyons d'abord les pays belligérants.

En ce qui concerne les exportations, celles-ci ont été les premières à subir le contre-coup: elles n'ont pu que diminuer notablement dans tous les pays belligérants. Car d'abord les gouvernements ont pris des mesures restrictives en ce qui concerne tout au moins les aliments et les matières premières, afin de les réserver pour les besoins nationaux et aussi d'empêcher qu'elles n'aillent alimenter les pays ennemis par l'intermédiaire des pays neutres ${ }^{1}$. Ces prohibitions n'ont guère touché, il est vrai, les produits manufacturés, mais ceux-ci étaient frappés par ailleurs, d'abord par le manque de main-d'œuvre, la plupart de leurs ouvriers et de leurs ingénieurs se trouvant enlevés par la mobilisation, soit pour le front, soit pour les manufactures de guerre - et plus tard par manque de matière première et de charbon. Enfin, quand, par suite de la prolongation de la guerre, les transports sur terre et sur mer sont devenus difficiles et qu'il a fallu les réserver pour les produits nécessaires à la défense nationale ou à l'alimentation, le gouvernement a dû limiter strictement les expéditions des industries travaillant pour l'exportation ${ }^{2}$.

On verra cette décroissance des exportations apparaître de façon bien frappante dans le tableau ci-après : encore a-t-elle été bien plus forte que les chiffres ne le montrent, car ces chiffres expriment non des quantités mais des valeurs. Or les prix ayant généralement doublé, cette hausse des prix a dans une grande mesure compensé et masqué la diminution réelle.

1 Le commerce direct avec les pays ennemis a été tout de suite prohibé sous les peines les plus sévères - et qui ont été plus d'une fois appliquées - même avec les maisons des pays neutres suspectes de représenter des intérêts allemands. Des « listes noires » de ces maisons à qui il était défendu de vendre ont été dressées officiellement.

Or de ce chef c'était déjà une grosse part de l'exportation supprimée, la France, par exemple, exportait 1.100 millions dans les pays de la quadruple alliance, dont 869 millions en Allemagne, soit presque un sixième de son exportation totale. D'ailleurs même les exportations dans les pays neutres ont été très sévèrement contrôlées de crainte que ces neutres ne jouent le rôle de simples intermédiaires.

2 À Saint-Étienne, par exemple, les fabricants de rubans et velours n'ont pu disposer que d'un certain nombre de wagons par semaine, parcimonieusement mesuré. 
En ce qui concerne les importations, tout au contraire, elles ont été dès le début fortement stimulées par les besoins de la Défense nationale et aussi pour suppléer à l'arrêt d'un grand nombre d'industries dans les pays belligérants. Et l'action de l'une et l'autre de ces causes n'a fait que grandir au cours de la guerre. Cependant après la deuxième ou troisième année de guerre les gouvernements des pays belligérants (ceux de l'Entente) en sont venus à prohiber ou à limiter strictement les importations, comme ils avaient fait pour les exportations, et cela pour deux motifs $1^{\circ}$ afin de réserver aux besoins nécessaires les moyens de transport de plus en plus raréfiés par la guerre sous-marine et de ne pas faire monter encore le fret déjà exorbitant; $2^{\circ}$ afin de ne pas augmenter indéfiniment le montant des achats à l'étranger et les nécessités fâcheuses qui en sont la conséquence, soit d'envoyer de l'or en paiement, soit de contracter des dettes et d'aggraver le cours du change, comme nous allons le voir. Il va sans dire que c'est surtout sur les articles de luxe et produits fabriqués que la prohibition des importations a porté : cependant même là où les prohibitions législatives n'ont pas agi, celles résultant de la rareté et de la cherté des transports ont eu à peu près le même effet.

Et pourtant, à regarder les chiffres des importations et leur ascension vertigineuse au cours des quatre années de guerre-déjà révolues — en France ils ont plus que doublé - on pourrait croire que les causes stimulantes ont seules agi et que celles restrictives n'ont eu qu'un effet insignifiant? Mais il faut faire ici la même remarque que tout à l'heure à propos des exportations : il faut prendre garde que cette énorme augmentation est presque uniquement due à la hausse des prix qui ont doublé aussi au cours de ces même quatre années — et non à un accroissement en quantités.

Néanmoins, comme c'est par les différences en valeurs et non par les différences en quantité que se mesure la balance du commerce, il en est résulté que dans tous les pays belligérants cette balance est devenue de plus en plus défavorable jusqu'à atteindre des chiffres énormes, quelque 15 milliards de francs pour la France en 1917 et à peu près autant pour l'Angleterre. Ajoutez que les autres facteurs qui peuvent rétablir la balance des comptes et que nous avons énumérés ci-dessus (p. 12-15), coupons de valeurs à toucher sur l'étranger, dépenses des voyageurs, commissions des banquiers, etc., se sont évanouis, en tout ou en partie, par suite de la guerre, surtout en ce qui concerne la France et l'Italie ${ }^{1}$. Quant à l'Angleterre, elle a pu du moins bénéficier d'une grosse source de revenus, celle du fret perçu pour les transports maritimes, et qui aurait pu être bien pus grande encore si une grande partie de la flotte de commerce n'avait dû être

\footnotetext{
La France n'a guère pu tirer parti de son riche portefeuille de valeurs étrangères parce que la plus grosse part venait soit des pays alliés qu'il fallait plutôt aider (comme les valeurs russes ou belges), soit au contraire des pays ennemis (comme les valeurs autrichiennes ou turques) et par conséquent irrécouvrables. Mais, par contre, la France a bénéficié des énormes dépenses faites chez elle par les armées anglaises, belges, américaines, portugaises, et qui ont représenté cent fois plus que toutes les dépenses faites naguère par les touristes en villégiature.
} 
réquisitionnée pour les besoins de la guerre ou pour les approvisionnements des alliés ${ }^{1}$.

Quant aux Empires de l'Europe centrale, leur commerce a subi les mêmes épreuves mais aggravées par un blocus plus efficace. Cependant ce blocus ne portait au début, conformément aux Déclarations de la Conférence de Londres, que sur les marchandises classées comme contrebande de guerre et ne s'est que peu à peu étendu à toutes les marchandises, non seulement celles à destination ou de provenance d'Allemagne, mais même celles à destination de pays neutres lorsqu'il y avait lieu de croire qu'elles étaient destinées en réalité à l'Allemagne. Néanmoins le blocus n'a jamais été hermétique parce que l'Allemagne est entourée d'une ceinture de petits pays neutres qui, sans contrevenir au droit international, pouvaient lui vendre non seulement leurs produits nationaux, mais aussi les produits d'outre-mer importés par leur intermédiaire. Et les bénéfices de ces opérations étaient assez grands pour les stimuler. Pour y mettre un terme, les États de l'Entente ont «contingenté » les pays neutres, c'est-à-dire n'ont permis l'importation chez eux que dans les limites des importations antérieures à la guerre $^{2}$. Et, d'autre part, la plupart des États neutres limitrophes de l'Allemagne, inquiets de voir drainer de chez eux les produits nécessaires à leur subsistance, ont prohibé les exportations, du moins pour les produits alimentaires — mais ils n'ont pu empêcher la contrebande, surexcitée par l'énorme différence des prix. Les

1 Voici les chiffres du commerce international de quelques pays belligérants durant les quatre années 1914-1917, avec l'année 1913 comme terme de comparaison. Ces chiffres sont pris dans le Bulletin de Statistique générale de la France, sauf ceux de 1917 pour la France : car, à partir de cette date, on a arrêté leur publication ; ceux que nous avons inscrits sont donc purement conjecturaux, mais nous les croyons plutôt au-dessous de la réalité. Même ceux officiels de 1916 sont ail-dessous des chiffres réels parce qu'ils ont été établis sur les prix de 1915. Pour ne pas surcharger le tableau, nous ne marquons que les milliards et les centaines de millions :

\begin{tabular}{|c|c|c|c|c|c|}
\hline & $\underline{1913}$ & $\underline{1914}$ & $\underline{1915}$ & $\underline{1916}$ & $\underline{1917}$ \\
\hline Importation & 8,4 & 6,4 & 11,0 & 15,1 & 20 \\
\hline \multirow[t]{2}{*}{ Exportation } & 6,9 & 4,9 & 3,9 & $\underline{5,1}$ & $\underline{6}$ \\
\hline & $-\overline{1,5}$ & $-\overline{1,5}$ & $-\overline{7,1}$ & $-\overline{\mathbf{1 0 , 0}}$ & -14 \\
\hline & \multicolumn{5}{|c|}{ ANGLETERRE } \\
\hline Importation & 19,2 & 15,1 & 19 & 23,9 & 26,8 \\
\hline \multirow[t]{3}{*}{ Exportation } & 16,0 & 10,8 & 9,7 & 15,2 & 15,0 \\
\hline & $-3,2$ & $-4,3$ & $-\overline{9,3}$ & $-8,7$ & $-\overline{11,8}$ \\
\hline & \multicolumn{5}{|c|}{ ITALIE } \\
\hline Importation & 3,6 & 2,9 & 4,7 & 8,4 & 7,7 \\
\hline \multirow[t]{2}{*}{ Exportation } & $\underline{2,5}$ & 2,2 & $\underline{2,5}$ & $\underline{3,1}$ & 2,2 \\
\hline & $-1,1$ & $-0,7$ & $-2,2$ & $-5,3$ & 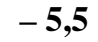 \\
\hline
\end{tabular}

Nous n'avons pas les chiffres de la Russie, mais on sait que l'exportation avait presque disparu ou du moins était tombée à un septième : l'importation ordinaire aussi, mais celle-ci avait été compensée en partie par des importations de guerre.

2 C'est ainsi qu'il a fallu créer en Suisse une société pour la surveillance des importations (la S. S. S.) ayant charge de vérifier si les importations sont bien réellement destinées à la Suisse - mais les formalités qui résultent de ce contrôle n'étaient pas faites évidemment pour stimuler nos exportations. 
chiffres du commerce international des Empires du Centre n'ont pas été publiés, mais à en juger par le cours du change dont nous allons parler, il semble que le blocus ait frappé surtout leurs exportations et que leur importation ait été relativement moins atteinte - quoique le régime de disette dont on a fait grand bruit invitât à croire le contraire.

Voilà pour les pays belligérants. Si nous regardons maintenant aux pays neutres, il est évident que la situation doit être intervertie. Elle doit être caractérisée par un énorme accroissement des exportations, une diminution des importations et, comme résultante, une balance du commerce présentant un gros excédent créditeur, un change des plus favorables et une véritable inondation d'or. Tels sont, en effet, les phénomènes qui ont caractérisé la situation des pays neutres et surtout des États-Unis, aussi longtemps qu'ils sont restés pays neutres et même après qu'ils ont pris place dans les rangs des belligérants parce que, même alors, grâce à leurs énormes ressources, ils n'ont pas cessé d'être les pourvoyeurs en subsistances, en munitions, en argent et en hommes, des pays de l'Entente. Les exportations des États-Unis ont presque triplé de 1913 à 1918, s'élevant au chiffre prodigieux de plus de 30 milliards de francs ${ }^{1}$ — toutefois, rappelons, une fois de plus, qu'une grosse part de cette augmentation est due à la hausse des prix : mais ce fait ne diminue pas l'importance de leur créance sur l'Europe - et dans leurs caisses sont venus s'amonceler plus de 15 milliards d'or, plus du quart de tout le stock d'or du monde ! Mais il en a été plus ou moins de même de tous les autres pays neutres, des pays Scandinaves qui, pour ne pas en être encombrés, ont dû suspendre la frappe de l'or (voir Vol. I, p. 436), de l'Espagne, qui a connu, pour la première fois, ce que le roi Alphonse a qualifié « d'indigestion de richesses »; de la Hollande, et aussi, quoique dans une moindre mesure, de la Suisse ${ }^{2}$ et des Républiques de l'Amérique du Sud.

Il est assez difficile de trouver dans les perturbations créées par l'état de guerre des arguments pour ou contre le protectionnisme ou le libre-échange. Elles se prêtent, en effet, à des interprétations en sens opposé. On peut dire que puisque dès le début de la guerre les États belligérants se sont empressés d'abolir les droits sur les denrées alimentaires (pour la France, les droits sur le blé ont été abrogés dès le

1 Voici les chiffres de commerce des États-Unis dans ces cinq dernières années (en milliards de francs), d'après le World Almanach (l'année commerciale finissant au 30 juin) :

$\begin{array}{lcccc}\text { Exportation } & \frac{\mathbf{1 9 1 3 - 1 4}}{12.2} & \frac{\mathbf{1 9 1 4 - 1 5}}{14.2} & \frac{\mathbf{1 9 1 5 - 1 6}}{22,4} & \frac{\mathbf{1 9 1 6 - 1 7}}{32,6} \\ \text { Importation } & \underline{9.8} & \underline{8.6} & \underline{11,3} & \underline{\mathbf{1 3 , 7}} \\ & +\mathbf{2 . 4} & \mathbf{5 . 6} & \mathbf{1 1 , 1} & +\mathbf{1 8 , 9}\end{array}$

2 Il est facile de comprendre que la Suisse ait été le moins favorisé des pays neutres. Se trouvant encerclée entre quatre grands États belligérants, sans issue sur la mer, sans communication avec les autres pays neutres, ne pouvant suffire à sa propre consommation, surtout en pain et en charbon, elle n'a pu vendre aux belligérants que ses produits nationaux en échange de son pain quotidien. C'est seulement dans le commerce de banque, ses banques ayant servi de lieu d'asile aux capitaux affolés, qu'elle a pu réaliser des bénéfices. 
31 juillet 1914, la veille de la mobilisation ${ }^{1}$; en Allemagne, en septembre) — c'est bien la preuve que l'on attendait de cette abrogation une baisse du prix, donc une réfutation sans réplique de la thèse que les droits de douane sont payés par l'étranger. Mais, en sens inverse, les protectionnistes n'ont pas manqué de faire valoir le fait que tous ces États avaient failli être réduits à merci, faute de moyens de subsistances, pour en conclure à la nécessité pour tout pays de se rendre indépendant de l'étranger (ci-dessus, p. 45).

Comme suite à ce chapitre sur la politique commerciale pendant la guerre, un autre sur la politique commerciale après la guerre semblerait indiqué — mais il serait prématuré en ce moment et d'ailleurs hors de propos dans un livre comme celui-ci ${ }^{2}$. Tout ce qu'on peut dire c'est qu'elle se trouvera cruellement tiraillée entre des buts contradictoires : - d'une part, besoin de pousser à l'exportation et de s'ouvrir les marchés des pays amis ou même neutres ${ }^{3} ;$ - d'autre part, nécessité de procurer des ressources à l'État par les douanes et préoccupation d'assurer pour l'avenir l’indépendance économique ${ }^{4}$.

1 Les droits sur les blés ont été ultérieurement rétablis lorsque les moyens de transport sont devenus difficiles et que l'État à dû prendre le monopole de l'importation du blé : à vrai dire, les droits de douane n'avaient plus aucun intérêt ni protectionniste ni même fiscal, puisque c'est l'État importateur qui les paye à l'État douanier.

2 Nous avons traité cette question dans un article de la Revue d'Économie Politique (mai-juin 1911), La politique commerciale après la guerre.

3 Une grande Association Nationale d'expansion économique a été créée pour développer l'exportation.

Pour développer l'exportation c'est surtout une organisation nouvelle bancaire qui paraît nécessaire. En effet, le commerçant français ne consent pas généralement à faire des crédits à long terme parce que les lettres de change qui sont à plus de trois mois de date ne sont pas " bancables », comme on dit, c'est-à dire ne peuvent être escomptées ou réescomptées par la Banque de France (I, p. 546). Or, pour trouver des acheteurs dans les pays d'outre-mer (Extrême-Orient, Amérique du Sud) il faut non seulement accorder les délais nécessaires pour l'envoi de la marchandise et le retour de l'argent, mais même le plus souvent laisser à l'acheteur, qui n'a pas beaucoup d'argent, le temps de s'en procurer en revendant la marchandise. C'est donc un an, peut-être deux, qu'il faut compter. Le vendeur ne peut attendre aussi longtemps pour rentrer dans ses fonds; il faut donc que des banques spéciales à long crédit soient organisées en vue de l'exportation - avec des agences à l'étranger.

4 La France, et après elle l'Angleterre, viennent de dénoncer tous les traités commerciaux (1918) pour avoir les mains libres. 


\section{XI \\ Les perturbations du change pendant la guerre.}

$\underline{\text { Retour à la table des matières }}$

Nous avons expliqué (I, p. 549) ce qu'est le change. Nous avons vu que les variations du cours du change expriment la balance des comptes entre pays. Quand un pays, toute balance faite des créances et dettes, reste débiteur de l'étranger, alors pour ne pas être obligé d'envoyer son or en paiement, il recherche tout titre de créance sur l'étranger (généralement des lettres de change) qui lui permettra de payer par compensation ; et le papier sur l'étranger se trouvant ainsi recherché fait prime, c'est-à-dire qu'il se négocie au-dessus de la valeur qu'il donne droit de toucher, au-dessus du pair, comme on dit. Si, au contraire, toute balance faite, le solde est créditeur, en ce cas le pays, au lieu d'avoir à envoyer de l'or, est appelé à en recevoir : il n'a donc plus besoin de faire des paiements ni de rechercher pour cela le papier sur l'étranger, et la valeur de ce papier tombe au-dessous du pair ${ }^{1}$.

En temps normal, ces variations sont renfermées dans d'étroites limites, quelques centièmes, parce que lorsqu'elles les dépassent, le pays débiteur, plutôt que de subir cette prime, préfère recourir au mode de paiement direct, c'est-à-dire envoyer du numéraire. Mais, depuis la guerre, ce mode de paiement direct est devenu très difficile pour les États belligérants parce qu'ils ont eu besoin de retenir tout leur or pour servir de garantie aux énormes émissions de billets de banque. Et même toute exportation d'or et d'espèces métalliques a été interdite pour les particuliers. Elle n'a été autorisée que pour les Banques d'État ; il fallait bien en effet réserver pour celles-ci la possibilité d'effectuer les paiements à l'étranger, mais elles se sont efforcées de les réduire au minimum. Dans ces conditions il était inévitable que le change ne devînt très défavorable dans tous les pays belligérants, c'est-à-dire que le prix du papier sur l'étranger ne montât très au-dessus du pair, non plus seulement de quelques centièmes, mais de 15, 20, 50 p. 100 et au delà,

1 Les États-Unis, jusqu'à la guerre, malgré un excédent d'exportations sur les importations variant entre 2 et 3 milliards de francs, restaient débiteurs vis-à-vis de l'Europe d'un solde annuel à peu près égal, car les intérêts de leurs emprunts et les dépenses de leurs nationaux en voyage, sans oublier les dots de leurs héritières prenant pour maris des fils de l'aristocratie du vieux continent, faisaient beaucoup plus que compenser l'excédent de la balance du commerce. Mais depuis la guerre la situation s'est complètement intervertie: en même temps que le solde créditeur de leur exportation s'accroissait énormément (environ 35 milliards de francs pour les trois premières années de la guerre), leur dette vis-à-vis de l'Europe se convertissait en créance, d'abord par le rachat de leurs valeurs que vendent les capitalistes anglais, puis par leurs prêts à l'Entente. 
selon la situation économique des divers pays belligérants ${ }^{1}$. Et inversement, puisqu'il s'agit d'un mouvement de bascule, le papier des pays belligérants (traites, billets de banque, valeurs quelconques) s'est trouvé déprécié dans une proportion égale sur toutes les places des pays neutres.

Cette hausse du change a des résultats très fâcheux pour les pays belligérants. Elle augmente, dans la même proportion que cette hausse, le prix de toutes les marchandises achetées à l'étranger, prix déjà énormément enflés par la loi de l'offre et de la demande et encore majorés par le coût inouï du transport par mer ${ }^{2}$. Il faut penser que, sur 15 à 20 milliards d'importation, un change de 15 p. 100 représente pour la France, par exemple, une majoration de prix de 2 à 3 milliards pour chaque année de guerre !

N'y avait-il pas quelques moyens d'enrayer cette hausse du change ?

Si : il y en a même quatre : malheureusement aucun des quatre n'était d'un emploi aisé dans les circonstances créées par la guerre.

Le premier, c'est de se procurer « du change », comme on dit, c'est-à-dire des lettres de change ou valeurs mobilières payables sur l'étranger et de s'en servir comme paiement par compensation. Mais en ce qui concerne les lettres de change, elles ne peuvent être fournies que par des ventes à l'étranger ; or, nous venons de voir que précisément un des effets de la guerre avait été de tarir en partie cette source, l'exportation ${ }^{3}$. En ce qui concerne les valeurs sur l'étranger, la France en avait un beau portefeuille, une quarantaine de milliards; (voir ci-après) : malheureusement, la plus grande partie se trouvait composée, soit de valeurs sur les pays alliés (Russes surtout, quelque peu Belges), soit au contraire sur les pays ennemis (Autriche-Hongrie, Turquie); or, ni les unes ni les autres n'étaient utilisables, quoique pour des raisons inverses, ni les premières, à cause de la solidarité financière qui unissait les pays de l'Entente - il a fallu prêter à la Russie et à la Belgique, loin de tirer sur eux - ni les secondes, parce qu'elles étaient irrécouvrables. Ce qu'il aurait fallu c'était « des valeurs » sur les pays neutres, et celles-là précisément se trouvaient rares dans les portefeuilles français, si ce n’est celles espagnoles ${ }^{4}$.

1 À ce jour (mai 1918), en France, le cours du change est de 10 p. 100 environ au-dessus du pair pour le papier sur l'Angleterre ou les États-Unis, de 40 p. 100 pour le papier sur la Suisse, de 60 p. 100 pour celui sur l'Espagne.

2 C'est bien pis pour l'Italie qui, par suite de la perte de moitié sur son papier, devait payer tout ce qu'elle achète à l'étranger le double du prix réel, et en plus le fret, ce qui triplait le prix !

3 En temps normal, la hausse du change sur l'étranger a précisément cet effet d'augmenter l'offre du papier sur l'étranger parce que le supplément de profil qu'y trouvent les exportateurs les stimule à augmenter leurs exportations (p. 8). Mais en temps de guerre, ce mécanisme automatique ne peut plus guère jouer, les exportations étant réglementées et même interdites pour les pays ennemis ou suspects.

4 Le gouvernement français a adressé de pressants appels aux capitalistes pour leur demander de lui prêter les titres sur les pays neutres qu'ils pouvaient posséder et leur a offert même une petite 
Le second, c'est de se résigner à envoyer de l'or en paiement, mais on comprend qu'avec une émission de billets qui progressivement s'est élevée, à l'heure où nous écrivons, à 27 milliards de francs, la Banque de France ne se soit résignée qu'à regret à se dessaisir du précieux métal (c'est le cas de le dire) qui constitue la garantie de ses billets ${ }^{1}$. Heureusement qu'elle a réussi, en faisant appel à la bonne volonté du public, à collecter dans le pays, au cours des trois années 1915-1918, près de $21 / 2$ milliards d'or et elle a pu, en conséquence, envoyer au dehors, aux États-Unis surtout, un peu plus de 1 milliard et, en outre, déposer en garantie à la Banque d'Angleterre près de 2 milliards d'or sans réduire son encaisse $^{2}$.

Le troisième moyen c'est tout simplement de ne pas payer ! c'est-à-dire d'emprunter au créancier lui-même la somme qu'on lui doit, en lui remettant en paiement des bons payables après la guerre. C'est à ce moyen qu'a eu recours la France, surtout avec les États-Unis, mais aussi plus tard avec la Suisse et l'Espagne. L'Italie aussi en a usé sur une grande échelle ${ }^{3}$.

Ce procédé, qui, entre créanciers et débiteurs individuels, fournirait une scène de théâtre assez comique, a donné de bons résultats, notamment entre la France et les États-Unis : le change s'est stabilisé. Mais il n'a pas eu le même heureux effet en ce qui concerne le change avec la Suisse ; et pour l'Italie aussi, quoique ses emprunts au dehors aient égalé et même un peu dépassé le déficit de sa balance commerciale, ils n'ont pu relever le change. Au reste, même au cas où le moyen réussit, il est clair que la difficulté se trouve par là ajournée plutôt que résolue.

Et le dernier moyen, c'est de réduire au minimum les importations, puisque c'est là, sinon la seule, du moins la cause principale des paiements à faire à l'étranger et, par conséquent, de la hausse du change. C'est pourquoi les

prime. L'Angleterre a pris même certaines mesures coercitives à cette même fin. Mais il ne semble pas que ni dans l'un ni dans l'autre pays les résultats de ces appels aient été bien importants.

1 « Notre constante préoccupation a été de réduire autant que possible les sorties d'or du pays » (Rapport à l'assemblée générale de la Banque de France de 1917).

2 Et même en l'augmentant considérablement, si l'on compte dans l'encaisse, comme le fait le bilan de la Banque, l'or déposé en Angleterre. À ce jour, (mai 1918), l'encaisse est de 5.634 millions se décomposant ainsi :

\begin{tabular}{lr} 
Or à la Banque & 3.342 \\
Argent à la Banque & 256 \\
Or à l'étranger & $\underline{2.037}$ \\
\hline $\mathbf{5 . 6 3 5}$
\end{tabular}

À la veille de la guerre, l'encaisse était seulement de 3.900 millions.

3 À cet effet le pays acheteur ouvre un crédit mensuel au pays vendeur, crédit garanti par un dépôt de valeurs, autant que possible en titres de rente ou obligations sur le pays vendeur. Tel est le cas pour l'Espagne, par exemple. 
gouvernements, dans la plupart des pays belligérants, ont prohibé les importations de tous les articles non indispensables à la défense nationale ou à l'alimentation. Et les Ligues privées se sont efforcées de faire la leçon au public en lui enseignant que la restriction de nos consommations était commandée comme moyen d'enrayer non seulement la hausse des prix mais aussi celle du change.

La baisse du change a été très inégale selon les pays belligérants, mais il n'est pas possible d'expliquer ces inégalités simplement par la balance du commerce ${ }^{1}$.

Pour l'Angleterre, l'énorme accroissement des importations peut suffire à expliquer la perte sur le change. Pour la France, en outre de l'accroissement des importations, on ne peut contester que l'augmentation de l'émission des billets de banque ait agi aussi. Pour la Russie, les deux causes et, en outre, l'insécurité politique ont accumulé leurs effets. Pour l'Italie, l'augmentation des importations a eu peut-être moins d'influence que la disparition des recettes provenant des villégiatures des étrangers en même temps que celles provenant des envois de ses émigrants.

Voici le cours du change pour les principaux pays belligérants pris sur les places de Suisse (Bâle et Genève), en tant pour cent. Nous mettons en regard de chaque pays la baisse minima avec l'indication de la date à laquelle elle a été atteinte jusqu'au jour où nous écrivons) :

$\begin{array}{ll} & \text { BELLIGÉRANTS } \\ \text { France } & -28 \text { p. } 100 \text { (mai 1918). } \\ \text { Angleterre } & -27 \text { p. } 100(-1918) . \\ \text { Italie } & -54 \text { p. } 100(-1918) \\ \text { États-Unis } & -26 \text { p. } 100(-1918) . \\ \text { Russie } & -80 \text { p. } 100 \text { (fin 1917). } \\ \text { Allemagne } & -51 \text { p. } 100 \text { (octobre 1917). } \\ \text { Autriche-Hongrie } & -61 \text { p. } 100 \text { (-1917) } \\ & \text { NEUTRES } \\ \text { Hollande } & +8 \text { p. } 100 \text { (novembre 1916). } \\ \text { Suède } & +31 \text { p. } 160 \text { (octobre, 1917). } \\ \text { Espagne } & +19 \text { p. } 100 \text { (mai 1908). }\end{array}$

Depuis les dates des minima portées à ce tableau, les cours du change se sont notablement relevés pour les Empires du Centre et un peu pour la Russie. Au jour où nous écrivons (mai 1918), la perte n'est plus que de 31 p. 100 pour l'Allemagne et de 55 p. 100 pour l'Autriche.

Ce qui est curieux c'est que le cours du change sur les pays neutres: Hollande, Suède, Danemark, qui avaient monté très au-dessus du pair (au delà de 30 p. 100 pour la Suède sont redescendus au pair et même un peu au-dessous en 1918 (sauf l'Espagne) : cela ne peut s'expliquer que par des causes spéciales à la Suisse.

Il va sans dire que ces cours pris sur un marché neutre ne sont pas les mêmes que ceux cotés dans les pays belligérants. Ainsi, en France, le papier sur l'Espagne est coté à ce jour non à 19 p. 100, mais à 60 p. 100 au-dessus du pair !

À la date d'octobre 1918, les cours du change indiqués se sont considérablement relevés pour les pays de l'Entente et ont baissé pour les deux Empires. En Suisse, le papier sur la France ne perd que 11 p. 100, sur l'Angleterre 8 p. 100, Italie 23 p.100, États-Unis 5 p. 100 mais l'Allemagne perd 37 p. 100, l'Autriche 54 p. 100. Le papier sur les pays neutres, Hollande, Norvège, Suède, Espagne est à peu près au pair. 
Mais en ce qui concerne les Empires du Centre, l'explication est plus difficile. En effet, on ne saurait dire de l'Allemagne ce que nous venons de dire de la France, à savoir que ses importations aient beaucoup augmenté au cours de la guerre ; au contraire, en ce qui concerne les importations d'outre-mer, elles ont presque totalement été supprimées par suite du blocus maritime, tout au moins dès la seconde année de la guerre ; et en ce qui concerne même les importations des pays limitrophes de l'Allemagne, elles ont été très réduites, du moins à partir de la troisième année de la guerre, parce que ces pays neutres ont été eux-mêmes sévèrement rationnés par les puissances de l'Entente afin d'empêcher qu'ils ne puissent ravitailler l'Allemagne. Il semble donc que l'Allemagne étant devenue, par le fait du blocus, une sorte d'État, isolé obligé de vivre sur lui-même, le papier sur l'Allemagne aurait dû être rare sur les places étrangères et par conséquent, loin de baisser, aurait dû monter au-dessus du pair.

Quelle explication en donner alors? On a cherché la raison dans une dépréciation de la monnaie de papier. Sans nul doute la dépréciation de la monnaie de papier détermine une baisse égale dans le change, comme on le voit pour les pays de l'Amérique du Sud (I, p. 554). Mais si cette explication peut être fondée en ce qui concerne le papier autrichien parce qu'il paraît avoir été émis en quantité disproportionnée avec les capacités économiques du pays, il n'en a pas été de même en Allemagne où l'émission a été maintenue longtemps dans des proportions modérées et où même en ce moment elle est encore notablement inférieure à celle de la France.

Reste encore une explication possible, c'est que la baisse du change sur un pays, au cours d'une guerre, ait pour principale cause la prévision de sa défaite, et que le cours des changes devienne ainsi ce que Paul Leroy-Beaulieu a qualifié d'un mot spirituel : la cote des paris. Il est assez vraisemblable en effet que des causes psychologiques et politiques agissent comme facteurs dans le cours des changes, ne fût-ce par exemple qu'en déterminant ceux qui croient à la défaite d'un pays à se défaire à tout prix de toutes les valeurs qu'ils possèdent sur ce pays, ou, mieux encore, parce que les opérations de change sont matières de spéculation tout comme les opérations de Bourse et que par conséquent il suffit de croire que le change baissera pour que cette prévision le fasse baisser réellement.

Ce qui semblerait justifier cette explication, c'est que les variations du change paraissent avoir parfois coïncidé avec les événements politiques ou militaires: notamment à la suite de la Révolution russe, le change de l'Allemagne et de l'Autriche s'est fortement relevé sans qu'on puisse pourtant l'attribuer à une modification quelconque dans la balance de leur importation et exportation.

En somme, les causes qui déterminent le cours du change sont à la fois : commerciales (balance du commerce) ; financières (dépréciation de la monnaie) ; politiques (confiance dans l'avenir du pays), et de là leur inextricable complexité. 


\section{XII \\ L'échange international en ce qui concerne les capitaux et les personnes.}

$\underline{\text { Retour à la table des matières }}$

L'échange des marchandises n'est pas la seule forme du commerce international; il y en a deux autres : l'échange des capitaux et l'échange des personnes. Sans doute, les mots d'échange et de commerce ne doivent pas être pris ici à la lettre, car quand il s'agit des personnes elles sont hors commerce, comme disent les jurisconsultes. Et quant aux capitaux, de deux choses l'une : ou il s'agit de capitaux concrets, en nature (machines, matières premières, etc.), et en ce cas ils rentrent dans la catégorie des marchandises; ou il s'agit du capital abstrait, en monnaie ou valeurs, et en ce cas, étant partout identique à lui-même, il ne peut faire l'objet d'un échange. Mais il n'en est pas moins vrai qu'il y a une exportation et une importation des capitaux, une émigration et une immigration des personnes ; cette circulation internationale tend à prendre des proportions aussi considérables que celle des marchandises et a donné lieu à des controverses non moins passionnées et qui vont s'intensifier particulièrement après la guerre. Néanmoins, ces deux autres aspects des relations internationales sont généralement laissés dans l'ombre dans les Traités d'économie politique ${ }^{1}$; nous ne pourrons donner ici qu'un aperçu simplement indicatif des grosses questions qui s'y réfèrent.

Il y a d'ailleurs une solidarité entre ces trois modes de circulation. Les relations commerciales tendent à déterminer à la longue des exportations ou importations de capitaux, et inversement quand un pays devient emprunteur il tend à devenir exportateur en vertu d'une loi économique déjà expliquée (ci-dessus, p. 8). Et même nous allons voir que précisément les tarifs protecteurs ont pour résultat de stimuler la création d'entreprises étrangères dans le pays protégé. De même, toute immigration prolongée tend à créer un courant commercial du pays d'origine des immigrants au pays adoptif, car ces immigrants constituent tout naturellement une clientèle et des centres de propagande. D'ailleurs, nous savons que toute relation de créancier à débiteur entre pays tend à se régler en envois de marchandises (cidessus, p. 7).

Ces deux nouvelles formes de relations internationales donnent lieu aux mêmes querelles que celle que nous avons exposée à propos du protectionnisme : ce sont les mêmes arguments de part et d'autre et qui procèdent de deux mêmes principes

1 Nous ne connaissons qu'un livre où ces trois aspects de l'échange international se trouvent mis sur le même plan et traités parallèlement : Economic Protectionism, par Grunzel (Bibliothèque Carnegie) 
antagonistes, sinon inconciliables : - d'une part, ceux qui pensent que la politique économique d'un pays doit viser à l'autonomie, à l'indépendance, et que, par conséquent, toute pénétration de marchandises, de capitaux ou de personnes venant de l'étranger risque de constituer une emprise et un danger contre lequel il faut se garder ; - d'autre part, ceux qui pensent que cette pénétration dans tous les domaines, et l'interdépendance qu'elle crée entre les nations est une condition indispensable du progrès pour chacune et pour toutes.

\section{$\S$ 1. Exportation et importation de capitaux.}

\section{Retour à la table des matières}

Ce mouvement prend une importance grandissante au fur et à mesure que le développement des moyens de crédit, la multiplication des banques, la facilité des relations entre ces banques et leur clientèle, confère aux capitaux une sorte d'ubiquité. On évalue à 900 milliards de francs la somme de capitaux investis sous forme de valeurs mobilières (titres de rente, actions, obligations, etc.) : sur cet énorme total, environ 700 milliards peuvent être considérés comme des valeurs nationalisées, sédentaires, et 200 milliards au moins comme valeurs internationales, véritable monnaie internationale. Mais ce chiffre est encore loin de représenter la circulation totale des capitaux, car ce n'est pas seulement sous la forme de valeurs mobilières que les capitaux se déplacent : ils vont s'investir aussi bien sous la forme de terres, de maisons, d'installation d'usines, de navires.

À l'inverse des marchandises, pour lesquelles c'est l'importation seulement qui a suscité les attaques des protectionnistes, tandis que l'exportation est considérée comme éminemment favorable — pour les capitaux c'est leur exportation qui est condamnée et flétrie, tandis que leur importation est généralement assez bien accueillie. Mais il n'y a là qu'une contradiction apparente et si on se place au point de vue mercantiliste le raisonnement est très logique : en effet, si on applaudit à l'importation des marchandises c'est parce qu'elle fait entrer l'or dans le pays, mais l'exportation des capitaux le fait sortir, et vice versa.

Il faut donc, pour plus de clarté, considérer séparément l'exportation et l'importation.

$1^{\circ}$ L'exportation des capitaux ou, comme on dit plus simplement, les placements à l'étranger, a fait l'objet de dénonciations violentes, surtout en France, parce que c'est de tous les pays celui qui les pratique sur la plus large échelle, et a suscité une campagne contre les grands établissements de crédit dont nous avons 
déjà parlé (I, p. 534) ; on les accusait surtout de s'être faits les instruments de ces placements à l'étranger ${ }^{1}$.

Voici les principaux arguments allégués :

a) Argument économique. L'exportation des capitaux prive le pays d'une partie des ressources nécessaires pour alimenter son industrie, pour exploiter ses ressources naturelles, pour faire vivre sa population ouvrière - et tout cela au profit du pays étranger auquel on apporte ce capital. Par suite de la désertion de ce capital, le taux de l'intérêt tendra à s'élever, le taux des salaires à baisser, la production nationale à fléchir ;

b) Argument fiscal. L'exportation des capitaux a pour but, ou du moins pour résultat, d'éluder le paiement des impôts, acte de désertion d'autant plus antipatriotique que ces impôts vont devenir plus écrasants et que la charge en retombera sur ceux restés fidèles au poste ;

c) Argument politique. L'exportation des capitaux, particulièrement sous forme de souscription aux emprunts d'États étrangers, mais aussi de commandite de certaines entreprises industrielles, telles que fabriques d'armes, constructions navales, chemins de fer à caractère stratégique ou politique (chemin de fer de Bagdad, par exemple), peut avoir pour résultat de fournir des armes à l'ennemi de demain et constituer par là un acte de trahison.

Ces arguments avaient ému le gouvernement et, déjà, avant la guerre, certaines mesures répressives avaient été prises et d'autres plus sévères avaient été

La somme des valeurs étrangères appartenant à des Français était évaluée avant la guerre à plus de 40 milliards de francs, non compris les capitaux placés en achat de maisons (très nombreuses en Suisse) ni les entreprises individuelles. Pour l'Angleterre, le chiffre de ses placements au dehors est près du double, 90 à 100 milliards de francs. Seulement il faut remarquer que la moitié de ce gros total représente des placements dans les colonies anglaises (Indes, etc.), en sorte qu'il n'y a que 40 à 50 milliards de placements à l'étranger proprement dits. Or la France n'a qu'une infime portion de son portefeuille (2 à 3 milliards) placée dans ses colonies; le montant des capitaux français placés à l'étranger est donc presque égal à celui des capitaux anglais comme chiffre absolu et représente près du double comme chiffre proportionnel à sa fortune. Voici, d'après M. Neymark, comment était composé, avant la guerre, le portefeuille de la France :

Russie

Amérique du Sud

Espagne

Italie, Belgique, Roumanie

Égypte

Turquie

Autriche

Suisse, Hollande et pays Scandinaves

Allemagne

Colonies françaises
12

12

4

4

3

3

2,5

1

0,5

$\frac{4}{46}$ 
annoncées ${ }^{1}$. Notamment il était devenu de règle que le gouvernement intervenait dans les émissions d'emprunts étrangers en France et n'accordait l'autorisation, tout au moins quand il s'agissait d'emprunts d'États, que moyennant certains avantages à consentir par l'État emprunteur, tels de réserver une part de l'emprunt pour des commandes à l'industrie française ou de faire certaines concessions sur son tarif de douanes. Quant à l'évasion fiscale, l'État s'était efforcé de l'entraver par des conventions avec les pays étrangers, notamment avec l'Angleterre et la Belgique, règlementant les ouvertures des successions.

Comment le gouvernement peut-il empêcher le prêt des capitaux à l'étranger ? En refusant d'autoriser l'inscription de l'emprunt à la Bourse de Paris. Sans doute, cette exclusion n'empêche nullement les capitalistes français avertis, surtout ceux qui ont leurs banquiers à l'étranger, de souscrire à ces emprunts. Mais elle rend la souscription impossible ou du moins très difficile pour la masse des petits capitalistes, surtout si les grands établissements de crédit, dont en tant que clients ils suivent aveuglément les indications, s'associent au boycottage gouvernemental.

On songeait même à des mesures plus radicales telles que la prohibition des titres au porteur, le titre nominatif devant devenir la seule forme légale. Nul doute qu'après la guerre cette campagne ne soit reprise avec plus d'ardeur, car on trouvera un argument de plus dans la nécessité de réserver pour la reconstitution du pays le capital qui pourra rester encore en France ${ }^{2}$.

Quoique cette politique ait été généralement approuvée par l'opinion publique, nous la croyons plutôt fâcheuse. Elle froisse la fierté des pays à qui on veut imposer ces conditions ${ }^{3}$. Elle les oblige à chercher d'autres prêteurs et leur apprend ainsi que la France n'a point, comme on le croyait volontiers, le monopole

\footnotetext{
Dans un rapport à la Chambre sur le budget de 1910, un député, qui a été depuis ministre des Finances, avait parlé de «l'hervéisme des capitaux ». Et un autre ministre des Finances du parti radical avait aussi parlé en termes sévères de ceux qui plaçaient leurs fonds dans les coffresforts de l'étranger et leur avait prédit «certaines surprises » sous la forme de conventions fiscales internationales.

Les socialistes ne sont pas plus favorables :

« L'exportation de notre épargne, écrivait l'un d'eux dans l'Humanité, a aussi cette conséquence réactionnaire qu'elle rend les capitalistes français de plus en plus indépendants vis-à-vis de la classe ouvrière et par suite de plus en plus indifférentes à ses revendications ».

Mais en Allemagne c'est le parti conservateur et agrarien qui proteste contre l'émigration des capitaux.

2 Au cours de la guerre l'exportation des capitaux a été complètement arrêtée, non seulement par la prohibition de sortie du numéraire et des titres, mais par l'interdiction de toute émission de valeurs, sauf avec autorisation du gouvernement; et tout récemment (avril 1918 une loi a interdit même l'ouverture de comptes dans des banques à l'étranger.

3 Peu de temps avant la guerre, à propos d'un emprunt que le ministre des Finances du gouvernement des Jeunes Turcs était venu chercher en France, le journal Le Tanine se plaignait en termes amers des conditions qu'on avait voulu imposer et concluait : "Il vaut mieux rester affamé que de recourir à l'argent de ceux qui, en nous le prêtant, se croient nos bienfaiteurs ».
} 
du prêt des capitaux ${ }^{1}$. Elle porte préjudice aux capitalistes français eux-mêmes, car, naturellement, en détournant les emprunteurs, elle réduit la demande et, par suite, le taux de l'intérêt.

Toute cette argumentation s'inspire d'une idée tout à fait erronée, à notre avis, à savoir que le pays qui prête fait un acte de libéralité, voire une sorte de sacrifice, au profit du pays emprunteur ${ }^{2}$; on se représente cette opération comme celle de la transfusion du sang entre individus et on en conclut soit qu'une telle générosité doit être déconseillée au nom de l'intérêt national, qu'on a qualifié d'égoïsme sacré, soit tout au moins qu'elle doit être payée de retour par des concessions réciproques. Pourtant quand il s'agit de prêts entre particuliers, on n'est point disposé à croire, à moins qu'il ne s'agisse d'un prêt d'ami, que le prêteur se sacrifie pour l'emprunteur, ni que celui-ci lui doive aucune gratitude ni autre rémunération que l'intérêt stipulé. Bien moins encore un tel point de vue est-il admissible pour les prêts à l'étranger quand on sait à quelles conditions, souvent léonines, pour ne pas dire usuraires, ils sont consentis ${ }^{3}$. On comprend donc que le pays emprunteur soit assez mécontent quand, en outre de telles conditions, on lui demande des concessions, des garanties et, par-dessus le marché, une éternelle gratitude.

En admettant même que le prêt à l'étranger ait été fait dans des conditions normales, il est bien évident qu'il n'aurait pu se faire si le prêteur n'avait cru y trouver profit. Il est arrivé plus d'une fois, il est vrai, que cet espoir ne s'est pas réalisé ; en ce cas, c'est un accident qui n'était pas assurément dans les intentions du prêteur. Mais généralement le placement à l'étranger a été très profitable aux capitalistes et, ce qui est plus important encore, il est avantageux pour le pays, car il est très utile pour un pays d'avoir des créances sur l'étranger. C'est, comme nous l'avons vu, le moyen de s'assurer une balance des comptes favorable et un change favorable. Au cours de la guerre actuelle, on a eu à regretter que le portefeuille de la France ne fût pas encore mieux garni qu'il ne l'était en valeurs étrangères (cidessus, p. 110). Ce n'est pas seulement au point de vue de la balance du commerce mais aussi de la sécurité qu'il est utile pour un pays de ne pas avoir « tous ses œufs

1 Le prêt à la Turquie, dont nous venons de parler, fut accordé. Mais à la même époque (1912) le prêt à la Bulgarie fut refusé et elle dut s'adresser à l'Allemagne.

Au reste le gouvernement allemand suit la même politique : il l'a même inaugurée.

2 C'est ainsi qu'avant la guerre un homme qui occupait une haute situation dans les transports maritimes, M. Charles Roux, parlant au gouvernement, disait : « Nous souhaitons que M. le Ministre des Affaires étrangères ne perde pas de vue que si nous n'hésitons pas à payer un large tribut aux emprunts étrangers, nous sommes en droit d'exiger que les bénéficiaires de ces emprunts s'adressent aux chantiers français » ... Ainsi c'est le prêteur qui "paie tribut » à l'emprunteur !

3 Les exemples à citer seraient innombrables. Sans donner de noms, des emprunts dans les conditions suivantes ne sont pas rares: l'État emprunteur (disons la Chine, par exemple) reconnaîtra avoir reçu 100 francs à 6 p. 100 sur lesquels il ne lui sera versé que 80 francs, et sur ces 80 elle devra en laisser 40 en achats dans le pays prêteur : elle ne recevra donc, en réalité, que 40 (plus les livraisons en nature) sur lesquels elle devra payer 6 francs, ce qui représente donc 15 p. 100 d'intérêt réel. 
dans le même panier » : en cas de guerre ou de révolution, les valeurs étrangères ne seront pas dépréciées et pourront faire l'objet d'arbitrages avantageux ${ }^{1}$.

Quant au risque de fraude pour le fisc, on confond généralement deux faits d'ordre différent : le fait de placer son argent en valeurs étrangères et le fait de déposer ses valeurs (françaises ou étrangères) dans des banques à l'étranger. Cette seconde opération seule, et non la première ${ }^{2}$, peut avoir pour but une évasion fiscale et encore cette présomption est-elle loin d'être toujours justifiée. Un capitaliste peut avoir intérêt à avoir un banquier dans une ville étrangère, soit parce qu'il a des intérêts dans cette ville, soit simplement parce qu'il se trouve mieux renseigné et mieux servi. Il a été de mode à un certain moment de faire blanchir son linge à Londres : pourquoi serait-il plus criminel d'y avoir un compte courant ? Il faut penser aussi qu'interdire les dépôts dans les banques étrangères ce serait conférer un monopole aux grandes banques françaises ; or, à en juger par les vives critiques auxquelles elles ont donné lieu (I, p. 533), il est permis de penser que les abus dénoncés ne feraient qu'augmenter. D'ailleurs, si serrées que puissent être les mailles du filet tendu par le fisc, il n'y aura jamais que les petits capitalistes, ignorant les combinaisons financières, qui s'y laisseront prendre. Le capital ne peut être saisi qu'autant qu'il est sous forme concrète, mais quand il s'est volatilisé sous forme de crédit, il devient insaisissable et c'est perdre son temps que de s'obstiner à le poursuivre.

Quant au risque de voir le capital prêté servir à concurrencer nos industries, voire même à préparer des armements contre nous, il suffit de faire remarquer que le même risque serait à prévoir pour l'exportation de matières premières (comme naguère le fer de nos mines de Briey) et à plus forte raison pour la vente à l'étranger de canons ou de navires de guerre. Pourtant, non seulement on ne s'y refuse pas, mais même dans chaque pays les gouvernements font tout leur possible, en France, en Allemagne, en Angleterre, pour aider leurs grandes maisons métallurgiques à vendre à l'étranger leurs canons ou leurs cuirassés, et enregistrent chaque commande comme une victoire pour l'industrie nationale ! Dira-t-on qu'on a le soin de ne les vendre qu'aux amis ? Nul ne peut dire quel sera l'allié ou

Au cours de la guerre, les Français n'ont pu réaliser que pour 500 millions de valeurs américaines, tandis que les Anglais en auraient vendu, dit-on, pour 2.800 millions et les Allemands eux-mêmes pour 1.250 millions.

M. Ribot, alors ministre des Finances, disait à la Chambre qu'il s'était toujours opposé aux mesures tendant à enlever aux titres leur caractère international : « c'est là une vue de politique fiscale mais non de financier ni d'économiste ».

C'est aussi ce que dit l'économiste italien Ferraris : «L'Italie a suivi une fausse politique à propos de placements à l'étranger... Nous avons même mis des taxes sur les placements étrangers. Si nous avions eu des sommes relativement larges employées à l'étranger, nous en aurions en de grands avantages en temps de paix et en temps de guerre » (La ricostruzione economica, dans la Nuova Antologia, $1^{\mathrm{er}}$ mars 1917).

2 En effet, les valeurs étrangères sont frappées d'un impôt comme les valeurs françaises (et même de 6 p. 100 au lieu de 5 p. 100), qu'elles soient déposées en France ou à l'étranger ; seulement il est vrai que pour celles déposées à l'étranger il n'y a pas de contrôle possible. 
l'ennemi du lendemain et il faut penser aussi que si le prêt accordé risque de servir à un ennemi, le refus de prêt risquera de nous créer un ennemi.

Reste l'argument économique que tout capital exporté est enlevé à l'industrie nationale. Assurément, l'industrie nationale a droit à être la première servie — et non moins l'industrie coloniale qui a été jusqu'à présent beaucoup trop négligée par les capitalistes français. Tel sera le cas après la guerre, mais en temps normal un pays vieux et riche doit avoir un trop plein d'épargne suffisant pour se déverser an dehors; surtout lorsque, comme c'est malheureusement le cas de la France, l'accroissement de son capital distance l'accroissement de sa population. Quand une jeune fille ne trouve plus à se marier dans sa ville natale, elle est bien obligée de s'expatrier : il en est de même du capital.

D'ailleurs, c'est une grande erreur de croire que le capital placé au dehors est perdu pour l'industrie nationale et le travail national ; il y revient successivement et très accru sous la forme des bénéfices réalisés. Tout placement de capital à l'étranger est une semaille qui doit donner sa moisson. Il ne faut pourtant pas oublier que ce sont les capitaux du Vieux Monde qui ont créé le Nouveau Monde et que toutes les richesses qu'il nous renvoie aujourd'hui sous forme d'aliments pour nos populations et de matières premières pour nos industries, et grâce auxquelles l'Europe Occidentale a pu devenir une incomparable ruche d'hommes et de richesses, n'auraient jamais vu le jour si le capital était resté à domicile.

Il est vrai que cette justification du placement à l'étranger ne vaut que pour les placements en entreprises industrielles et non pour ceux en emprunts d'État ; ceuxci, en effet, n'ont reçu que bien rarement un emploi reproductif et ne servent généralement qu'à des armements. Aussi, en ce qui les concerne, ne verrions-nous pas d'inconvénient à un contrôle de l'État ni même à ce qu'on s'efforçât de les restreindre, et nous avons déjà fait remarquer (I, p. 536) que ce que l'on peut à juste titre reprocher à nos grands établissements de crédit ce n'est pas tant d'avoir facilité les placements à l'étranger que de les avoir engagés surtout dans les emprunts d'État ${ }^{1}$. Mais en ce qui concerne les emprunts faits par des entreprises privées, ce n'est pas le rôle de l'État d'encourager ou d'empêcher tel ou tel placement : même en s'inspirant du souci de protéger l'épargne nationale, il risque de donner de fort mauvais conseils financiers et d'assumer par là une responsabilité fâcheuse ${ }^{2}$.

1 Les capitaux prêtés par la France à la Russie ont été évalués à 18 milliards, dont 13 milliards d'emprunts d'État et 5 milliards seulement en chemins de fer et valeurs industrielles: la proportion n'est donc pas même d'un tiers. Mais une partie des prêts en fonds d'État était sortie des portefeuilles français avant la guerre et, d'autre part, la valeur indiquée pour les rentes doit être celle au pair qui déjà avant la guerre était notablement supérieure au cours réel. La somme totale des emprunts russes en France a été évaluée récemment par le ministre des Finances à 7 milliards francs seulement.

2 C'est ainsi qu'en ce moment nous voyons le gouvernement français se croire obligé de payer les coupons des emprunts russes.

Cette politique de contrôle financier risque aussi d'entraîner des complications diplomatiques et même des exécutions militaires, car l'État étant intervenu dans la négociation de l'emprunt, s'il 
$2^{\circ}$ L'importation des capitaux étrangers semble, à première vue, ne pouvoir trouver qu'un accueil favorable - et cela précisément par les mêmes motifs qui font redouter leur exportation — n'est-ce pas un enrichissement pour le pays ? Mais si le capital est toujours le bienvenu, il s'en faut que le capitaliste étranger le soit également. Or l'un ne va pas sans l'autre. Sans doute, si le capitaliste étranger se borne à souscrire aux emprunts de la défense nationale, ou même à acheter hôtels à Paris ou châteaux en Touraine, on lui fera fête: mais s'il se rend propriétaire de domaines, de mines, s'il installe des entreprises industrielles ou des banques, s'il achète des actions de société industrielle ou financière dans des proportions suffisantes pour y exercer une action prépondérante, on considérera comme un très grand danger cette mainmise du capital étranger sur l'industrie, les finances et les ressources naturelles du pays. On y verra comme une sorte d'annexion, occulte et pacifique mais non moins dangereuse, de notre territoire ${ }^{1}$.

Il est à remarquer que l'intensification du régime protectionniste a eu précisément ce résultat inattendu de stimuler l'immigration des capitaux étrangers sous la forme d'entreprises industrielles. En effet, les industriels dont les produits se trouvaient frappés de droits quasi prohibitifs ont eu l'idée ingénieuse, ne pouvant faire entrer leurs produits, d'entrer eux-mêmes et de venir installer leurs fabriques ou leurs succursales en arrière de la ligne des douanes : leurs produits se trouvant ainsi nationalisés n'auraient plus de droits à payer. Cette tactique tendait à se généraliser avant la guerre - entreprises allemandes et anglaises en France et en Italie, entreprises françaises en Espagne et en Russie, etc. — à ce point que l'on pouvait voir venir le jour où le système douanier fonctionnerait à vide, les concurrents étant installés dans la place.

Dès lors, le protectionnisme a dû déplacer ses batteries et, ne se bornant plus à viser les produits étrangers, a cherché des moyens de défense contre les entreprises étrangères ou à participations étrangères ; et de là tout un ensemble de mesures

arrive que l'emprunteur étranger devienne insolvable, l'État se croit moralement engagé à réclamer l'exécution des engagements dont il s'est fait comme caution et à les exiger manu militari. On pourrait citer bien des exemples plutôt scandaleux de forces navales mises au service de créances douteuses. Dans les congrès internationaux, un projet avait été discuté pour les interdire dorénavant : c'est celui de M. Drago, ministre de l'Argentine. Les États-Unis ne tolèrent plus ces mesures de contrainte vis-à-vis des Républiques de l'Amérique.

Depuis mars 1918 le paiement des coupons de la rente russe que le gouvernement français avait pris à sa charge a été suspendu - mais ces coupons seront acceptés pour moitié en souscription de l'emprunt national.

1 La participation des capitaux allemands dans les mines de la Lorraine française (Briey), dans les mines et installations métallurgiques près de Caen, dans les maisons de gros de vins de Champagne, dans d'innombrables banques et hôtels-palaces, a fait assez de bruit.

Pourtant la Chambre de Commerce de Caen par une délibération en 1910, déclara que « si nous trouvons naturel que l'étranger vienne acheter nos pommes, nos beurres et aussi nos chevaux pour remonter sa cavalerie militaire, nous ne voyons aucun inconvénient à ce qu'il vienne acheter notre minerai. Ne mettons aucune barrière pour empêcher l'arrivée de capitaux qui apporteront dans notre région une augmentation de main-d'œuvre et de travail ». 
législatives déjà proposées et qui feront peut être après la guerre l'objet d'ententes internationales. Mentionnons seulement un droit de contrôle de l'État sur toutes les entreprises sous forme de sociétés par actions et l'exigence que la majorité, au moins du capital-actions appartienne à des Français. Et comme un tel contrôle est presque impossible avec des titres au porteur, on a songé à interdire l'émission de titres au porteur pour ne reconnaître d'autre forme que celle du titre nominatif.

Ces deux questions, celle de la nationalité des sociétés et celle des titres au porteur, ont fait l'objet de nombreuses études ${ }^{1}$ : nous ne pouvons les discuter ici, d'autant moins qu'elles ont plutôt un caractère juridique qu'économique, mais en restant sur le terrain économique nous croyons que l'une et l'autre de ces restrictions ne pourraient que porter un grave préjudice aux intérêts du pays, tout particulièrement à un moment où il aura le plus pressant besoin de recourir au capital étranger pour remplacer la somme énorme de ses capitaux détruits et où il ne pourra de longtemps compter sur l'épargne pour combler ces vides. Sans doute, on répondra que ces mesures ne seront prises que contre certains capitaux étrangers. Mais de telles différenciations ne se laissent pas facilement mettre en forme de lois et d'ailleurs les capitaux étrangers que l'on vise auront un assez vaste champ d'emploi et chez eux et dans l'Europe orientale pour n'avoir pas souci de venir s'insinuer chez nous. Quant à l'abolition du titre au porteur, elle ne paraît pas réalisable en fait ${ }^{2}$, mais si même on réussissait à l'imposer, on aurait supprimé précisément ce qui a fait la puissance du capital, la facilité de déplacement - le capital étant des trois facteurs de la production le seul qui en soit doué parfaitement. Et, à moins de supposer que tous les pays du monde n'acceptent cette loi, les pays qui auraient supprimé les titres au porteur se trouveraient très désavantagés dans la concurrence mondiale vis-à-vis de ceux qui les auraient maintenus. Il ne faut pas oublier que la création des titres au porteur a été considérée à juste titre comme une des inventions les plus fécondes dans l'histoire économique (I, p. 492).

\section{§ 2. Émigration et immigration des personnes.}

$\underline{\text { Retour à la table des matières }}$

Le déplacement des personnes d'un pays à l'autre ${ }^{3}$ se présente de nos jours sous deux formes principales: celle de la main-d'œuvre, c'est-à-dire de la population ouvrière, et celle du tourisme, c'est-à-dire des voyageurs riches.

Voir notamment dans la Revue politique et parlementaire 1916-1917 une série d'études sur la législation des étrangers par notre regretté collègue Thaller et sur la nationalité des sociétés par M. Landry, député.

2 La loi exige la forme nominative déjà dans plusieurs pays, en Angleterre, États Unis, Canada, mais à quoi sert-elle ? À rien, car ce sont les banques qui inscrivent les titres à leur nom et délivrent aux déposants des certificats au porteur qui remplacent les vrais titres et rendent les mêmes services.

3 Pour l'émigration en général, voir vol. I, p. 139. 
Il ne faut pas croire que cette dernière soit d'importance négligeable. Nous avons vu déjà (p. 14) que les dépenses faites par les étrangers étaient, pour les pays qui avaient la chance de les attirer et de les retenir, un des moyens les plus efficaces de rendre créditrice la balance des comptes, ou tout an moins de compenser l'infériorité de leur exportation par ce qu'on a appelé d'un mot juste « les exportations sur place », c'est-à-dire les achats faits par les étrangers. Et nul doute qu'après la guerre, les pays belligérants, qui auront un si urgent besoin de faire rentrer l'or et de payer leurs dettes, ne cherchent dans « l'industrie du tourisme un moyen de suppléer à l'insuffisance de leur exportation ${ }^{1}$.

Si l'immigration riche sous la forme de tourisme ne peut guère trouver d'adversaires, il n'en est pas de même quand il s'agit d'étrangers venant s'installer à demeure $^{2}$. Quoique la ligne de démarcation entre la villégiature et la résidence habituelle ne soit pas facile à tracer, cependant l'instinct xénophobe sait bien la reconnaître : il se montre très défiant et même agressif contre ceux qu'il qualifie de métèques et s'efforce de défendre contre cette infiltration la pureté de la race et la tradition nationale. À cette fin, il réclame l'application d'un contrôle plus sévère quand il s'agit de résidents et des restrictions en ce qui concerne la naturalisation, c'est-à-dire une politique inverse de celle qu'on pratiquait naguère et qui tendait à faciliter, même à imposer, la naturalisation afin de suppléer à notre faible natalité.

Quant aux immigrants proprement dits, certains pays, surtout les États-Unis, les soumettent à un contrôle impitoyable afin d'écarter les «indésirables ». Avant la guerre, on se préoccupait de la concurrence que la main-d'œuvre étrangère risquait de faire à la population ouvrière ; après la guerre, ce sera la préoccupation inverse qui dominera : celle de trouver, dans une Europe où la population aura été décimée, la main-d’œuvre nécessaire pour remplacer les vides. Cette nécessité sera urgente surtout pour la France : elle devra l'accepter de bon cœur ; les étrangers l'ont bien servie dans la légion étrangère; leurs services ne seront pas moins précieux dans l'armée industrielle. Mais ce ne sera pas facile, car chaque pays aura assez à faire chez soi pour employer toute sa main-d'œuvre disponible. On ne voit guère que l'Italie et, dans une moindre proportion l'Espagne, qui pourront encore exporter « des bras » et ils mettront certainement à profit la surenchère qui en sera faite. Les pays qui en auront besoin devront plutôt offrir des faveurs que recourir à

1 En France on a déjà créé des Écoles professionnelles «d'hôteliers en vue de remplacer les maîtres d'hôtels étrangers. Et dans un article de la Revue du Touring Club on évaluait à 3 milliards ce que pourraient apporter annuellement les voyageurs étrangers ( 3 millions de voyageurs à 1.000 francs chacun!). On se propose de tirer meilleur parti de nos nombreuses villes d'eaux dont les recettes ne sont évaluées qu'à 120 ou 130 millions, tandis que celles des villes d'eaux d'Allemagne sont évaluées à 8 ou 900 millions.

2 La France est de tous les pays vieux un de ceux où les étrangers sont les plus nombreux et c'est la marque d'un attrait dont elle doit être fière : cependant la proportion n'atteint pas 3 p. 100 (1.160.000 sur 39.200.000 en 1911). En Suisse, elle s'élève à près de 20 p. 100 (600.000 sur $3.900 .000)$ : il est vrai que depuis la guerre on commence à s'en préoccuper, mais c'est plutôt par crainte que sa neutralité n'en soit compromise. 
des mesures tracassières. Il faudra sans doute recourir, comme on l'a fait déjà pour les travaux de la guerre, à la population indigène de l'Afrique et de l'Asie — mais alors se posera pour nos pays d'Europe, comme elle s'est déjà posée pour l'Amérique du Nord et l'Australie, la très grave question de la concurrence entre deux catégories de travailleurs - les blancs d'un côté, les jaunes et noirs de l'autre — dont les exigences et les besoins sont à des niveaux tout à fait différents (nous retrouverons cette question dans le chapitre du Salaire).

Quant au pays d'origine des émigrants pauvres, il n'aurait à s'en plaindre que s'il manquait de main-d’œuvre, mais précisément dans ce cas une telle émigration serait tout à fait invraisemblable : quand elle a lieu c'est au contraire qu'elle le débarrasse d'un trop plein de population qui pèserait sur le taux des salaires. Il est vrai qu'il faut inscrire au débit du compte de cette émigration tous les frais qui ont été faits pour amener ces émigrants à l'âge adulte et aussi les petits pécules qu'ils emportent avec eux, mais il faut inscrire d'autre part au crédit du compte tout l'argent que les émigrants renverront à leur famille ou qu'ils rapporteront dans leur pays quand ils y reviendront (plus de 400 millions pour l'Italie) — et s'ils s'y fixent comme colons, il faut inscrire les bénéfices qu'ils procureront au commerce national en restant ses clients et ses propagandistes.

Cependant quand il s'agit d'émigrants riches, le pays d'origine ne voit pas toujours d'un œil très favorable ses nationaux porter leur argent à l'étranger et parfois prend certaines mesures pour les enrayer (voir ci-après, dans la Consommation, l'absentéisme) ${ }^{1}$.

Il est probable que ces difficiles questions seront résolues par des dispositions législatives très restrictives en principe, mais largement corrigées par des conventions de réciprocité qui permettront d'établir des différenciations selon les pays.

Aux États-Unis on a proposé des impôts spéciaux sur les voyageurs américains qui, à ce qu'on croit, dépenseraient près de 3 milliards de francs à l'étranger - et aussi sur les dots que les filles des milliardaires américains vont apporter à des maris d'Europe.

En France, au cours de la guerre, le préfet d'une grande ville a refusé les passeports à ceux qui désiraient aller passer l'été en Suisse, par ce motif qu'ils feraient acte plus patriotique en passant leur villégiature en France. 